\title{
Calibration of a Solar Absolute Cavity Radiometer with Traceability to the World Radiometric Reference
}

Ibrahim Reda

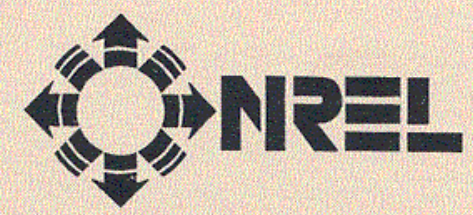

National Renewable Energy Laboratory 1617 Cole Boulevard Golden, Colorado 80401-3393

A national laboratory of the U.S. Department of Energy Managed by Midwest Research Institute for the U.S. Department of Energy under Contract No. DE-AC36-83CH10093 


\section{NOTICE}

This report was prepared as an account of work sponsored by an agency of the United States government. Neither the United States government nor any agency thereof, nor any of their employees, makes any warranty, express or implied, or assumes any legal liability or responsibility for the accuracy, completeness, or usefulness of any information, apparatus, product, or process disclosed, or represents that its use would not infringe privately owned rights. Reference herein to any specific commercial product, process, or service by trade name, trademark, manufacturer, or otherwise does not necessarily constitute or imply its endorsement, recommendation, or favoring by the United States govemment or any agency thereof. The views and opinions of authors expressed herein do not necessarily state or reflect those of the United States government or any agency thereof.

Available to DOE and DOE contractors from:

Office of Scientific and Technical Information (OSTI)

P.O. Box 62

Oak Ridge, TN 37831

Prices available by calling (615) 576-8401

Available to the public from:

National Technical Information Service (NTIS)

U.S. Department of Commerce

5285 Port Royal Road

Springfield, VA 22161

(703) 487-4650 
Reda, Ibrahim(M.S., Electrical Engineering)

Calibration of a Solar Absolute Cavity Radiometer with Traceability to the World Radiometric Reference.

\begin{abstract}
This report describes the present method of establishing traceability of absolute cavity radiometers to the World Radiometric Reference (WRR) through the process employed in the International Pyrheliometer Comparisons (IPC). This method derives the WRR reduction factor for each of the participating cavity radiometers. An alternative method is proposed, described, and evaluated as a way to reduce the uncertainty in the comparison process. The two methods are compared using a sample of data from the recent IPC-VIII conducted from september 25th to October 13th, 1995 at the World Radiation Center in Davos, Switzerland. A description of absolute cavity radiometers is also included, using a PMO- 6 as an example of active cavity radiometers, and a $\mathrm{HF}$ as an example of passive cavity radiometers.
\end{abstract}




\section{Acknowledgements}

There are a number of people I would like to thank who made this project possible. First, I wish to thank my colleague and friend, Chester Wells, for his infinite wisdom and continuous support. A debt of gratitude is extended to another colleague and friend, Tom stoffel, for his trust and confidence in my abilities. I am also grateful to John Hickey for his continuous support, and to Claus Fröhlich and José Romero at PMOD/WRC for their assistance during IPCVIII.

Additionally, I would like to extend my deepest and sincerest thanks to all NREL staff that provided help with this publication specifically Jim Treadwell, Bev Kay, Mary Raye, Mary-Margaret Coates and Penny Sadler.

My greatest gratitude goes to my wife, Mary Alice and my family for their continuous support, patience and encouragement. 


\section{Table of Contents}

CHAPTER 1

Introduction . . . . . . . . . . . . . . . . . . . 1

1.1 The World Radiometric Reference . . . . . 1

1.2 Radiometry at the Physikalisch

Meteorologisches Observatorium Davos (PMOD). 3

1.3 Organization and sequence . . . . . . . . 4

CHAPTER 2

PMO-6 Absolute Cavity Radiometer . . . . . . . 5

2.1 Description . . . . . . . . . . . . 5

2.2 Operation . . . . . . . . . . . . . 5

CHAPTER 3

HF Absolute Cavity Radiometer . . . . . . . . . . 9

3.1 Description . . . . . . . . . . . . 9

$3.2 \mathrm{HF}$ Electrical Calibration Procedure and Operation . . . . . . . . . . . . 13

CHAPTER 4

International Pyrheliometer Comparisons IPC-VIII . 16

4.1 Introduction . . . . . . . . . . . . . . 16

4.2 Data Acquisition and Evaluation . . . . 16

4.3 Calibration requirements . . . . . . . 19

Chapter 5

PMOD/WRC Method to Determine the WRR . . . . . 21

CHAPTER 6

Proposed Method to Determine the WRR . . . . . . 29

CHAPTER 7

Calculation of WRR Reduction Factor of HF28968 . 36

7.1 PMOD/WRC method . . . . . . . . . . 36

7.2 Proposed method . . . . . . . . . . . 45 
Chapter 8

Observations and Conclusions . . . . . . . . 55

Figures

Fig. 2.1 The Detector System for PMO-6. . . . . . . . 6

Fig. 3.1 HF Sensing Element, Front View. . . . . . 10

Fig. 3.2 HF Sensing Element, Side View. . . . . . . 10

Fig. 3.3 Eppley Hichey-Frieden System Diagram . . . . 12

Fig. 4.1 Timing for Different Instrument Types During IPC-VIII. . . . . . . . . . . . 17

Fig. 5.1 PMO2 Ratio to PMO2 . . . . . . . . . . . . 24

Fig. 5.2 PMO5 Ratio to PMO2 . . . . . . . . . . . . 24

Fig. 5.3 CROM2L Ratio to PMO2 . . . . . . . . . . . 25

Fig. 5.4 MK 67814 Ratio to PMO2 . . . . . . . . . . . 25

Fig. 5.5 HF18748 Ratio to PMO2. . . . . . . . . . . 26

Fig. 5.6 PAC3 Ratio to PMO2 . . . . . . . . . . . . . 26

Fig. 8.1 WRR Reduction Factors. . . . . . . . . . . 57

Fig. 8.2 Standard Deviations. . . . . . . . . . . . 58

Fig. 8.3 Means of WRR reduction Factors for the WSG . 59

Fig. 8.4 Change of the M Factor with Irradiance Calibration Levels and Time, 10/7/95. . . . . 60

Fig. 8.5 Change of the M Factor with Irradiance Calibration Levels and Time, 10/11/95 . . . .61

Fig. 8.6 Change of the M Factor Irradiance Calibration Levels and Time, 10/12/95 . . . .62

Fig. 8.7 Change of the Temperature with Time and Irradiance Calibration Levels, 10/7/95 . . . 63

Fig. 8.8 Change of the Temperature with Time and Irradiance Calibration Levels, 10/11/95. . . 64

Fig. 8.9 Change of the Temperature with Time and Irradiance Calibration Levels, 10/12/95. . . 65

Fig. 8.10 Change of M Factor with Temperature for 7, 11, and 12 October 1995. . . . . . . . . . . 66

Fig. 8.11 Irradiance Readings with Time and Irradiance Calibration Levels . . . . . . . . . 69 
Tables

Table 7.2 PMOD/WRC Method . . . . . . . . . . 38

Table 7.2 Proposed Method . . . . . . . . . . . . 47

Table 8.1 WRR Reduction Factor for HF28968. . . . . . 56

Table 8.2 Change of the M Factor for HF28968. . . . . 67

References. . . . . . . . . . . . . . . . 70 


\section{CHAPTER 1}

\section{Introduction}

\subsection{The World Radiometric Reference}

The World Meteorological Organization (WMO) is an intergovernmental organization sponsored by the United Nations through which the United States and more than 160 other nations cooperate in meteorological and weather related science and engineering. The WMO promotes the development of reference instruments; conducts world wide and regional field comparisons and evaluations; and recommends test and calibration methods, and the corrections applied. WMO sanctions the Physikalisch Meteorologisches Observatorium Davos (PMOD) as its World Radiation Center to establish, maintain, and propagate to users the engineering measurement scale for solar radiation measurements called the World Radiometric Reference (WRR). This measurement scale is used by all nations that acquire and report solar radiation measurement data for weather and meteorological purposes, for solar energy and engineering purposes, and for space research.

The accuracy, precision, and stability of the WRR is crucial for current scientific and engineering activities. These activities include the developing, testing, and using solar energy devices and technologies; meteorological, weather and global climate change measurements and research; and solar research from space. ${ }^{1}$ WRR was established through special comparisons, in 1977, of 15 absolute cavity radiometers of 9 types. Since WRR was established, the goal has been to ascertain and maintain its stability, accuracy, and precision through the World Standard Group (WSG) instruments. ${ }^{2}$ This is necessary so that scientists and engineers have a common internationally accepted reference 
for technical data and can accurately measure trends, such as changes in the world climate.

The following seven absolute cavity radiometers (three from the United States and four from Europe) now form the World Standard Group (WSG) that maintain WRR:

1. *PACRAD III: Built by and on indefinite loan from the United States' National Aeronautics and Space Administration.

2.*PMO-2: Built by and contributed by the Physikalisch Meteorologisches observatorium Davos, Switzerland.

3. PMO-5: Built by and contributed by the Physikalisch Meteorologisches Observatorium Davos, Switzerland.

4. ${ }^{*}$ CROM-2: Built by and contributed and operated by the Institute Royal Meteorologique de Belgique, Belgium.

5.*CROM-3: Built by and contributed and operated by the Institute Royal Meteorologique de Belgique, Belgium.

6. TMI-67814: Built by Technical Measurements, Inc. (TMI) and loaned from the National Renewable Energy Laboratory, Golden, CO, USA.

7. HF-18748: Built and contributed by The Eppley Laboratory Newport, RI, USA.

The four asterisked $(*)$ instruments were part of the original group of instruments that were used in the initial development and definition of WRR; they have served as part of the WSG ever since. ${ }^{1}$ 


\subsection{Radiometry at the Physikalisch Meteorologisches Observatorium Davos (PMOD)}

The design and construction of absolute radiometers at PMOD started in the early seventies. Due to their primary use, the measurement of solar irradiance, these radiometers are optimized to measure irradiances around $1 \mathrm{Kw} / \mathrm{m}^{2}$. The first model built was the PMO-2, which is since 1975 one of the World Standard Group (WSG) realizing the World Radiometric Reference (WRR). Since then a more refined version of the PMO radiometers (PMO-6) has been developed. Such instruments are used for the solar constant experiments of PMOD and for the subsistence of the World Standard Group. ${ }^{2}$

In order to assess the uncertainties of this kind of absolute radiometry more accurately, an important effort was put into the development of independent laboratory experiments. These are called characterization and consist of the accurate determination of all deviations of the radiometer from its ideal behavior. ${ }^{2}$

The calibration factor of absolute cavity radiometers is a function of: radiation loss $\left(E_{R}\right)$, non-equivalence of the radiative and electrical heating $\left(\mathrm{E}_{\mathrm{NB}}\right)$, scattered light $\left(E_{S T}\right)$, diffraction losses $\left(E_{D}\right)$, lead heating effect $\left(E_{L B}\right)$ and area of the precision aperture. It is the uncertainty of these factors that determines the accuracy of the radiometer. The following accuracies were achieved in characterizing the PMO- 6 absolute cavity radiometers:

a) The precision aperture diameter is measured with an accuracy greater than $\pm 0.5 \mu \mathrm{m}( \pm 0.02$ percent $)$, and roundness with accuracy greater than $\pm 0.2 \mu \mathrm{m}$.

b) The radiation loss is measured with an accuracy on the 
order of \pm 0.005 percent.

c) The non-equivalence between solar irradiance and electrical heating is measured with accuracy \pm 0.05 percent.

d) The scattered light is measured with accuracy \pm 0.01 percent.

e) The leads heating is measured with accuracy \pm 0.001 percent.

f) The diffraction losses correction is normally neglected in solar measurements and as the different radiometers have very similar corrections, this effect is left out. ${ }^{2}$

\subsection{Organization and sequence}

This report is divided into eight chapters. Chapter 2 describes the PMO- 6 absolute cavity radiometer as an example of active cavity radiometers. Chapter 3 describes first, the $\mathrm{HF}$ absolute cavity radiometer as an example of passive cavity radiometers; second, its recommended electrical calibration procedure during the outdoor comparisons of absolute cavity radiometers. Chapter 4 contains the calibration procedure of the International Pyrheliometer Comparisons IPC-VIII. Chapter 5 describes the PMOD method used to derive the WRR reduction factors for all the participating instruments, including those in the World Standard Group (WSG). Chapter 6 describes the proposed method to derive the WRR reduction factors in an effort to reduce the random component. Chapter 7 contains the calculations (using the two methods) of the WRR reduction factors for, HF28968 absolute cavity radiometer and each of the WSG instruments, using a sample of data collected during IPC-VIII. Chapter 8 reports the observations and conclusions. 


\section{CHAPTER 2}

\section{PMO-6 Absolute Cavity Radiometer}

\subsection{Description}

The design of the PMO- 6 absolute cavity radiometer is based on the principle of an electrically calibrated differential heat flux transducer with a cavity for the efficient absorption of the radiation to be measured. The cavity, which has an inverted cone inside a cylindrical shield, is painted with a specular black paint and is tied to a heat sink through a stainless steel thermal impedance. For the measurement of solar radiation, a view-limiting baffle mounted in front of the detector provides a full field of view of 5 degrees (the detector system is shown in Fig. 2.1). Only the primary cavity is used for radiation measurements. The temperature difference across the thermal impedance, sensing the heat flux, is measured with resistance thermometers mounted on the two cavities and not between the primary cavity and the heat sink. This differential arrangement compensates for the sudden changes in temperature of the heatsink and the rapid pressure changes, as long as the thermal time constants of the two cavity-thermal-impedance systems are equal. ${ }^{2}$

\subsection{Operation}

The instrument is operated in the "active" mode. That is, the temperature difference between the two cavities, the primary cavity and the compensating cavity, is kept constant by an automatic control loop for the current of the primary cavity's heater. Thus the difference in electrical power during the reference phase (electrical heating only) and during the irradiance phase (electrical and radiative 


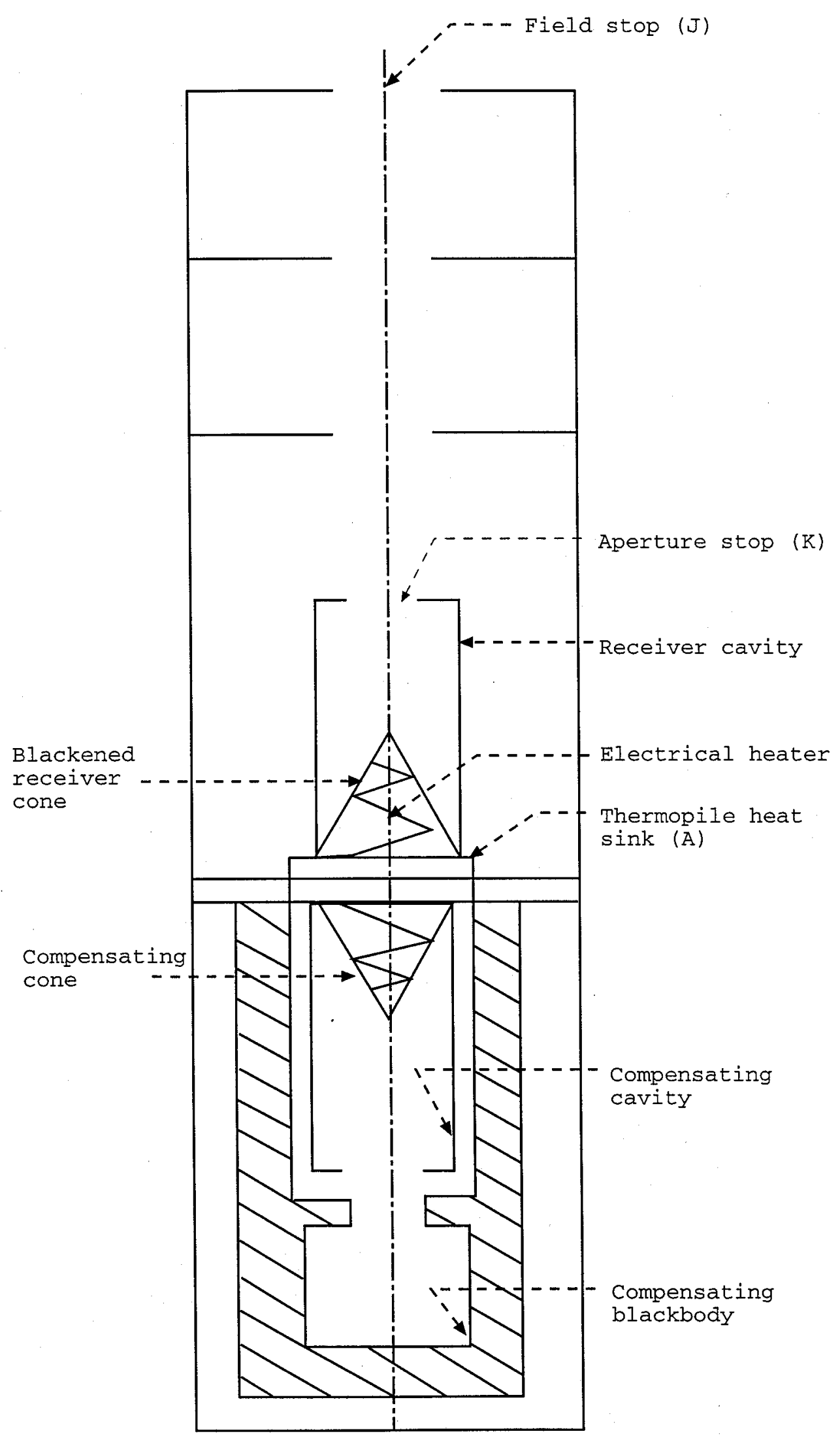

Fig.2.1 The Detector System for PMO-6 
heating) is proportional to the incoming radiation, $S$,

$$
S=k\left(P_{\text {closed }}-P_{\text {open }}\right),
$$

where:

$$
\begin{aligned}
\mathrm{P}_{\text {closed }}= & \text { the electrical power (voltage times current) } \\
& \text { applied to the primary cavity when no } \\
& \text { radiation is applied to it and the primary } \\
& \text { aperture's shutter is closed. This power is } \\
& \text { always kept at equilibrium with the power } \\
& \text { applied to the compensating cavity using a } \\
& \text { current control loop } \\
\mathrm{P}_{\text {open }}= & \text { the power measured at the primary cavity when } \\
& \text { the solar radiation is applied and the } \\
& \text { primary aperture's shutter is open. }
\end{aligned}
$$

In equation (2.1), the parameter $k$ is the calibration factor,

$$
k=\frac{E_{R} \cdot E_{N E} \cdot E_{S T} \cdot E_{D} \cdot E_{L H}}{A_{P}},
$$

where:

$E_{\mathrm{R}}=$ the radiation losses coefficient due to the finite reflectivity and the infrared emission of the heated black coating of the cavity

$E_{\mathrm{NB}}=$ the non-equivalence coefficient due to the effect of different temperature distributions during electrical and combined radiative and electrical heating 


$$
\begin{aligned}
E_{S T}= & \text { the scattered light coefficient produced by the } \\
& \text { light reflected from the precision aperture to } \\
& \text { the baffle and back into the cavity } \\
E_{D}= & \text { the diffraction losses coefficient due to } \\
& \text { diffracted light in the cavity } \\
E_{L B}= & \text { the lead heating effect coefficient due to the } \\
& \text { heating of leads feeding the current to the } \\
& \text { cavity heater } \\
A_{\mathrm{P}}= & \text { the area of the precision aperture. }
\end{aligned}
$$


CHAPTER 3

HF Absolute Cavity Radiometer

\subsection{Description}

The self-calibrating absolute cavity radiometer model HF, manufactured by The Eppley Laboratory, has been a reference standard level device since 1978. The sensor was originally developed for measurements from satellites and rockets. It consists of a balanced cavity receiver pair attached to a circular wire-wound and plated thermopile (Figs. 3.1, 3.2). The blackened cavity receivers are fitted with heater windings which allow for absolute operation using the electrical substitution method, which relates radiant power to electrical power in SI units (International system).

The forward cavity views the direct solar beam through a precision aperture having an area of $50 \mathrm{~mm}^{2}$. The rear receiver views an ambient temperature blackbody. The $\mathrm{HF}$ radiometer element with baffle tube and blackbody are fitted into an outer tube that encloses the instrument. ${ }^{3}$

The cavity radiometer is operated, and the required parameters are measured, using an appropriate control box. The cavity can be operated in either manual or automatic mode. In the manual mode, the shutter can be controlled remotely from the control box and the data from the digital multimeter is logged manually. In the automatic mode, the cavity is controlled through a computer program, normally Quick Basic or Visual Basic. The program controls all operations, calculates sensitivities and irradiance results, performs first level statistical analysis, and stores and backs up all data. The control functions include shutter control, setting of the calibration heater power level, 


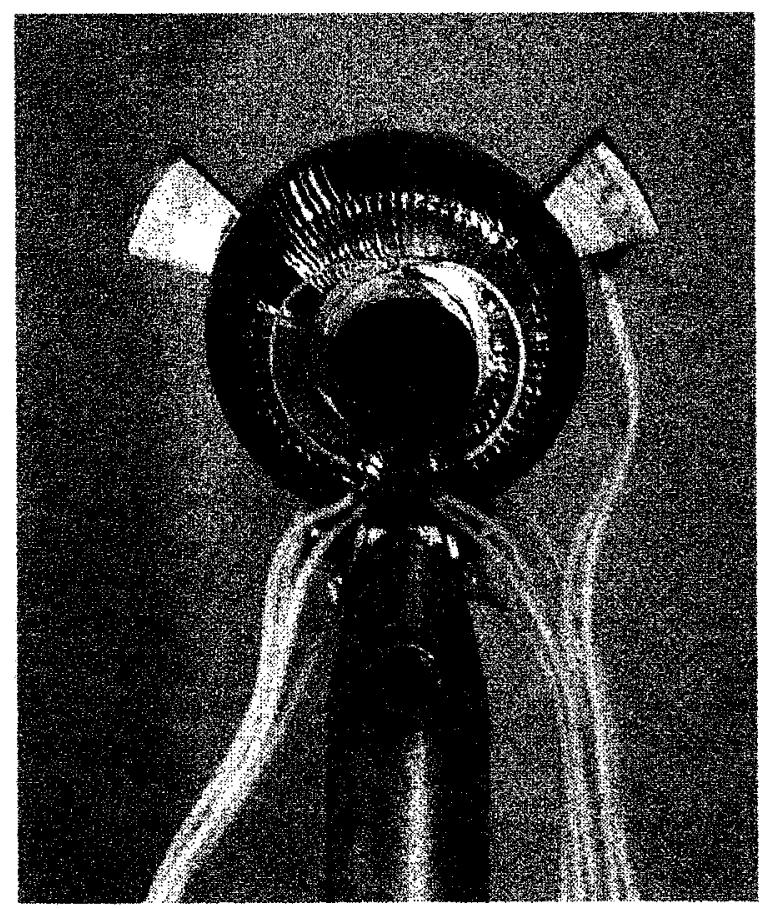

Fig. 3.1 HF Sensing Element, Front View

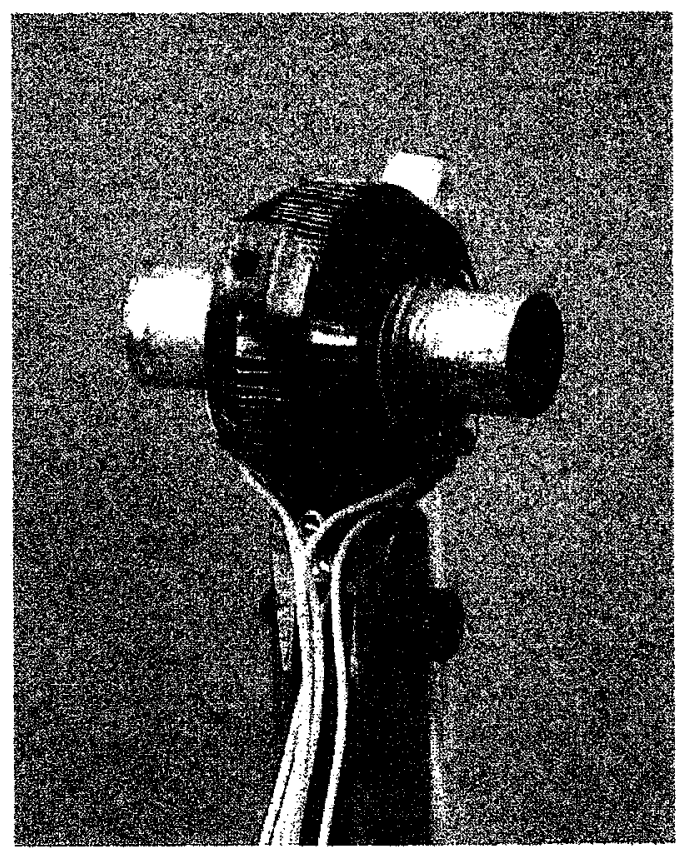

Fig.3.2 HF sensing Element, side View 
activation of the calibration heater circuit, selection of the signals to be measured, and control of the digital multimeter measurement functions and ranges. The measured parameters include the thermopile signal; the heater voltage (approximately 2.0 to $2.7 \mathrm{~V}$ ); and the heater current (approximately 15 to $20 \mathrm{~mA}$, which is measured as the voltage drop across a $10 \mathrm{ohm}$ precision resistor connected in series with the heater). The instrument temperature may also be measured using an internally mounted thermistor. The digital multimeter resolution of $100 \mathrm{nV}$ allows for a thermopile signal measurement with resolution of $0.1 \mu \mathrm{V}$ which is equivalent to approximately $0.1 \mathrm{~W} / \mathrm{m}^{2}$ ( $1 \mathrm{mV}$ thermopile signal is equivalent to approximately $1000 \mathrm{w} / \mathrm{m}^{2}$ of solar irradiance) (see simplified function diagram in Fig. 3.3).

The HF absolute cavity radiometer can be run in either active mode (similar to the PMO- 6 discussed Chapter 2) or passive mode. Usually, the cavity is used in the passive mode and that is how it is calibrated and operated in all the International Pyrheliometer Comparisons (IPC). In the passive mode, the electrical power is applied only to the heater of the forward cavity to calculate its sensitivity at certain solar irradiance level (the calibration interval), and then turned off during the solar irradiance measurement. But in the active mode the electrical power is applied to both the forward cavity and the rear cavity, and it stays on during both the calibration interval and the solar irradiance measurement. 


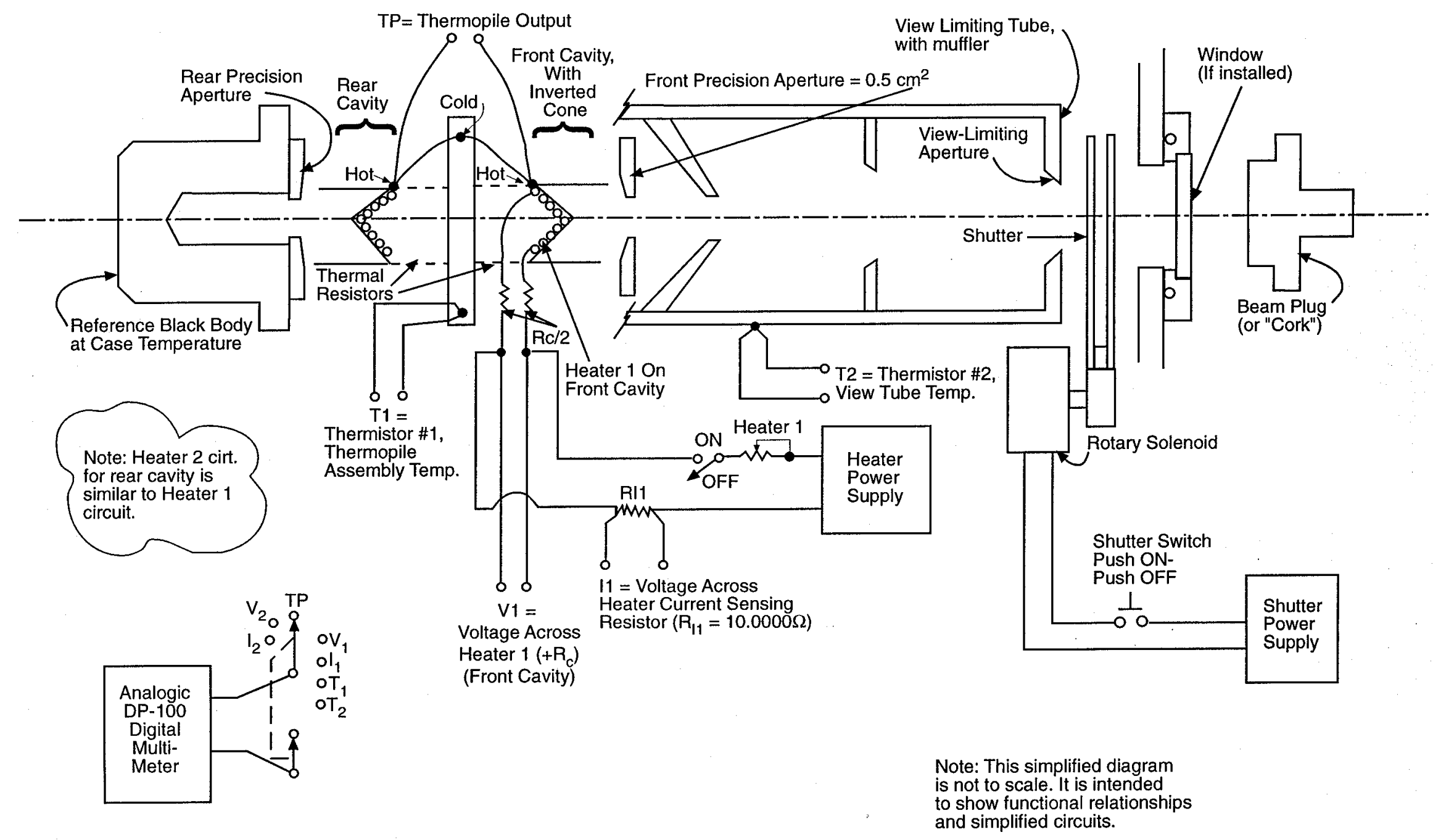




\subsection{HF Electrical Calibration Procedure and operation}

The following procedure is recommended during the comparisons of absolute cavity radiometers to reduce the errors in measuring the cavity zero and $\mathrm{TP}_{\mathrm{e}}$ (thermopile output voltage due to electrical power).

a) Mount the radiometer on the tracker, and adjust the system so that the radiometer is perfectly aligned with the sun's normal incidence.

b) Connect cable from the control unit to the radiometer, turn on the control unit, and let the whole system warm up for at least 1 hour to stabilize with the outdoor environment.

c) On the radiometer, block the solar irradiance using the metal beam plug provided, and close the shutter by pressing the Shutter ON/OFF switch.

d) On the control unit, set the Function switch to TP (Thermopile) position and Heater 1 and Heater 2 switches to off (electrical power is turned off) with the Low/High switches on Low positions.

e) Wait until the reading on the Digital Multimeter (DMM) stabilizes (90 to 120 seconds), and record the reading of the DMM as $\mathrm{TP}_{0}$ (Thermopile Zero) in mVDC.

f) Remove the metal beam plug from the radiometer, open the shutter and wait for 30 to 60 seconds, and record the DMM reading as $\mathrm{TP}_{\mathrm{s}}$ (thermopile output voltage due to solar irradiance) in mVDC.

g) Estimate the solar irradiance change during the solar 
irradiance measurement interval, and record it as $\pm x$ in mVDC.

h) Close the shutter, turn on Heater 1 and adjust Heater 1 control until the DMM reading equals $\mathrm{TP}_{\mathrm{s}} \pm \mathrm{x}$. Wait until the DMM reading stabilizes (40 to 90 seconds), and record the reading as $\mathrm{TP}_{\mathrm{e}}$ in $\mathrm{mVDC}$.

i) Set the Function switch to V1 position, wait until heater voltage reading on DMM stabilizes (15 seconds), and record the reading as $V_{1}$ in $V D C$.

j) Set the Function switch to II, wait until heater current reading on DMM stabilizes (15 seconds), and record the reading as $\mathrm{V}_{\mathrm{R}}$ in $\mathrm{VDC}$ (measured as a voltage reading because it is the voltage drop across a precision $10 \mathrm{ohm}$ resistor $R_{I}$ that is connected in series with the heater for accurate current measurement).

k) Calculate the multiplier factor at the solar irradiance level being measured, $M\left(\mathrm{~W} / \mathrm{m}^{2} / \mathrm{mV}\right)$,

$$
M=\frac{\frac{V_{R I}}{R_{I}} *\left(V_{1}-\frac{V_{R I}}{R_{I}} * R_{C}\right) * C_{f} * 10^{4}}{T P_{e}-T P_{0}},
$$

where:

$$
\begin{aligned}
R_{c}= & \text { the heater leads correction resistance, } \\
& \text { which typically is } 0.066 \mathrm{ohm} \\
\mathrm{C}_{\mathrm{F}}= & \text { the calibration factor provided by the } \\
& \text { manufacturer. } \mathrm{C}_{\mathrm{f}} \text { is approximately } 2 \text { because the } \\
& \text { aperture area is } 0.5 \mathrm{~cm}^{2} \text { (value differs for } \\
& \text { different radiometers). }
\end{aligned}
$$


1) Set the Function switch to $T P$, turn off Heater 1 and at the same time open the shutter (to keep the thermal heat of the cavity as close as possible to the solar irradiance level through the transition).

m) To calculate the solar irradiance $\left(\mathrm{W} / \mathrm{m}^{2}\right)$, multiply each $\mathrm{TP}$ reading taken from the $\mathrm{DMM}(\mathrm{mV})$ by the factor $M$ calculated during the calibration.

n) After taking a number of readings in a period of time (usually that period is 10 to 30 minutes), perform the calibration once again and note the $M$ factor and cavity zero readings. Then, linearly interpolate the $\mathrm{M}$ factor and cavity zero values for each irradiance reading, then recalculate the irradiance. 
CHAPTER 4

International Pyrheliometer Comparisons IPC-VIII

\subsection{Introduction}

The Executive Council of the World Meteorological Organization (WMO) authorized the 8th International Pyrheliometer Comparisons (IPC-VIII) to be held at the Physikalisch Meteorologisches Observatorium Davos, World Radiation Center (PMOD/WRC) from 9/25/95 to 10/13/95. The technical organization was delegated to PMOD/WRC, whereas the overall responsibility for ratification and dissemination of the final results rests with the WMO Commission for Instruments and Methods of Observation (CIMO) Working Group on Radiation and Atmospheric Turbidity Measurements.4.5 Sixty five participants representing thirty eight countries participated in the comparison. A WRR reduction factor will be calculated for each participating solar cavity radiometer. For a cavity radiometer to be traceable to the World Radiometric Reference, each of its irradiance readings will be multiplied by its WRR reduction factor. The method of calculating the WRR reduction factor described in this chapter has been used by PMOD/WRC for the past several International Pyrheliometer Comparisons, and it might be used for IPC-VIII.

\subsection{Data Acquisition and Evaluation}

\section{a) Timing}

The measurements are taken in runs lasting 21 minutes with a basic sampling of 90 seconds. Voice announcements before and buzzer signals during each event are used to inform the participants about the sequence. ${ }^{6}$ The timing for the different instrument types is shown in Fig. 4.1. 


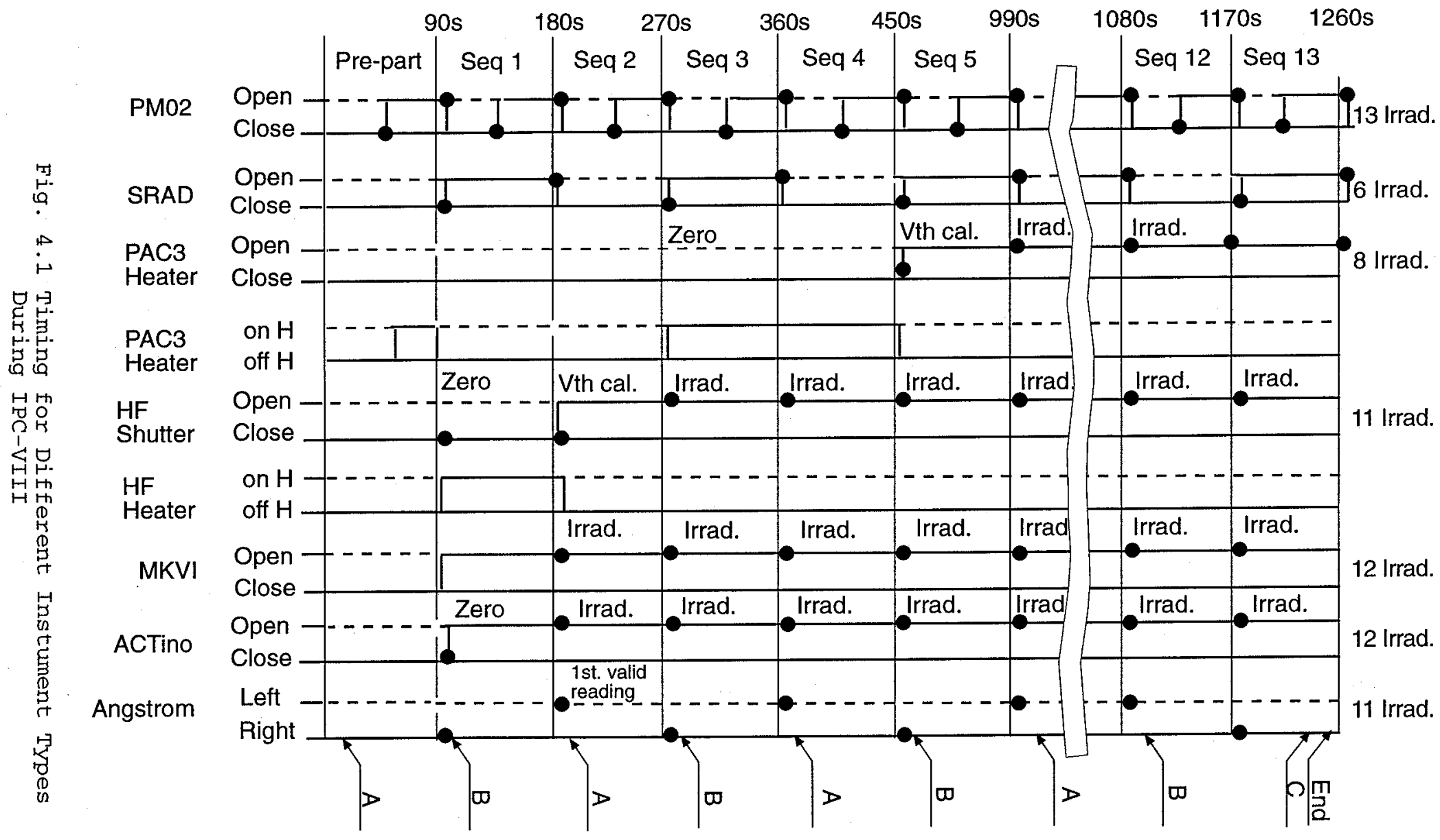

A: Please shade and heat the right hand strip

B: Please shade and heat left hand strip

- Reading

End: Please check your zero point

$\mathrm{C}$ : The series is over 
For nine instruments, of which HF28968 was one, the first irradiance reading was at 90 seconds after $T_{0}$, and a total of 13 irradiance readings per run were recorded, which resulted in a larger data sample than the other participating instruments.

b) Acquisition

The analog data-acquisition system is based on eight parallel DVM HP3478A with scanners and is used for WSG instruments, the radiometers of PMOD/WRC, and the auxiliary data. For the input data from the participants, BurrBrown types TM27 and TM2700 microterminals are used. The whole system is controlled by an HP computer series 9200 , which also stores and evaluates the data. ${ }^{6}$ For HF28968 and a small group of other instruments, the data were entered manually on a PC then copied to a floppy disk at the end of each day.

c) Data evaluation

For each instrument the irradiance and ratio to PMO2 is obtained with the corresponding evaluation procedure. After each run, a summary of measured values and evaluated irradiances is printed and distributed for checking by the participants and, if necessary, the raw data are edited for gross errors. Updated summaries with the mean values of ratio and the standard deviation for each instrument are made available during the course of the comparison. ${ }^{6}$

PMO2 is used as the working reference instrument. The irradiance values of PMO2 are obtained with the algorithm of the active cavity radiometers with $P_{c 10 s e d}$ as mean of the closed readings (no sun irradiance) and after the current open phase (sun irradiance). At the end of the open phase, 
eight $\mathrm{P}_{\text {open }}$ readings are taken, separated by approximately 0.7 second. The first of these readings is used as reference for the values entered by participants and the WSG instruments at the appropriate time. The standard deviation of these eight irradiance readings is also used as a quality control parameter to judge the stability of the solar irradiance for the data point to minimize the effect of different time constants between different types of instruments, so if the standard deviation is higher than 0.3 percent of reading, the data point would be rejected. ${ }^{6}$

\section{d) Auxiliary data}

The meteorological parameters are taken from the automatic weather station of the Swiss Meteorological Service located at PMOD/WRC. From this system 10 minutes values are available which are averaged over the period of a run. The values are air temperature, atmospheric pressure, global irradiance, and sky radiation. Close to the measuring benches, the wind speed and direction is measured, not as a meteorological parameter, but as an indication at the measuring site. Moreover, an instrument temperature and the daily ozone values are also given. Sunphotometer measurements are used to determine total vertical optical depth. ${ }^{6}$

\subsection{Calibration requirements}

a) Radiation source:

- The radiation source is the sun, with recommended irradiance level greater than $700 \mathrm{~W} / \mathrm{m}^{2}$ during measurement runs. ${ }^{6}$ 
b) Measuring equipment:

- Digital multimeters with at least $0.05 \%$ of reading resolution, accurate and stable over at least 1 year, including temperature drift, better than $\pm 0.1 \%$ of reading. DMM should be protected from sun and wind and it should be connected to signals using shielded low-noise cabling.

- Sun tracker's admissible misalignment is $\pm 0.25^{\circ}$ slope angle.

c) Environmental variables:

- Wind speed should be low, particularly if blowing from the direction of the sun's azimuth $\pm 30^{\circ}$.

- Cloud cover should be less than 1/8, clouds at an angular distance larger than $15^{\circ}$, and link turbidity factor as low as possible.

- Ambient air temperature and pressure changes, in principle, have no influence on Absolute Cavity Radiometers. ${ }^{6}$ 


\section{Chapter 5}

\section{PMOD/WRC Method to Determine the WRR Reduction Factor for Each of the Participating Instruments}

The nomenclature used in this chapter has been developed to clarify the PMOD/WRC procedure. Steps (a) through (d) are used to establish the ratio of each participating instrument in IPC-VIII (including the WSG instruments) to PMO2, which is the transfer instrument for the whole procedure. Steps (e) and (f) are used to compute the $\mathrm{WRR}_{\mathrm{IPCB}, \mathrm{k}}$ reduction factor for each instrument in the WSG using PMO2 as a transfer instrument. Steps (g) through (i) are not used by WRC/PMOD but have been added here to show that using the technique in step (f) produces no difference between the means of the $W_{R R} R_{I P C 8, k}$ and the $W_{R R} R_{\text {IPC , k }}$ reduction factors for the same WSG instruments. Similarity of the means is the primary assumption of this method. Step ( $j$ ) is used to calculate the $W_{R R_{I P C 8, k}}$ reduction factor for each participating instrument. Step (k) is used to show how well WRR is defined by the WSG.

a) For each reading, calculate the ratio of the irradiance reading of each participating instrument, including the WSG instruments, to the irradiance reading of PMO2, $R_{j, k}$,

$$
R_{j, k}=\frac{I_{j, k}}{I_{j, \text { MOO2 }}},
$$

where:

$$
\begin{aligned}
I_{j, k}= & \text { the jth irradiance reading of the } \mathrm{kth} \\
& \text { instrument }\left(\mathrm{W} / \mathrm{m}^{2}\right) \\
I_{j, \mathrm{PMO} 2}= & \text { the } j \text { th irradiance reading of } \mathrm{PMO} 2\left(\mathrm{~W} / \mathrm{m}^{2}\right) .
\end{aligned}
$$


b) Calculate the mean of the ratios $R_{j, k}$ for each participating instrument, $\overline{\mathrm{R}}_{\mathrm{k}}{ }_{\mathrm{k}}$,

$$
\bar{R}_{k}^{\prime}=\frac{\sum_{j=1}^{N} R_{j, k}}{N},
$$

where $\mathrm{N}$ is the number of irradiance readings.

c) Calculate the standard deviation of the ratios $R_{j, k}$ for each instrument, $\mathrm{SD}^{\prime}{ }^{\prime}$,

$$
S D_{k}^{\prime}=\sqrt{\frac{\sum_{j=1}^{N}\left(R_{j, k}-\bar{R}_{k}^{\prime}\right)^{2}}{N-1}} .
$$

d) Values of $R_{j, k}$ that deviate more than 0.3 percent from the mean $\bar{R}_{k}{ }_{k}$ are rejected, and a new $\bar{R}_{k}$ and $S D_{k}$ are calculated using Equations 5.2 and 5.3.

e) In order to define the World Radiometric Reference (WRR) for IPC-VIII, the results of the WSG are analyzed by the Commission for Instruments and Methods of Observation (CIMO). This commission then decides which of the seven reference instruments will define WRR for IPC-VIII. The reference instruments for IPC-VIII are PMO2, PMO5, CROM2L, CROM3L and MKVI67814 only. PACRAD III had an insect inside the cavity in April 1992. After the instrument was cleaned, its ratio to PMO2 decreased from 0.99917 to 0.9975 and has stayed the same since then. HF18748, which had an insect during IPC-VII, was not considered for defining WRR for IPC-VIII. Both instruments have not acquired enough measurement history to show the stability of their ratios 
to PMO2. Figs. 5.1 through 5.6 show the ratios of each of the WSG to PMO2 since 1990 .

f) For each of the WSG instruments, calculate the $\mathrm{WRR}_{\mathrm{IPC} 8, x}$ reduction factor using the following procedure:

i. Calculate the ratios $W_{I P C 8, k}$

$$
W_{I P C 8, k}=W R R_{I P C 7, k} * \frac{\bar{R}_{k}}{W R R_{I P C 7, P M O 2}}
$$

where:

$$
\begin{aligned}
W_{\text {IRC7 }}= & \text { the WRR reduction factor for the kth } \\
& \text { instrument in the WSG during IPC-VII } \\
\overrightarrow{\mathrm{R}}_{\mathrm{k}} & =\text { the mean of ratios of the irradiance } \\
& \text { reading of the kth instrument in the WSG } \\
& \text { to the irradiance reading of PMO2 for } \mathrm{N} \\
& \text { readings (after rejecting the outlier } \\
& \text { ratios) } \\
= & \text { the WRR reduction factor of PMO2 } \\
& \text { calculated during IPC-VII. }{ }^{45}
\end{aligned}
$$

ii. Calculate the mean of the ratios $W_{I P C 8, x}, M_{8}$,

$$
M_{8}=\frac{\sum_{k=1}^{n} W_{I P C 8, k}}{n},
$$

where $\mathrm{n}$ is the number of WSG instruments that defines WRR during IPC-VIII. 
World Standard Group

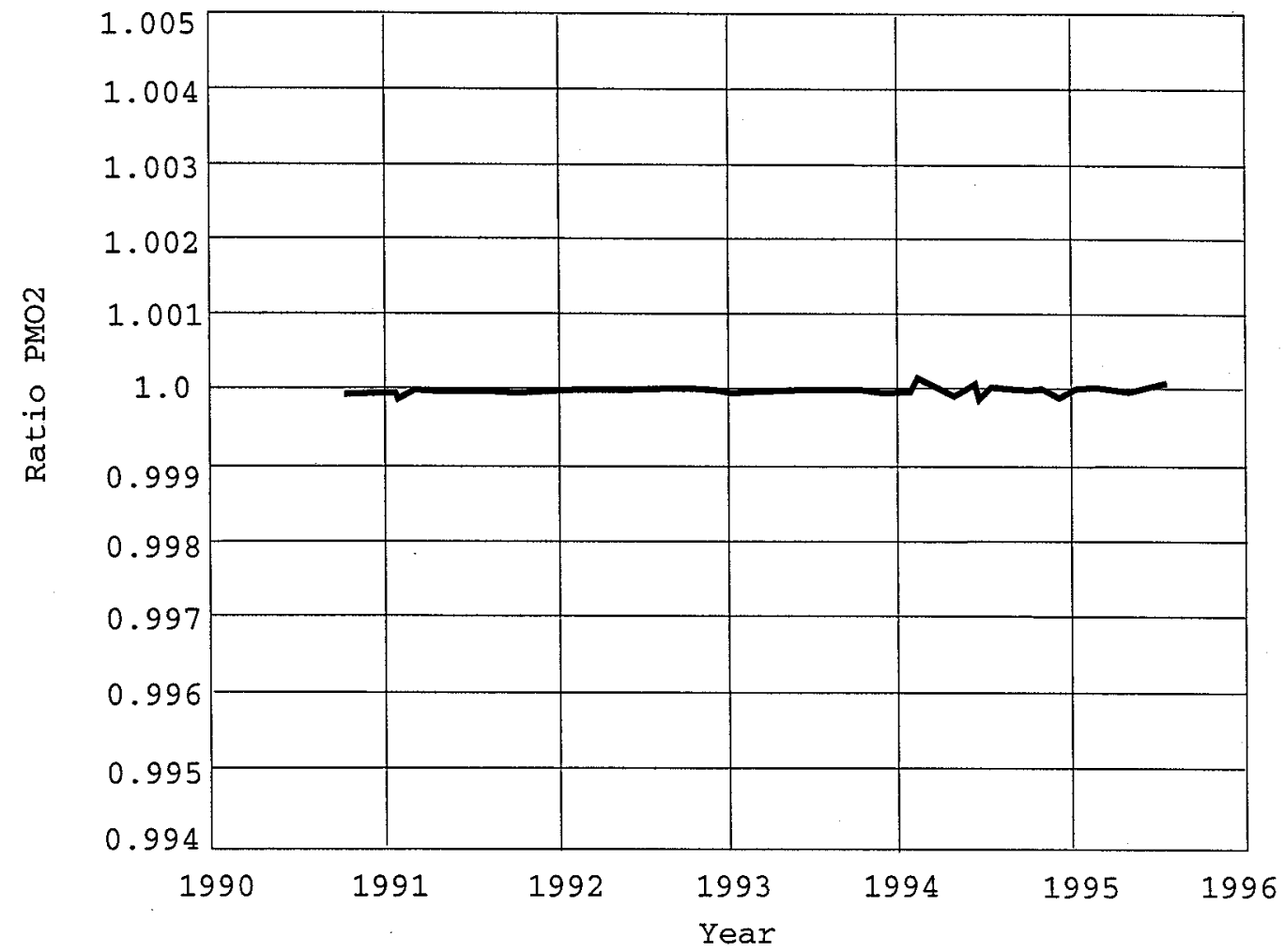

Fig.5.1 PM02 Ratio to PMO2

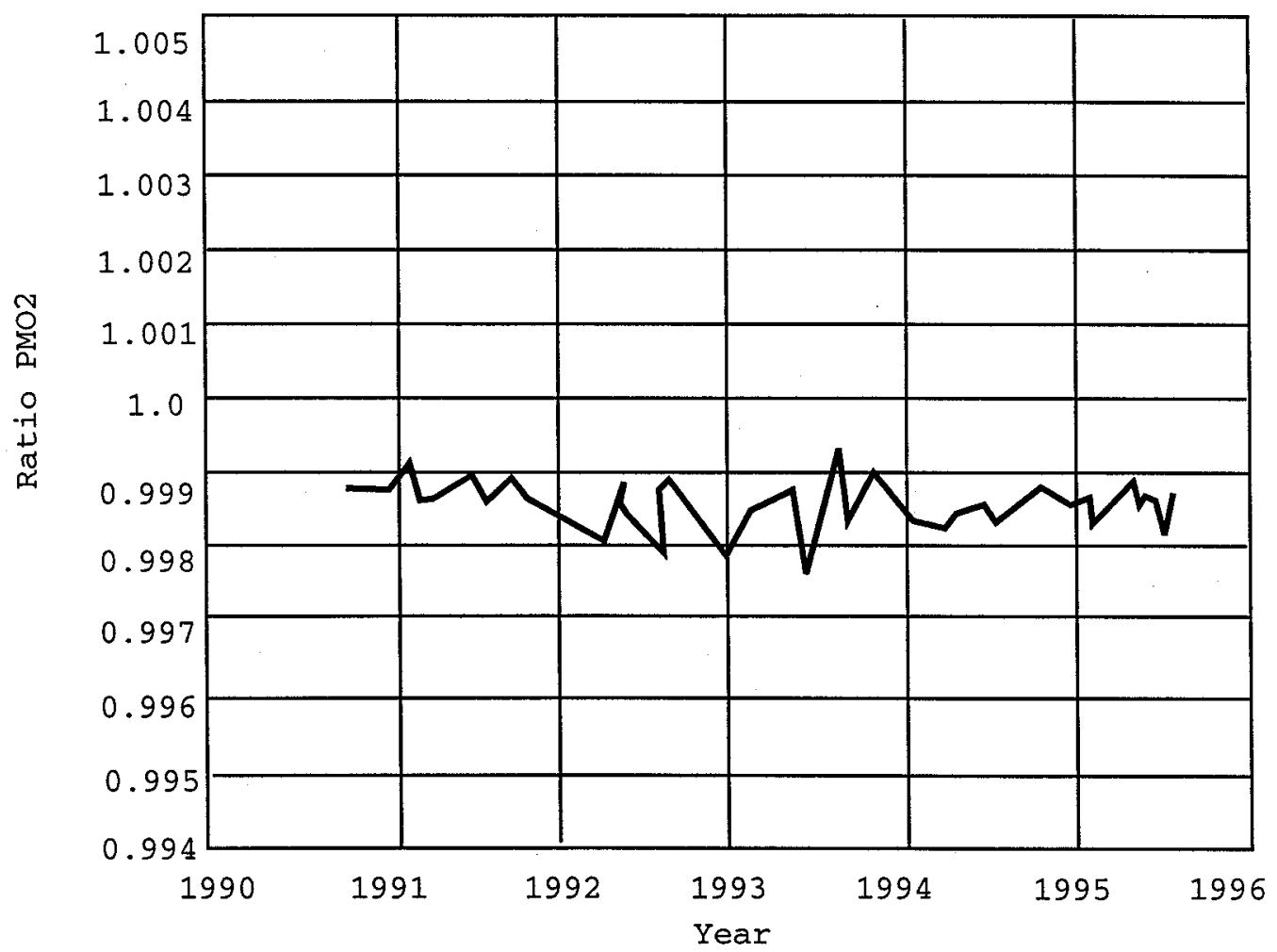

Fig.5.2 PM05 Ratio to PMO2 


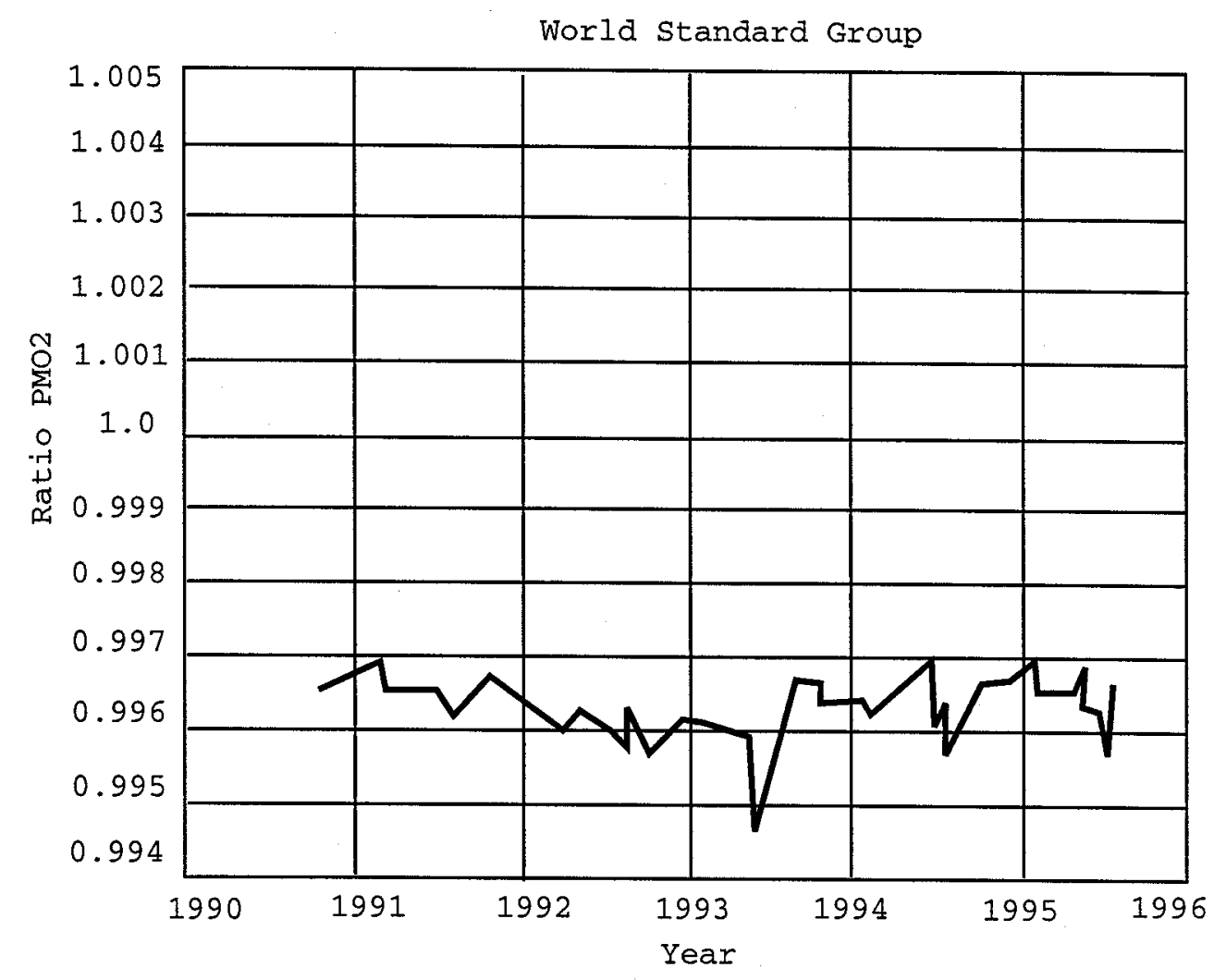

Fig.5.3 CROM2L Ratio to PMO2

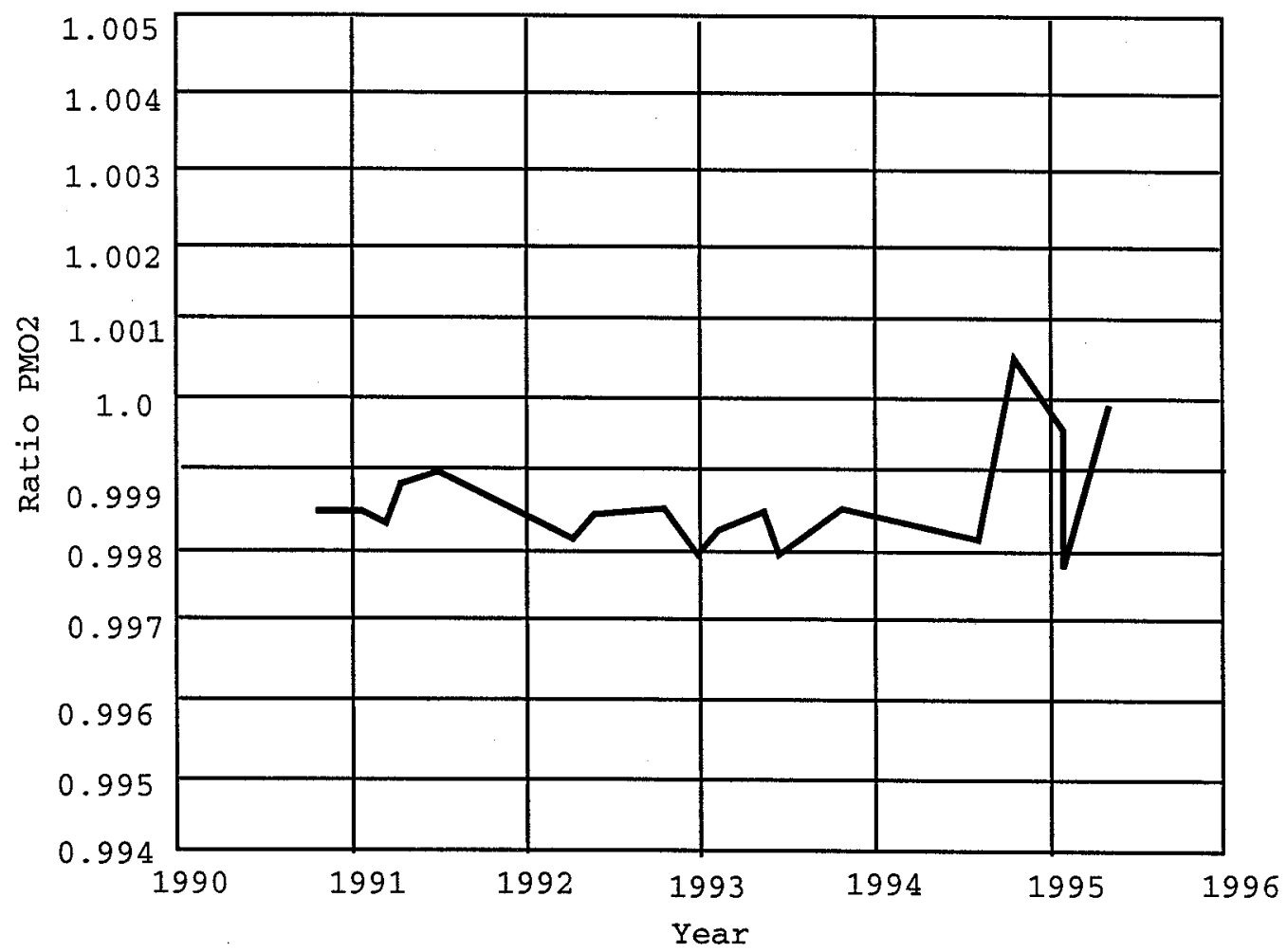

Fig.5.4 MK 67814 Ratio to PMO2 


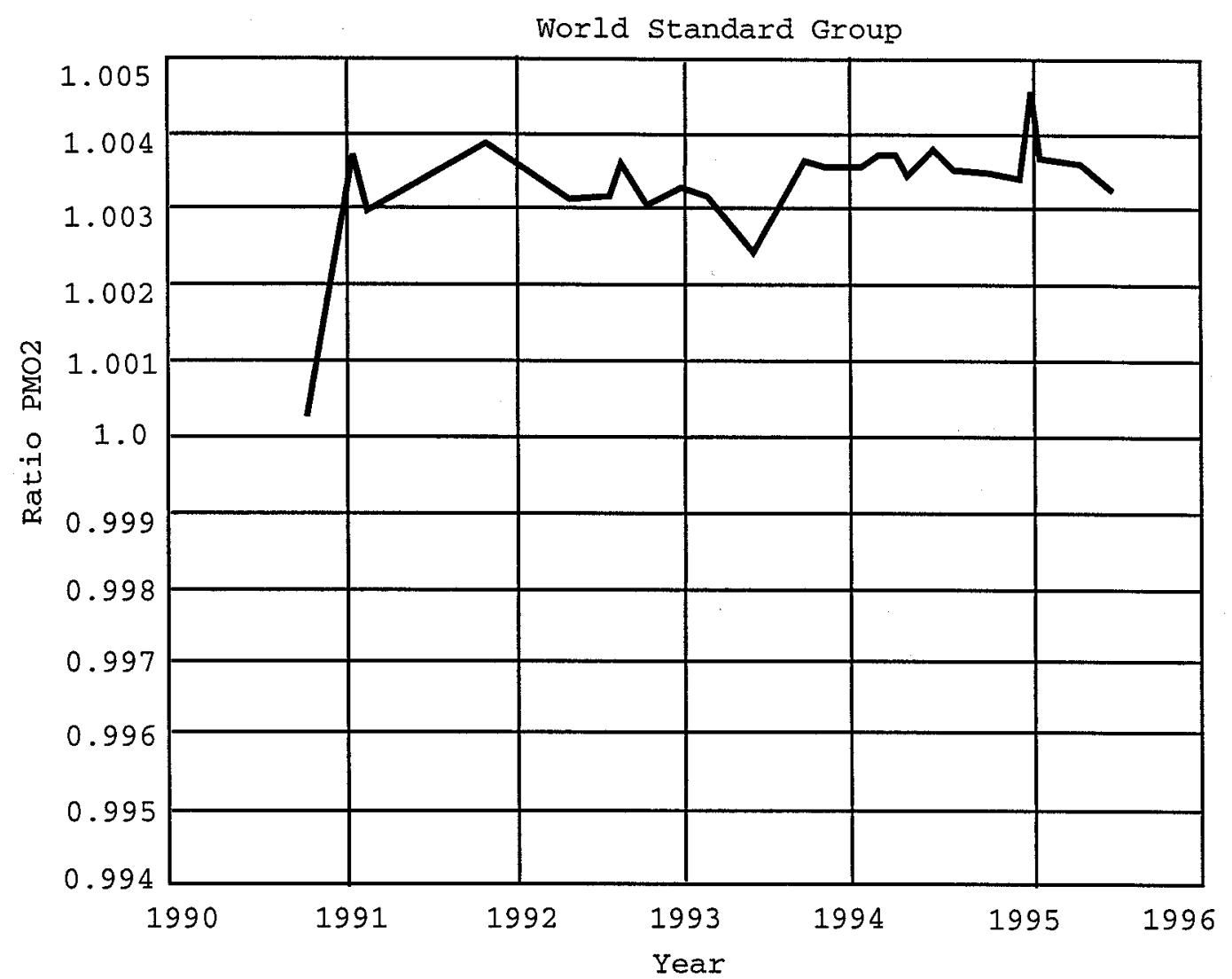

Fig. 5.5 HF18748 Ratio to PMO2

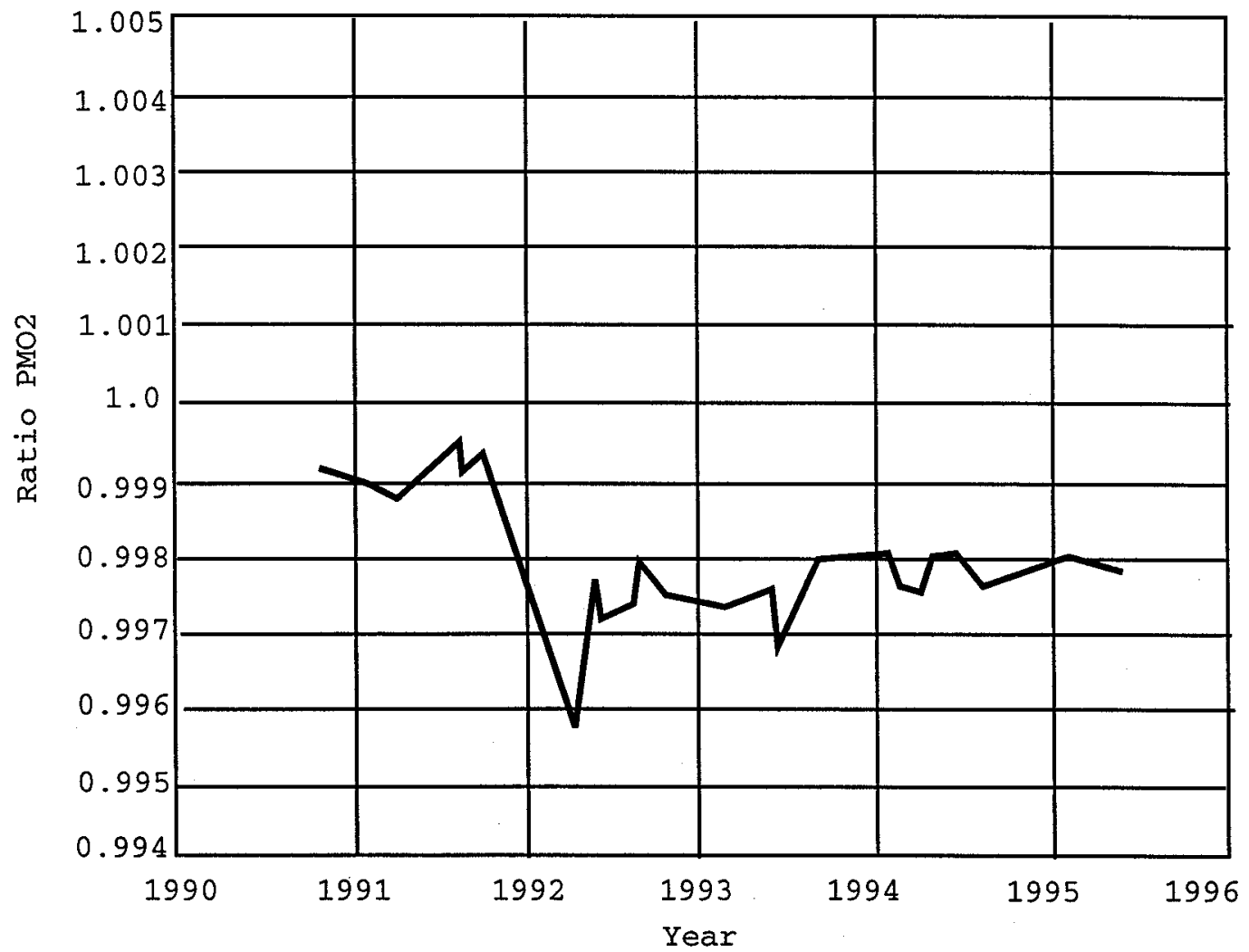

Fig. 5.6 PAC3 Ratio to PMO2 
iii. Calculate the deviation of each $\mathrm{W}_{\mathrm{IPC}, \mathrm{k}}$ from the mean $M_{8}, D_{\text {IPC8,k, }}$

$$
D_{I P C B, k}=W_{I P C B, k}-M_{8}
$$

iv. Finally, calculate the $W_{R R} R_{I P C 8, k}$ reduction factor for each instrument in the WSG,

$$
W R R_{I P C 8, k}=W R R_{I P C 7, k}-D_{I P C 8, k} \quad(5.7)
$$

g) Calculate the mean, $\mathrm{M}_{\mathrm{IPC} 8}$, of the $\mathrm{WRR}_{\mathrm{IPC}, \mathrm{k}}$ reduction factors of the WSG instruments,

$$
M_{I P C 8}=\frac{\sum_{k=1}^{n} W R R_{I P C 8, k}}{n} .
$$

h) Calculate the mean, $M_{I P C 7}$, of the $W_{R R_{I P C 7, k}}$ reduction factors of the same WSG instruments that are used to derive $M_{\text {IPcs }}$,

$$
M_{I P C 7}=\frac{\sum_{k=1}^{n} W R R_{I P C 7, k}}{n} .
$$

i) Calculate the change of the mean of WRR reduction factors of the WSG instruments, D,

$$
D=M_{I P C 8}-M_{I P C 7}
$$

D should equal zero because the primary assumption of this 
method is that the mean of WRR reduction factors of the WSG is constant.

j) Calculate the $\mathrm{WRR}_{\mathrm{IPC}, \mathrm{k}}$ for each participating instrument,

$$
W R R_{I P C 8, k}=\frac{W R R_{I P C 8, P M O 2}}{\bar{R}_{k}}
$$

k) Calculate the mean of $W_{R R} R_{\text {Ipcs }}$ reduction factors for all the participating instruments in IPC-VIII that have $W_{R R} R_{I P C 7}$ reduction factors, including the WSG, to evaluate how well WRR is represented by the WSG. ${ }^{4,5}$ 


\section{CHAPTER 6}

\section{Proposed Method to Determine the WRR Reduction Factor for Each of the Participating Instruments}

This method is based on the fact that the standard deviations of the WRR reduction factors of the WSG are different. Thus, the influence of the instrument that has larger standard deviation on determining the reference irradiance at a specific time should be less than the influence of the instrument that has a smaller standard deviation.' Step (a) divides the whole population of data into different samples, each of which represent a different group of instruments from the WSG. Steps (b) through (j) are used to calculate the weighting factor for each of the WSG instruments for each data sample. Steps (k) through (m) are used to calculate the WRR reduction factor and the standard deviation for each of the WSG instruments for IPC-VIII. Step (n) is used to recalculate the new weighting factor for each of the WSG instruments for each data sample because the standard deviations of the WRR(IPC8) reduction factors are different from the standard deviations calculated in step (f). Steps (o) through ( $r$ ) are used to calculate the WRR reduction factor and the standard deviation for each of the participating instruments in IPC-VIII. Steps (s) through (u) are used to evaluate the change in the mean of the WRR reduction factors of the WSG. Step $(v)$ is used to evaluate how well WRR is represented by the WSG.

a) After determining the instruments from the WSG that would define WRR for IPC-VIII, divide the whole population of irradiance readings into samples. Each sample should have at least three participating instruments of the WSG and the participating instruments should be the same in each sample (see pages 47 and 48 ). 
b) Multiply each irradiance reading of each instrument of the WSG by the instrument's WRR reduction factor from IPCVII,

$$
I_{j, k}=i_{j, k} * W R R_{I P C 7, k}, \quad(6.1)
$$

where $i_{j, k}$ is the $j$ th irradiance reading of the $k t h$ instrument of the WSG $\left(\mathrm{W} / \mathrm{m}^{2}\right)$.

c) Calculate the reference irradiance, I" ref.,f, for each reading,

$$
I^{\prime \prime}{ }_{\text {ref., } j}=\frac{\sum_{k=1}^{n} I_{j, k}}{n},
$$

where $\mathrm{n}$ is the number of instruments from the WSG that participated in the $j$ th irradiance reading.

d) Calculate the ratio of the reference irradiance of each reading to the original irradiance reading of each instrument, $\mathrm{R}^{\prime \prime}{ }_{j, k}$,

$$
R_{j, k}^{\prime \prime}=\frac{I^{\prime \prime}{ }_{r e f, j}}{i_{j, k}}
$$

e) Calculate the mean of all the ratios $R^{\prime \prime}{ }_{j, k}$ for each of the WSG instruments, $\overline{\mathrm{R}}^{\prime}{ }_{\mathrm{k}}$ ' 


$$
\bar{R}_{k}^{\prime \prime}=\frac{\sum_{j=1}^{N} R_{j, k}^{\prime \prime}}{N},
$$

where $\mathrm{N}$ is the number of irradiance readings of the $\mathrm{kth}$ instrument in the whole population.

f) Calculate the standard deviation of the ratios $R^{\prime \prime}{ }_{j, k}$ for each of the WSG instruments using the whole population, $S D^{\prime \prime}{ }_{k}$,

$$
S D^{\prime \prime}{ }_{k}=\sqrt{\frac{\sum_{j=1}^{N}\left(\bar{R}^{\prime \prime}{ }_{k}-R^{\prime \prime}{ }_{j, k}\right)^{2}}{N-1}} .
$$

g) Reject all the ratios, $R^{\prime \prime}{ }_{j, k}$, that deviate more than 0.3 percent from the mean $\overline{\mathrm{R}}^{\prime \prime}{ }_{\mathrm{k}}$. It is most important to reject also the irradiance reading from which that rejected ratio was derived, because that irradiance reading will affect the value of the reference irradiance. Then, recalculate the ratios, $\mathrm{R}_{j, k}{ }_{j, k}$ their means, $\overline{\mathrm{R}}_{k}{ }_{k}$, and their standard deviations, $\mathrm{SD}^{\prime}{ }_{\mathrm{k}}$, using Equations $6.3,6.4$ and 6.5 .

h) Calculate the total bias error, $B_{k}$, for each instrument of the WSG. The main source of bias errors is the digital multimeter used to measure electrical signals such as heater voltage, heater current, thermopile voltage, and thermistor resistance. 


$$
B_{k}=\sqrt{\sum_{g=1}^{m}\left(B_{g, k}\right)^{2}},
$$

where $B_{g, k}$ is the gth bias error for the kth instrument.

i) Calculate the total uncertainty for each of the WSG instruments, $\mathrm{U}_{99, \mathrm{k}}$,

$$
U_{99, k}^{\prime}=B_{K}+2 * S D_{k}^{\prime} \text {. }
$$

j) Calculate the weighting factor for each of the WSG instruments for each data sample, $W_{n, k}$. The number and type of participating instruments from the WSG are going to be different for each sample, which will result in different weighting factors for each sample,

$$
W_{n, k}^{\prime}=\frac{\left(\frac{1}{U_{99, k}^{\prime}}\right)^{2}}{\sum_{k=1}^{n}\left(\frac{1}{U_{99, k}^{\prime}}\right)^{2}},
$$

where $\mathrm{n}$ is the number of participating instruments from the WSG in the sample.

k) Recalculate the weighted reference irradiance of the WSG for each irradiance reading, using $\mathrm{WRR}_{\mathrm{IPC} 7, \mathrm{x}}$ reduction factors, $I_{\text {ref., j, }}$ 


$$
I_{r e f, j}^{\prime}=\sum_{k=1}^{n} W_{n, k}^{\prime} * W R R_{I P C 7, k^{*}} * i_{j, k}
$$

1) Calculate the ratio of each of the weighted reference irradiance to the original irradiance reading of each of the WSG instruments, $R_{j, k}$,

$$
R_{j, k}=\frac{I_{r e f, j}^{\prime}}{i_{j, k}}
$$

where $i_{j, k}$ is the original irradiance reading (without being multiplied by the WRR reduction factor) of the kth WSG instrument $\left(\mathrm{W} / \mathrm{m}^{2}\right)$.

m) Calculate the mean and the standard deviation of the ratios $R_{j, k}$ for the $\mathrm{kth}$ instrument of the WSG using Equations 6.4 and 6.5 . The mean is the $W_{R R} R_{I P C 8, k}$ reduction factor for the kth instrument of the WSG and the standard deviation is the $\mathrm{SD}_{\mathrm{IPC}, \mathrm{k}}$ for the same instrument.

n) From the standard deviations in step (m) recalculate the weighting factor, $W_{n, k}$, for each of the WSG instruments using Equations 6.7 and 6.8. Each data sample will have different weighting factors.

o) Using the $W_{R R} R_{\text {IPC }, x}$ reduction factor for each of the WSG, calculate the weighted reference irradiance for each irradiance reading, $I_{\text {ref..j, }}$

$$
I_{\text {ref.,j }}=\sum_{k=1}^{n} W_{n, k} * W R R_{I P C 8, k} * i_{j, k} .
$$


p) For each of the participating instruments calculate the ratio of the weighted reference irradiance to the instrument irradiance reading, $\mathrm{WRR}_{\mathrm{IPC}, j, k}$,

$$
W R R_{I P C 8, j, k}=\frac{I_{r e f_{.}, j}}{i_{j, k}} .
$$

q) Calculate the $\mathrm{WRR}_{\mathrm{IPCB}, \mathrm{k}}$ reduction factor for each of the participating instruments,

$$
W R R_{I P C 8, k}=\frac{\sum_{j=1}^{N} W R R_{I P C 8, j, k}}{N} .
$$

r) Calculate the standard deviation for each participating instrument, $\mathrm{SD}_{\mathrm{IPCB}, \mathrm{k}}$,

$$
S D_{I P C B, k}=\sqrt{\frac{\sum_{j=1}^{N}\left(W R R_{I P C 8, k}-W R R_{I P C 8, j, k}\right)^{2}}{N-1}} .
$$

s) Calculate the mean of $W_{R R} R_{I P C B, k}$ reduction factors for the WSG, $\mathrm{M}_{\mathrm{IPC8}}$,

$$
M_{I P C 8}=\sum_{k=1}^{n} \frac{W R R_{I P C 8, k}}{n},
$$

where $\mathrm{n}$ is the total number of instruments from the WSG that defines the WRR for IPC-VIII.

t) Calculate the mean of $W_{R R_{I P C}, k}$ reduction factors for the 
WSG instruments that define the WRR for IPC-VIII, $M_{I P C 7}$,

$$
M_{I P C 7}=\sum_{k=1}^{n} \frac{W R R_{I P C 7, k}}{n} . \quad(6.16)
$$

u) Calculate the change of the mean of WRR, D,

$$
D=M_{I P C 8}-M_{I P C 7}
$$

$D$ is the change of the mean of WRR that should be monitored at every WSG comparison, and after a period of time the two methods should be evaluated through a comparison using an absolute cavity radiometer or a group of absolute cavity radiometers that is more accurate.

v) Calculate the mean of $\mathrm{WRR}_{\mathrm{IPC}, \mathrm{k}}$ reduction factors for all the participating instruments, including the WSG instruments, that have $\mathrm{WRR}_{\mathrm{IPC} 7, \mathrm{k}}$ reduction factors and compare it with the mean of $W_{R R_{I P C 8, k}}$ reduction factor for the WSG instruments. This comparison allows one to evaluate how well WRR is represented by the WSG instruments for IPCVIII. 


\section{CHAPTER 7}

\section{Calculation of WRR Reduction Factor of HF28968 \\ Using the PMOD/WRC and the Proposed Methods}

In this chapter, the WRR reduction factor for HF28968 is calculated using the PMOD/WRC method and then the proposed method. The data used in the calculations are raw data that were collected during the comparison (IPC-VIII) under clear skies and around solar noon. The calculated WRR reduction factor in this chapter might differ from the WRR reduction factor assigned by PMOD/WRC due to using a small data sample. Tables 7.1 and 7.2 are the printout of a spreadsheet software used for the calculations.

\subsection{PMOD/WRC method}

The following rows, cells, or columns in Table 7.1 describe the sequence of the PMOD/WRC procedure used to calculate the WRR reduction factor for $\mathrm{HF} 28968$.

a) Columns $B$ through $G$ contain the irradiance readings for the WSG instruments and HF28968.

b) Columns $H$ through $L$ contain the ratios of each irradiance reading to $\mathrm{PMO} 2$.

c) Cells H137 through 1137 contain the means of the ratios to $\mathrm{PMO} 2$ in their corresponding column $(\mathrm{e} . \mathrm{g} ., \mathrm{cell} \mathrm{H} 137$ is the mean of the ratios in cells $\mathrm{H} 2$ through $\mathrm{H134}$ ).

d) Cells H139 through 1139 contain the standard deviations of the means of the ratios in step (c).

e) Cells H152 through $L 152$ contain the means of the ratios 
to PMO2 after rejecting the ratios that are 0.3 percent lower or higher than the mean.

f) Cells H154 through L154 contain the standard deviations for the means in step (e).

g) Cells M3 through Q3 contain the WRR reduction factors for the WSG Instruments from IPC-VII.

h) Cells M5 through $Q 5$ contain the ratios calculated using Equation 5.4 .

i) Cell N6 contains the mean of the ratios in step (h).

j) Cells M8 through Q8 contain the difference between the mean in cell $\mathrm{N} 6$ and each of the ratios in cells M5 through Q5 respectively.

k) Cells M10 through Q10 cotain the WRR reduction factors for the WSG instruments from IPC-VIII, which are calculated by subtracting cells M8 through Q8 from cells M3 through Q3 respectively.

1) Cells 013 and 014 contain the means of the WRR reduction factors of the WSG instruments during IPC-VII and IPC_VIII. The two means should equal if the data were processed properly.

m) Cells 017 and 018 contain the WRR reduction factor and the standard deviation of HF28968. 


\begin{tabular}{|c|c|c|c|c|c|c|c|}
\hline & A & B & C & D & $E$ & $\mathbf{F}$ & $\mathbf{G}$ \\
\hline 1 & Date/Time & PMO2 & PMO5 & CROM2L & CROM3R & MK67814 & HF28968 \\
\hline 2 & $10 / 2 / 95$ & & & & & & \\
\hline 3 & $11: 22: 30$ & 1023.9 & & & & & 1023.5 \\
\hline 4 & $11: 24: 00$ & 1022.2 & 1020.7 & 1019 & 1028.2 & & 1022.9 \\
\hline 5 & $11: 25: 30$ & 1020.5 & & & & & 1022.4 \\
\hline 6 & $11: 27: 00$ & 1021.2 & 1020.3 & 1020.7 & 1029.8 & & 1021.7 \\
\hline 7 & $11: 28: 30$ & 1020.1 & & & & & 1019.7 \\
\hline 8 & $11: 30: 00$ & 1018.6 & 1018.1 & 1019.1 & 1027.6 & & 1019.1 \\
\hline 9 & $11: 31: 30$ & 1019.4 & & & & & 1021.4 \\
\hline 10 & $11: 33: 00$ & 1018.2 & 1017.8 & 1015.7 & 1018.5 & & 1020.1 \\
\hline 11 & $11: 34: 30$ & 1018.8 & & & & & 1020.5 \\
\hline 12 & $11: 36: 00$ & 1016.9 & 1015.8 & 1013.6 & 1015.9 & & 1017.7 \\
\hline 13 & $11: 37: 30$ & 1016.2 & & & & & 1017.6 \\
\hline 14 & $11: 39: 00$ & 1015.1 & 1013.4 & 1010.7 & 1011.2 & & 1016.9 \\
\hline 15 & $11: 40: 30$ & 1016 & & & & & 1017.7 \\
\hline 16 & $10 / 3 / 95$ & & & & & & \\
\hline 17 & $10: 19: 30$ & 934.2 & & & & & 933.8 \\
\hline 18 & $10: 21: 00$ & 932.6 & 931.9 & 929.1 & 935.6 & & 933 \\
\hline 19 & $10: 22: 30$ & 933.7 & & & & & 934.8 \\
\hline 20 & $10: 24: 00$ & 932.7 & 931.1 & 930 & 935.2 & & 934.9 \\
\hline 21 & $10: 25: 30$ & 936.3 & & & & & 936.9 \\
\hline 22 & $10: 27: 00$ & 938 & 936.6 & 934.4 & 939.3 & & 938.5 \\
\hline 23 & $10: 28: 30$ & 939.1 & & & & & 939.8 \\
\hline 24 & $10: 30: 00$ & 940.2 & 938.4 & 934.3 & 946.2 & & 941.1 \\
\hline 25 & $10: 31: 30$ & 939.9 & & & & & 941.8 \\
\hline 26 & $10: 33: 00$ & 942.5 & 941 & 939.9 & 942.5 & & 942.8 \\
\hline 27 & $10: 34: 30$ & 941.5 & & & & & 942 \\
\hline 28 & $10: 36: 00$ & 942 & 940.8 & 939.3 & 946.6 & & 943.1 \\
\hline 29 & $10: 37: 30$ & 943.6 & & & & & 945.4 \\
\hline 30 & $10 / 11 / 95$ & & & & & & \\
\hline 31 & $11: 01: 30$ & 938.1 & & & & & 939.9 \\
\hline 32 & $11: 03: 00$ & 938.6 & 938 & 936.4 & 934.1 & & 940.2 \\
\hline 33 & $11: 04: 30$ & 939.5 & & & & 939.6 & 941 \\
\hline 34 & $11: 06: 00$ & 941.6 & 940.5 & 939.3 & 939.3 & 941.9 & 942.8 \\
\hline 35 & $11: 07: 30$ & 942.2 & & & & 941.9 & 944.1 \\
\hline 36 & $11: 09: 00$ & 941.4 & 940.3 & 937.6 & 937.6 & 941.9 & 942.9 \\
\hline 37 & $11: 10: 30$ & 941.1 & & & & 941.9 & 942.3 \\
\hline 38 & $11: 12: 00$ & 941.9 & 940.4 & 941.1 & 941.1 & 941.9 & 942.8 \\
\hline 39 & $11: 13: 30$ & 948.3 & & & & 948.6 & 946.6 \\
\hline 40 & $11: 15: 00$ & 948.7 & 946.9 & 950 & 950 & 948.5 & 948.5 \\
\hline 41 & $11: 16: 30$ & 948.3 & & & & 948.5 & 948.9 \\
\hline 42 & $11: 18: 00$ & 946.7 & 945.8 & 944.6 & 944.6 & 946.3 & 950 \\
\hline 43 & $11: 19: 30$ & 947 & & & & 948.5 & 949.8 \\
\hline 44 & $11: 55: 30$ & 950.1 & & & & & \\
\hline 45 & $11: 57: 00$ & 950.8 & 949.4 & 953.3 & 953.3 & & 952.3 \\
\hline 46 & $11: 58: 30$ & 952.1 & & & & 948.3 & 952.1 \\
\hline 47 & $12: 00: 00$ & 951.9 & 951.4 & 951 & 951 & 950.7 & 954.2 \\
\hline 48 & $12: 01: 30$ & 951.6 & & & & 950.7 & 953.4 \\
\hline 49 & $12: 03: 00$ & 954.1 & 953.2 & 951.9 & 951.9 & 952.8 & 954.9 \\
\hline 50 & $12: 04: 30$ & 953.3 & & & & 952.9 & 955.1 \\
\hline 51 & $12: 06: 00$ & 954.7 & 954.4 & 956.9 & 956.9 & 955.2 & 956.8 \\
\hline 52 & $12: 07: 30$ & 954.8 & & & & 952.9 & 956.1 \\
\hline 53 & $12: 09: 00$ & 956.6 & 954.3 & 952 & 952 & 955.2 & 958 \\
\hline
\end{tabular}

Table 7.1 PMOD/WRC Method to Calculate WRR Reduction Factor for HF28968 


\begin{tabular}{|c|c|c|c|c|c|c|c|}
\hline & A & B & C & D & $E$ & $\mathbf{F}$ & G \\
\hline 54 & $12: 10: 30$ & 956.6 & & & & 955.2 & 959.7 \\
\hline 55 & $12: 12: 00$ & 956.9 & 956.4 & 958.8 & 958.8 & 957.6 & 959.8 \\
\hline 56 & $12: 13: 30$ & 955.1 & & & & 955.3 & 958.8 \\
\hline 57 & $12: 22: 30$ & 957.1 & & & & & 957.7 \\
\hline 58 & $12: 24: 00$ & 956.7 & 954.8 & 952.6 & 950.2 & & 957 \\
\hline 59 & $12: 25: 30$ & 958.6 & & & & 955.9 & 959.4 \\
\hline 60 & $12: 27: 00$ & 956.8 & 954.9 & 953.2 & 957.6 & 955.9 & 957.2 \\
\hline 61 & $12: 28: 30$ & 958.1 & & & & 955.9 & 958.8 \\
\hline 62 & $12: 30: 00$ & 960.2 & 958.4 & 957.1 & 964.9 & 958.3 & 962 \\
\hline 63 & $12: 31: 30$ & 958.5 & & & & 958.3 & 959.9 \\
\hline 64 & $12: 33: 00$ & 954.8 & 953.3 & 952.4 & 957 & 953.7 & 956.3 \\
\hline 65 & $12: 34: 30$ & 957.8 & & & & 958.3 & 960.3 \\
\hline 66 & $12: 36: 00$ & 959 & 957.4 & 955.5 & 963.6 & 958.3 & 960.7 \\
\hline 67 & $12: 37: 30$ & 958.7 & & & & 958.3 & 960.9 \\
\hline 68 & $12: 39: 00$ & 958 & 956.8 & 954.9 & 958.5 & 958.3 & 960.6 \\
\hline 69 & $12: 40: 30$ & 959.4 & & & & 958.3 & 961.3 \\
\hline 70 & $12: 49: 30$ & 955.9 & & & & & 956.5 \\
\hline 71 & $12: 51: 00$ & 953.6 & 953.2 & 951.5 & 952.8 & & 955.6 \\
\hline 72 & $12: 52: 30$ & 954.2 & & & & 951.5 & 956.5 \\
\hline 73 & $12: 54: 00$ & 953.5 & 952.5 & 949.2 & 952.8 & 949.1 & 954.3 \\
\hline 74 & $12: 55: 30$ & 956.3 & & & & 953.7 & 958.7 \\
\hline 75 & $12: 57: 00$ & 954.6 & 953.4 & 951.6 & 955.1 & 951.4 & 955.7 \\
\hline 76 & $12: 58: 30$ & 956.8 & & & & 953.7 & 956.5 \\
\hline 77 & $13: 00: 00$ & 953.8 & 952.7 & 951.2 & 954.5 & 951.4 & 955.7 \\
\hline 78 & $13: 01: 30$ & 951.6 & & & & 949.1 & 953.4 \\
\hline 79 & $13: 03: 00$ & 954 & 952.7 & 950.1 & 955.3 & 951.4 & 954.6 \\
\hline 80 & $13: 04: 30$ & 952 & & & & 949.1 & 953.7 \\
\hline 81 & $13: 06: 00$ & 949.3 & 948.3 & 954.4 & 948 & 946.9 & 951.2 \\
\hline 82 & $13: 07: 30$ & 949.9 & & & & 949.1 & 952.6 \\
\hline 83 & $13: 16: 30$ & 946.3 & & & & & 946.5 \\
\hline 84 & $13: 18: 00$ & 945.8 & 943.8 & 942.2 & 945.6 & & 946 \\
\hline 85 & $13: 19: 30$ & 943.9 & & & & 942.4 & 944.7 \\
\hline 86 & $13: 21: 00$ & 942.5 & 940.6 & 938.8 & 940.9 & 940.2 & 943.2 \\
\hline 87 & $13: 22: 30$ & 940.9 & & & & 940.2 & 942 \\
\hline 88 & $13: 24: 00$ & 937.3 & 936.5 & 936 & 941.4 & 935.9 & 938.7 \\
\hline 89 & $13: 25: 30$ & 937.7 & & & & 935.8 & 938.7 \\
\hline 90 & $13: 27: 00$ & 937.8 & 935.7 & 933.7 & 938.4 & 935.9 & 938.7 \\
\hline 91 & $13: 28: 30$ & 937 & & & & 935.9 & 937.3 \\
\hline 92 & $13: 30: 00$ & 934.4 & 933.5 & 931.2 & 935.1 & 933.6 & 934.7 \\
\hline 93 & $13: 31: 30$ & 933.4 & & & & 933.6 & 935.6 \\
\hline 94 & $13: 33: 00$ & 937.9 & 936 & 933.3 & 937.6 & 935.9 & 938.7 \\
\hline 95 & $13: 34: 30$ & 935.1 & & & & 933.7 & 936.5 \\
\hline 96 & $13: 43: 30$ & 926.3 & & & & & 927.3 \\
\hline 97 & $13: 45: 00$ & 927.6 & 926.3 & 924.3 & 928.3 & & 929.1 \\
\hline 98 & $13: 46: 30$ & 926.6 & & & & 925.6 & 927 \\
\hline 99 & $13: 48: 00$ & 925.4 & 924.1 & 922.3 & 926.5 & 925.6 & 926.8 \\
\hline 100 & $13: 49: 30$ & 926.6 & & & & 925.6 & 927.7 \\
\hline 101 & $13: 51: 00$ & 923.5 & 922.3 & 920.8 & 925.3 & 923.5 & 924.6 \\
\hline 102 & $13: 52: 30$ & 922.3 & & & & 921.3 & 923.3 \\
\hline 103 & $13: 54: 00$ & 921.1 & 921 & 918.1 & 923.1 & 921.3 & 924.4 \\
\hline 104 & $13: 55: 30$ & 921.8 & & & & 921.3 & 922.7 \\
\hline 105 & $13: 57: 00$ & 921 & 919.6 & 916.9 & 920.7 & 921.3 & 922.5 \\
\hline 106 & $13: 58: 30$ & 918.2 & & & & 916.7 & 919.5 \\
\hline 107 & $14: 00: 00$ & 915.2 & 913.5 & 912.4 & 916.4 & 914.3 & 916.8 \\
\hline
\end{tabular}

Table 7.1 PMODNVRC Method to Calculate WRR Reduction Factor for HF28968 


\begin{tabular}{|c|c|c|c|c|c|c|c|}
\hline & $\mathbf{A}$ & B & C & D & $E$ & $\mathbf{F}$ & G \\
\hline 108 & $14: 01: 30$ & 914.9 & & & & 914.4 & 916.2 \\
\hline 109 & $10 / 12 / 95$ & & & & & & \\
\hline 110 & $11: 55: 30$ & 1000.2 & & & & & 1001.5 \\
\hline 111 & $11: 57: 00$ & 1000.6 & 999.7 & 997.9 & 1001.5 & & 1001.9 \\
\hline 112 & $11: 58: 30$ & 1000.5 & & & & 999.4 & 1002.1 \\
\hline 113 & $12: 00: 00$ & 1000.2 & 999.9 & 998.1 & 1002.3 & 999.3 & 1001.4 \\
\hline 114 & $12: 01: 30$ & 1001 & & & & 999.4 & 1001.8 \\
\hline 115 & $12: 03: 00$ & 1001.4 & 1000.2 & 994.8 & 1012.3 & 999.4 & 1002.6 \\
\hline 116 & $12: 04: 30$ & 1002 & & & & 999.4 & 1003.5 \\
\hline 117 & $12: 06: 00$ & 1003.1 & 1001.4 & 999.8 & 997 & 1001.4 & 1004 \\
\hline 118 & $12: 07: 30$ & 1002.2 & & & & 1001.5 & 1003.1 \\
\hline 119 & $12: 09: 00$ & 1001.8 & 1000.8 & 998.9 & 1007 & 1001.4 & 1003.2 \\
\hline 120 & $12: 10: 30$ & 1001.1 & & & & 999.5 & 1001.7 \\
\hline 121 & $12: 12: 00$ & 1000.7 & 1000.1 & 998.7 & 1005.6 & 999.5 & 1002 \\
\hline 122 & $12: 13: 30$ & 1000.4 & & & & 1001.5 & 1001.8 \\
\hline 123 & $12: 22: 30$ & 999.3 & & & & & 1001.1 \\
\hline 124 & $12: 24: 00$ & 1000.6 & 999.5 & 998.3 & 1000.5 & & 1001.9 \\
\hline 125 & $12: 25: 30$ & 999.5 & & & & 997.2 & 1001.5 \\
\hline 126 & $12: 27: 00$ & 1000.4 & 999.6 & 997.5 & 999.1 & 999.2 & 1001.5 \\
\hline 127 & $12: 28: 30$ & 1000 & & & & 997.2 & 1002 \\
\hline 128 & $12: 30: 00$ & 1000.3 & 998.9 & 999.9 & 999.8 & 999.2 & 1002.1 \\
\hline 129 & $12: 31: 30$ & 1000.1 & & & & 999.2 & 1002.1 \\
\hline 130 & $12: 33: 00$ & 1000.5 & 1000.4 & 998.9 & 996.3 & 999.2 & 1002.6 \\
\hline 131 & $12: 34: 30$ & 1000 & & & & 999.2 & 1002 \\
\hline 132 & $12: 36: 00$ & 998.9 & 997.4 & 995.4 & 1010.6 & 997.2 & 1001.7 \\
\hline 133 & $12: 37: 30$ & 999.5 & & & & 997.2 & 1001.1 \\
\hline 134 & $12: 39: 00$ & 999.5 & 997.2 & 997.4 & 995.1 & 997.2 & 1001.1 \\
\hline 135 & $12: 40: 30$ & 998.7 & & & & 997.2 & 1001 \\
\hline \multicolumn{8}{|l|}{136} \\
\hline \multicolumn{8}{|l|}{137} \\
\hline \multicolumn{8}{|l|}{138} \\
\hline \multicolumn{8}{|l|}{139} \\
\hline \multicolumn{8}{|l|}{140} \\
\hline \multicolumn{8}{|l|}{141} \\
\hline \multicolumn{8}{|l|}{142} \\
\hline \multicolumn{8}{|l|}{143} \\
\hline \multicolumn{8}{|l|}{144} \\
\hline \multicolumn{8}{|l|}{145} \\
\hline \multicolumn{8}{|l|}{146} \\
\hline \multicolumn{8}{|l|}{147} \\
\hline \multicolumn{8}{|l|}{148} \\
\hline \multicolumn{8}{|l|}{149} \\
\hline \multicolumn{8}{|l|}{150} \\
\hline \multicolumn{8}{|l|}{151} \\
\hline \multicolumn{8}{|l|}{152} \\
\hline \multicolumn{8}{|l|}{153} \\
\hline 154 & & & & & & & \\
\hline 155 & & & & & & & \\
\hline 156 & & & & & & & \\
\hline 157 & & & & & & & \\
\hline 158 & & & & & & & \\
\hline 159 & & & & & & & \\
\hline 160 & & & & & & & \\
\hline
\end{tabular}

Table 7.1 PMOD/WRC Method to Calculate WRR Reduction Factor for HF28968 


\begin{tabular}{|c|c|c|c|c|c|}
\hline & $\mathbf{H}$ & I & $\mathbf{J}$ & $\mathbf{K}$ & $\mathbf{L}$ \\
\hline 1 & PMO5/PMO2 & CROM2L/PMO2 & CROM3R/PMO2 & MK67814/PMO2 & HF28968/PMO2 \\
\hline 2 & $=R(j, P M O 5)$ & $=\mathrm{R}(\mathrm{j}, \mathrm{CROM} 2 \mathrm{~L})$ & $=R(j, C R O M 3 R)$ & $=R(j, M K 67814)$ & $=R(i, H F 28968)$ \\
\hline 3 & & & & & 0.9996093 \\
\hline 4 & 0.9985326 & 0.9968695 & 1.0058697 & & 1.0006848 \\
\hline 5 & & & & & 1.0018618 \\
\hline 6 & 0.9991187 & 0.9995104 & 1.0084215 & & 1.0004896 \\
\hline 7 & & & & & 0.9996079 \\
\hline 8 & 0.9995091 & 1.0004909 & 1.0088357 & & 1.0004909 \\
\hline 9 & & & & & 1.0019619 \\
\hline 10 & 0.9996071 & 0.9975447 & 1.0002946 & & 1.0018660 \\
\hline 11 & & & & & 1.0016686 \\
\hline 12 & 0.9989183 & 0.9967548 & 0.9990166 & & 1.0007867 \\
\hline 13 & & & & & 1.0013777 \\
\hline 14 & 0.9983253 & 0.9956655 & 0.9961580 & & 1.0017732 \\
\hline 15 & & & & & 1.0016732 \\
\hline \multicolumn{6}{|l|}{16} \\
\hline 17 & & & & & 0.9995718 \\
\hline 18 & 0.9992494 & 0.9962471 & 1.0032168 & & 1.0004289 \\
\hline 19 & & & & & 1.0011781 \\
\hline 20 & 0.9982846 & 0.9971052 & 1.0026804 & & 1.0023587 \\
\hline 21 & & & & & 1.0006408 \\
\hline 22 & 0.9985075 & 0.9961620 & 1.0013859 & & 1.0005330 \\
\hline 23 & & & & & 1.0007454 \\
\hline 24 & 0.9980855 & 0.9937247 & 1.0063816 & & 1.0009572 \\
\hline 25 & & & & & 1.0020215 \\
\hline 26 & 0.9984085 & 0.9972414 & 1.0000000 & & 1.0003183 \\
\hline 27 & & & & & 1.0005311 \\
\hline 28 & 0.9987261 & 0.9971338 & 1.0048832 & & 1.0011677 \\
\hline 29 & & & & & 1.0019076 \\
\hline \multicolumn{6}{|l|}{30} \\
\hline 31 & & & & & 1.0019188 \\
\hline 32 & 0.9993608 & 0.9976561 & 0.9952056 & & 1.0017047 \\
\hline 33 & & & & 1.0001064 & 1.0015966 \\
\hline 34 & 0.9988318 & 0.9975573 & 0.9975573 & 1.0003186 & 1.0012744 \\
\hline 35 & & & & 0.9996816 & 1.0020166 \\
\hline 36 & 0.9988315 & 0.9959635 & 0.9959635 & 1.0005311 & 1.0015934 \\
\hline 37 & & & & 1.0008501 & 1.0012751 \\
\hline 38 & 0.9984075 & 0.9991507 & 0.9991507 & 1.0000000 & 1.0009555 \\
\hline 39 & & & & 1.0003164 & 0.9982073 \\
\hline 40 & 0.9981027 & 1.0013703 & 1.0013703 & 0.9997892 & 0.9997892 \\
\hline 41 & & & & 1.0002109 & 1.0006327 \\
\hline 42 & 0.9990493 & 0.9977818 & 0.9977818 & 0.9995775 & 1.0034858 \\
\hline 43 & & & & 1.0015839 & 1.0029567 \\
\hline \multicolumn{6}{|l|}{44} \\
\hline 45 & 0.9985276 & 1.0026294 & 1.0026294 & & 1.0015776 \\
\hline 46 & & & & 0.9960088 & 1.0000000 \\
\hline 47 & 0.9994747 & 0.9990545 & 0.9990545 & 0.9987394 & 1.0024162 \\
\hline 48 & & & & 0.9990542 & 1.0018916 \\
\hline 49 & 0.9990567 & 0.9976942 & 0.9976942 & 0.9986375 & 1.0008385 \\
\hline 50 & & & & 0.9995804 & 1.0018882 \\
\hline 51 & 0.9996858 & 1.0023044 & 1.0023044 & 1.0005237 & 1.0021996 \\
\hline 52 & & & & 0.9980101 & 1.0013615 \\
\hline 53 & 0.9975957 & 0.9951913 & 0.9951913 & 0.9985365 & 1.0014635 \\
\hline
\end{tabular}

Table 7.1 PMOD/WRC Method to Calculate WRR Reduction Factor for HF28968 


\begin{tabular}{|c|c|c|c|c|c|}
\hline & $\mathrm{H}$ & 1 & $\mathbf{J}$ & K & $\mathbf{L}$ \\
\hline 54 & & & & 0.9985365 & 1.0032406 \\
\hline 55 & 0.9994775 & 1.0019856 & 1.0019856 & 1.0007315 & 1.0030306 \\
\hline 56 & & & & 1.0002094 & 1.0038739 \\
\hline 57 & & & & & 1.0006269 \\
\hline 58 & 0.9980140 & 0.9957144 & 0.9932058 & & 1.0003136 \\
\hline 59 & & & & 0.9971834 & 1.0008346 \\
\hline 60 & 0.9980142 & 0.9962375 & 1.0008361 & 0.9990594 & 1.0004181 \\
\hline 61 & & & & 0.9977038 & 1.0007306 \\
\hline 62 & 0.9981254 & 0.9967715 & 1.0048948 & 0.9980212 & 1.0018746 \\
\hline 63 & & & & 0.9997913 & 1.0014606 \\
\hline 64 & 0.9984290 & 0.9974864 & 1.0023041 & 0.9988479 & 1.0015710 \\
\hline 65 & & & & 1.0005220 & 1.0026101 \\
\hline 66 & 0.9983316 & 0.9963504 & 1.0047967 & 0.9992701 & 1.0017727 \\
\hline 67 & & & & 0.9995828 & 1.0022948 \\
\hline 68 & 0.9987474 & 0.9967641 & 1.0005219 & 1.0003132 & 1.0027140 \\
\hline 69 & & & & 0.9988535 & 1.0019804 \\
\hline 70 & & & & & 1.0006277 \\
\hline 71 & 0.9995805 & 0.9977978 & 0.9991611 & & 1.0020973 \\
\hline 72 & & & & 0.9971704 & 1.0024104 \\
\hline 73 & 0.9989512 & 0.9954903 & 0.9992659 & 0.9953854 & 1.0008390 \\
\hline 74 & & & & 0.9972812 & 1.0025097 \\
\hline 75 & 0.9987429 & 0.9968573 & 1.0005238 & 0.9966478 & 1.0011523 \\
\hline 76 & & & & 0.9967600 & 0.9996865 \\
\hline 77 & 0.9988467 & 0.9972741 & 1.0007339 & 0.9974837 & 1.0019920 \\
\hline 78 & & & & 0.9973728 & 1.0018916 \\
\hline 79 & 0.9986373 & 0.9959119 & 1.0013627 & 0.9972746 & 1.0006289 \\
\hline 80 & & & & 0.9969538 & 1.0017857 \\
\hline 81 & 0.9989466 & 1.0053724 & 0.9986306 & 0.9974718 & 1.0020015 \\
\hline 82 & & & & 0.9991578 & 1.0028424 \\
\hline 83 & & & & & 1.0002113 \\
\hline 84 & 0.9978854 & 0.9961937 & 0.9997885 & & 1.0002115 \\
\hline 85 & & & & 0.9984108 & 1.0008475 \\
\hline 86 & 0.9979841 & 0.9960743 & 0.9983024 & 0.9975597 & 1.0007427 \\
\hline 87 & & & & 0.9992560 & 1.0011691 \\
\hline 88 & 0.9991465 & 0.9986130 & 1.0043743 & 0.9985063 & 1.0014937 \\
\hline 89 & & & & 0.9979738 & 1.0010664 \\
\hline 90 & 0.9977607 & 0.9956281 & 1.0006398 & 0.9979740 & 1.0009597 \\
\hline 91 & & & & 0.9988260 & 1.0003202 \\
\hline 92 & 0.9990368 & 0.9965753 & 1.0007491 & 0.9991438 & 1.0003211 \\
\hline 93 & & & & 1.0002143 & 1.0023570 \\
\hline 94 & 0.9979742 & 0.9950954 & 0.9996801 & 0.9978676 & 1.0008530 \\
\hline 95 & & & & 0.9985028 & 1.0014972 \\
\hline 96 & & & & & 1.0010796 \\
\hline 97 & 0.9985985 & 0.9964424 & 1.0007546 & & 1.0016171 \\
\hline 98 & & & & 0.9989208 & 1.0004317 \\
\hline 99 & 0.9985952 & 0.9966501 & 1.0011887 & 1.0002161 & 1.0015129 \\
\hline 100 & & & & 0.9989208 & 1.0011871 \\
\hline 101 & 0.9987006 & 0.9970763 & 1.0019491 & 1.0000000 & 1.0011911 \\
\hline 102 & & & & 0.9989158 & 1.0010842 \\
\hline 103 & 0.9998914 & 0.9967430 & 1.0021713 & 1.0002171 & 1.0035827 \\
\hline 104 & & & & 0.9994576 & 1.0009764 \\
\hline 105 & 0.9984799 & 0.9955483 & 0.9996743 & 1.0003257 & 1.0016287 \\
\hline 106 & & & & 0.9983664 & 1.0014158 \\
\hline 107 & 0.9981425 & 0.9969406 & 1.0013112 & 0.9990166 & 1.0017483 \\
\hline
\end{tabular}

Table 7.1 PMOD/WRC Method to Calculate WRR Reduction Factor for HF28968 


\begin{tabular}{|c|c|c|c|c|c|}
\hline & $H$ & I & $\mathbf{J}$ & $\mathbf{K}$ & $L$ \\
\hline 108 & & & & 0.9994535 & 1.0014209 \\
\hline \multicolumn{6}{|l|}{109} \\
\hline 110 & & & & & 1.0012997 \\
\hline 111 & 0.9991005 & 0.9973016 & 1.0008995 & & 1.0012992 \\
\hline 112 & & & & 0.9989005 & 1.0015992 \\
\hline 113 & 0.9997001 & 0.9979004 & 1.0020996 & 0.9991002 & 1.0011998 \\
\hline 114 & & & & 0.9984016 & 1.0007992 \\
\hline 115 & 0.9988017 & 0.9934092 & 1.0108848 & 0.9980028 & 1.0011983 \\
\hline 116 & & & & 0.9974052 & 1.0014970 \\
\hline 117 & 0.9983053 & 0.9967102 & 0.9939189 & 0.9983053 & 1.0008972 \\
\hline 118 & & & & 0.9993015 & 1.0008980 \\
\hline 119 & 0.9990018 & 0.9971052 & 1.0051907 & 0.9996007 & 1.0013975 \\
\hline 120 & & & & 0.9984018 & 1.0005993 \\
\hline 121 & 0.9994004 & 0.9980014 & 1.0048966 & 0.9988008 & 1.0012991 \\
\hline 122 & & & & 1.0010996 & 1.0013994 \\
\hline 123 & & & & & 1.0018013 \\
\hline 124 & 0.9989007 & 0.9977014 & 0.9999001 & & 1.0012992 \\
\hline 125 & & & & 0.9976988 & 1.0020010 \\
\hline 126 & 0.9992003 & 0.9971012 & 0.9987005 & 0.9988005 & 1.0010996 \\
\hline 127 & & & & 0.9972000 & 1.0020000 \\
\hline 128 & 0.9986004 & 0.9996001 & 0.9995001 & 0.9989003 & 1.0017995 \\
\hline 129 & & & & 0.9991001 & 1.0019998 \\
\hline 130 & 0.9999000 & 0.9984008 & 0.9958021 & 0.9987006 & 1.0020990 \\
\hline 131 & & & & 0.9992000 & 1.0020000 \\
\hline 132 & 0.9984983 & 0.9964961 & 1.0117129 & 0.9982981 & 1.0028031 \\
\hline 133 & & & & 0.9976988 & 1.0016008 \\
\hline 134 & 0.9976988 & 0.9978989 & 0.9955978 & 0.9976988 & 1.0016008 \\
\hline 135 & & & & 0.9984980 & 1.0023030 \\
\hline 136 & MEAN= R(k)'= & & & & \\
\hline 137 & 0.9987391 & 0.9974337 & 1.0009826 & 0.9988273 & 1.0013782 \\
\hline 138 & $\operatorname{SD}(k)^{\prime}=$ & & & & \\
\hline 139 & 0.0005648 & 0.0020621 & 0.0037683 & 0.0011913 & 0.0008673 \\
\hline 140 & \multicolumn{5}{|c|}{ MEAN OF CROM2L/PMO2, REJECTING READINGS NUMBER I8,24,40,45,51, } \\
\hline 141 & \multicolumn{5}{|c|}{ 55,81 AND $115=8$ READINGS= } \\
\hline 142 & & 0.9970142 & & & \\
\hline 143 & & 0.0010445 & & & \\
\hline 144 & \multirow{2}{*}{\multicolumn{5}{|c|}{\begin{tabular}{|l} 
MEAN OF CROM3R/PMO2, REJECTING READING NUMBER J4,6,8,14,24,28, \\
$32,34,36,42,49,53,58,62,66,88,115,117,119,121,130,132$ AND 134= 23 READINGS=
\end{tabular}}} \\
\hline 145 & & & & & \\
\hline 146 & & & 1.0006416 & & \\
\hline 147 & & & 0.0012786 & & \\
\hline 148 & \multicolumn{5}{|c|}{ MEAN OF MK67814/PMO2 AFTER REJECTING READING NUMBER K73= } \\
\hline 149 & & & & 0.9988669 & \\
\hline 150 & & & & 0.0011865 & \\
\hline 151 & MEAN= R(k)= & & & & \\
\hline 152 & 0.9987391 & 0.9970142 & 1.0006416 & 0.9988669 & 1.0013782 \\
\hline 153 & $S D=$ & & & & \\
\hline 154 & 0.0005648 & 0.0010445 & 0.0012786 & 0.0011865 & 0.0008673 \\
\hline 155 & & & & & \\
\hline 156 & PMO2 & PMO5 & CROM2L & CPOM3R & MK67814 \\
\hline 157 & WRR $(\mathbf{I P C 7 , K ) =}$ & & & & \\
\hline 158 & 0.9994370 & 1.0006300 & 1.0029400 & 0.9989010 & 1.0009400 \\
\hline 159 & $W(I P C 8, K)=$ & & & & \\
\hline 160 & 1.0000000 & 0.9999313 & 1.0005087 & 1.0001049 & 1.0003690 \\
\hline
\end{tabular}

Table 7.1 PMOD/WRC Method to Calculate WRR Reduction Factor for HF28968 


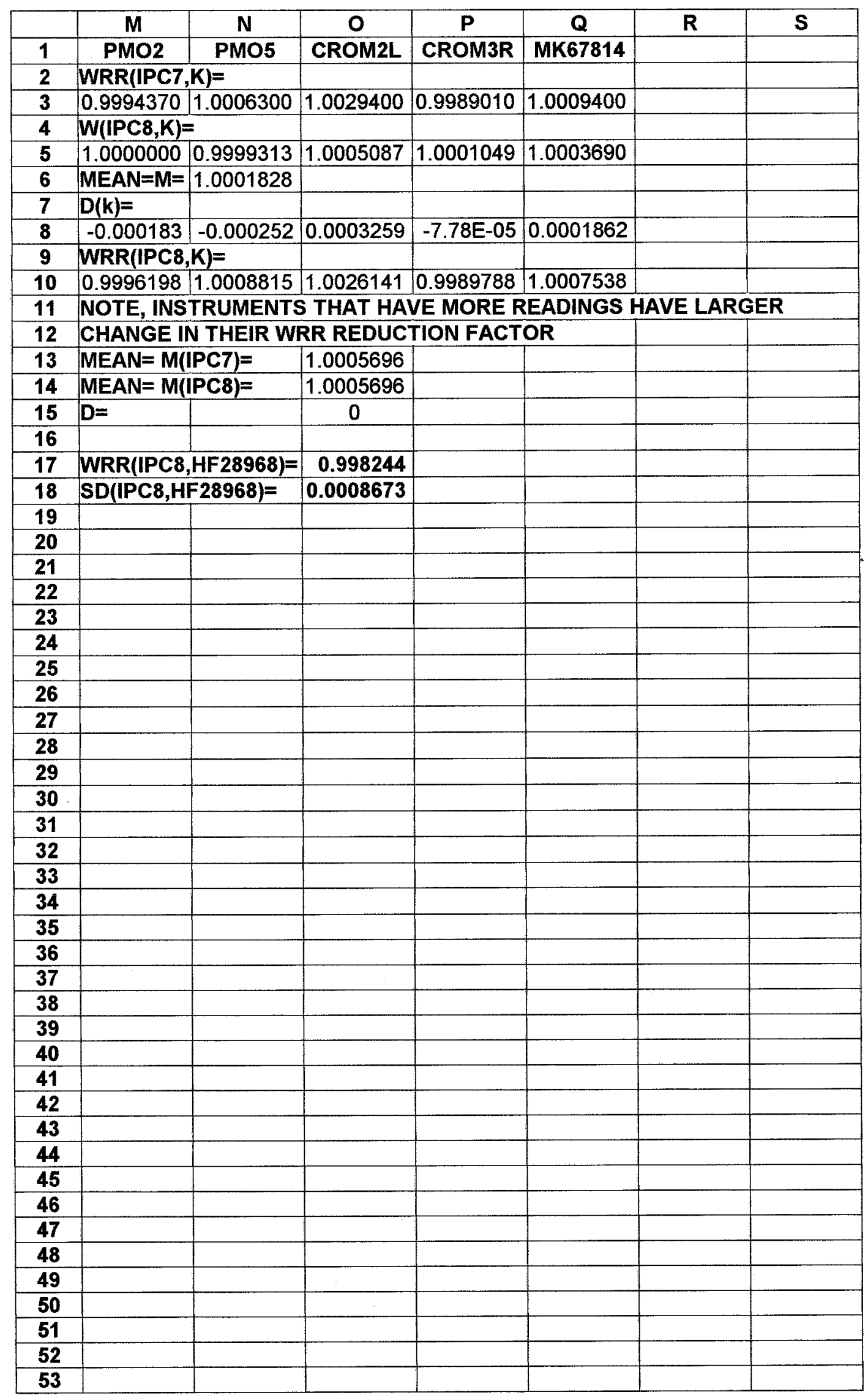

Table 7.1 PMOD/WRC Method to Calculate WRR Reduction Factor for HF28968 


\subsection{Proposed method}

The following rows, cells, or columns in Table 7.2 describe the sequence of the proposed method used to calculate the WRR reduction factor for HF28968.

a) Columns $B$ through $F$ contain the irradiance readings of the WSG instruments; the whole population of data is divided into seven samples. Rows 6 through 11, 13 through 25, 28 through 30,34 through 48, 51 through 52, 56 through 58 and 61 through 83 , are samples, $1,2,3,4,5,6$ and 7 respectively.

b) Columns $G$ through $\mathrm{K}$ contain the ratios of irradiances of the WSG instruments to a reference irradiance using Equations 6.1 through 6.3 .

c) Cells G86 through $\mathrm{k} 86$ contain the mean of ratios in step (b) after rejecting the outliers.

d) Cells G88 through K88 contain the standard deviations of the mean of ratios in step (c).

e) Cells G95 through K95, G97 through K97, G99 through K99, G101 through K101, G103 through K103, G105 through K105 and G92 through $\mathrm{K} 92$ contain the weighting factors for each of the WSG instruments for samples, $1,2,3,4,5,6$, and 7 respectively. The weighting factor is calculated using Equations 6.7 and 6.8 .

f) Column L contains a reference irradiance calculated using Equation 6.9 .

g) Columns $M$ through $Q$ contain the ratios of the irradiances 
in columns $B$ through $F$ to the reference irradiances in column L.

h) Cells M86 through Q86 contain the WRR reduction factors for the WSG instruments during IPC-VIII, which is the mean of the ratios in step ( $\mathrm{g}$ ).

i) Cells M88 through Q88 contain the standard deviations of the means in step ( $h$ ).

j) The weighting factors are recalculated in the same rows as in step (e) but using columns $M$ through $Q$ instead of columns $\mathrm{G}$ through $\mathrm{K}$.

k) Column $\mathrm{R}$ contains the reference irradiance calculated using Equation 6.11.

1) Column $S$ contains a sample of irradiance readings for HF28968 during IPC-VIII.

m) Column $T$ contains the ratio of column $R$ to column 1 .

n) Cell T86 contains the mean of the ratios in step (m), which is the WRR reduction factor for HF28968 during IPCVIII.

o) Cell T88 contains the standard deviation of the WRR reduction factor for HF28968 during IPC-VIII. 


\begin{tabular}{|c|c|c|c|c|c|c|}
\hline & A & B & C & D & $\mathbf{E}$ & $\mathbf{F}$ \\
\hline 1 & Date/Time & PMO2 & PMO5 & CROM2L & CROM3R & MK67814 \\
\hline 2 & \multicolumn{2}{|c|}{ WRR from (IPC7): } & & & & \\
\hline 3 & & 0.999437 & 1.00063 & 1.00294 & 0.998901 & 1.00094 \\
\hline \multicolumn{7}{|c|}{ - } \\
\hline 5 & $10 / 2 / 95$ & & & & & \\
\hline 6 & $11: 24: 00$ & 1022.2 & 1020.7 & 1019 & & \\
\hline 7 & $11: 27: 00$ & 1021.2 & 1020.3 & 1020.7 & & \\
\hline 8 & $11: 39: 00$ & 1015.1 & 1013.4 & 1010.7 & & \\
\hline 9 & $10 / 11 / 95$ & & & & & \\
\hline 10 & $11: 03: 00$ & 938.6 & 938 & 936.4 & & \\
\hline 11 & $12: 24: 00$ & 956.7 & 954.8 & 952.6 & & \\
\hline \multicolumn{7}{|l|}{12} \\
\hline 13 & $11: 33: 00$ & 1018.2 & 1017.8 & 1015.7 & 1018.5 & \\
\hline 14 & $11: 36: 00$ & 1016.9 & 1015.8 & 1013.6 & 1015.9 & \\
\hline 15 & $10 / 3 / 95$ & & & & & \\
\hline 16 & $10: 21: 00$ & 932.6 & 931.9 & 929.1 & 935.6 & \\
\hline 17 & $10: 24: 00$ & 932.7 & 931.1 & 930 & 935.2 & \\
\hline 18 & $10: 27: 00$ & 938 & 936.6 & 934.4 & 939.3 & \\
\hline 19 & $10 / 11 / 95$ & & & & & \\
\hline 20 & 12:51:00 & 953.6 & 953.2 & 951.5 & 952.8 & \\
\hline 21 & $13: 18: 00$ & 945.8 & 943.8 & 942.2 & 945.6 & \\
\hline 22 & $13: 45: 00$ & 927.6 & 926.3 & 924.3 & 928.3 & \\
\hline 23 & $10 / 12 / 95$ & & & & & \\
\hline 24 & $11: 57: 00$ & 1000.6 & 999.7 & 997.9 & 1001.5 & \\
\hline 25 & $12: 24: 00$ & 1000.6 & 999.5 & 998.3 & 1000.5 & \\
\hline \multicolumn{7}{|l|}{26} \\
\hline 27 & $10 / 3 / 95$ & & & & & \\
\hline 28 & $10: 33: 00$ & 942.5 & 941 & & 942.5 & \\
\hline 29 & $10 / 11 / 95$ & & & & & \\
\hline 30 & $11: 57: 00$ & 950.8 & 949.4 & & 953.3 & \\
\hline \multicolumn{7}{|l|}{31} \\
\hline \multicolumn{7}{|l|}{32} \\
\hline 33 & $10 / 11 / 95$ & & & & & \\
\hline 34 & $11: 06: 00$ & 941.6 & 940.5 & 939.3 & & 941.9 \\
\hline 35 & $11: 09: 00$ & 941.4 & 940.3 & 937.6 & & 941.9 \\
\hline 36 & $11: 18: 00$ & 946.7 & 945.8 & 944.6 & & 946.3 \\
\hline 37 & $12: 03: 00$ & 954.1 & 953.2 & 951.9 & & 952.8 \\
\hline 38 & $12: 09: 00$ & 956.6 & 954.3 & 952 & & 955.2 \\
\hline 39 & $12: 30: 00$ & 960.2 & 958.4 & 957.1 & & 958.3 \\
\hline 40 & $12: 36: 00$ & 959 & 957.4 & 955.5 & & 958.3 \\
\hline 41 & $13: 24: 00$ & 937.3 & 936.5 & 936 & & 935.9 \\
\hline 42 & $10 / 12 / 95$ & & & & & \\
\hline 43 & $12: 06: 00$ & 1003.1 & 1001.4 & 999.8 & & 1001.4 \\
\hline 44 & $12: 09: 00$ & 1001.8 & 1000.8 & 998.9 & & 1001.4 \\
\hline 45 & $12: 12: 00$ & 1000.7 & 1000.1 & 998.7 & & 999.5 \\
\hline 46 & $12: 33: 00$ & 1000.5 & 1000.4 & 998.9 & & 999.2 \\
\hline 47 & $12: 36: 00$ & 998.9 & 997.4 & 995.4 & & 997.2 \\
\hline 48 & $12: 39: 00$ & 999.5 & 997.2 & 997.4 & & 997.2 \\
\hline \multicolumn{7}{|l|}{49} \\
\hline 50 & $10 / 11 / 95$ & & & & & \\
\hline 51 & $11: 15: 00$ & 948.7 & 946.9 & & 950 & 948.5 \\
\hline 52 & $12: 06: 00$ & 954.7 & 954.4 & & 956.9 & 955.2 \\
\hline 53 & & & & & & \\
\hline
\end{tabular}

Table 7.2 Proposed Method to Calculate WRR reduction Factor for HF28968 


\begin{tabular}{|c|c|c|c|c|c|c|}
\hline & A & B & C & D & $\mathbf{E}$ & $\mathbf{F}$ \\
\hline \multicolumn{7}{|l|}{54} \\
\hline 55 & $10 / 11 / 95$ & & & & & \\
\hline 56 & $13: 06: 00$ & 949.3 & 948.3 & & & 946.9 \\
\hline 57 & $10 / 12 / 95$ & & & & & \\
\hline 58 & $12: 03: 00$ & 1001.4 & 1000.2 & & & 999.4 \\
\hline \multicolumn{7}{|l|}{59} \\
\hline 60 & $10 / 11 / 95$ & & & & & \\
\hline 61 & $11: 12: 00$ & 941.9 & 940.4 & 941.1 & 941.1 & 941.9 \\
\hline 62 & $12: 00: 00$ & 951.9 & 951.4 & 951 & 951 & 950.7 \\
\hline 63 & $12: 12: 00$ & 956.9 & 956.4 & 958.8 & 958.8 & 957.6 \\
\hline 64 & $12: 27: 00$ & 956.8 & 954.9 & 953.2 & 957.6 & 955.9 \\
\hline 65 & $12: 33: 00$ & 954.8 & 953.3 & 952.4 & 957 & 953.7 \\
\hline 66 & $12: 39: 00$ & 958 & 956.8 & 954.9 & 958.5 & 958.3 \\
\hline 67 & $12: 54: 00$ & 953.5 & 952.5 & 949.2 & 952.8 & 949.1 \\
\hline 68 & $12: 57: 00$ & 954.6 & 953.4 & 951.6 & 955.1 & 951.4 \\
\hline 69 & $13: 00: 00$ & 953.8 & 952.7 & 951.2 & 954.5 & 951.4 \\
\hline 70 & $13: 03: 00$ & 954 & 952.7 & 950.1 & 955.3 & 951.4 \\
\hline 71 & $13: 21: 00$ & 942.5 & 940.6 & 938.8 & 940.9 & 940.2 \\
\hline 72 & $13: 27: 00$ & 937.8 & 935.7 & 933.7 & 938.4 & 935.9 \\
\hline 73 & $13: 30: 00$ & 934.4 & 933.5 & 931.2 & 935.1 & 933.6 \\
\hline 74 & $13: 33: 00$ & 937.9 & 936 & 933.3 & 937.6 & 935.9 \\
\hline 75 & $13: 48: 00$ & 925.4 & 924.1 & 922.3 & 926.5 & 925.6 \\
\hline 76 & $13: 51: 00$ & 923.5 & 922.3 & 920.8 & 925.3 & 923.5 \\
\hline 77 & $13: 54: 00$ & 921.1 & 921 & 918.1 & 923.1 & 921.3 \\
\hline 78 & $13: 57: 00$ & 921 & 919.6 & 916.9 & 920.7 & 921.3 \\
\hline 79 & $14: 00: 00$ & 915.2 & 913.5 & 912.4 & 916.4 & 914.3 \\
\hline 80 & $10 / 12 / 95$ & & & & & \\
\hline 81 & $12: 00: 00$ & 1000.2 & 999.9 & 998.1 & 1002.3 & 999.3 \\
\hline 82 & $12: 27: 00$ & 1000.4 & 999.6 & 997.5 & 999.1 & 999.2 \\
\hline 83 & $12: 30: 00$ & 1000.3 & 998.9 & 999.9 & 999.8 & 999.2 \\
\hline \multicolumn{7}{|l|}{84} \\
\hline \multicolumn{7}{|l|}{85} \\
\hline \multicolumn{7}{|l|}{86} \\
\hline \multicolumn{7}{|l|}{87} \\
\hline \multicolumn{7}{|l|}{88} \\
\hline \multicolumn{7}{|l|}{89} \\
\hline \multicolumn{7}{|l|}{90} \\
\hline \multicolumn{7}{|l|}{91} \\
\hline \multicolumn{7}{|l|}{92} \\
\hline \multicolumn{7}{|l|}{93} \\
\hline \multicolumn{7}{|l|}{94} \\
\hline \multicolumn{7}{|l|}{95} \\
\hline \multicolumn{7}{|l|}{96} \\
\hline \multicolumn{7}{|l|}{97} \\
\hline \multicolumn{7}{|l|}{98} \\
\hline \multicolumn{7}{|l|}{99} \\
\hline \multicolumn{7}{|l|}{100} \\
\hline 101 & & & & & & \\
\hline 102 & & & & & & \\
\hline 103 & & & & & & \\
\hline 104 & & & & & & \\
\hline 105 & & & & & & \\
\hline
\end{tabular}

Table 7.2 Proposed Method to Calculate WRR reduction Factor for HF28968 


\begin{tabular}{|c|c|c|c|c|c|c|}
\hline & $\mathbf{G}$ & $\mathrm{H}$ & I & $\mathbf{J}$ & $K$ & $\mathbf{L}$ \\
\hline 1 & $\mathbf{R}^{\prime \prime}(\mathrm{j}, \mathrm{PMO})$ & $R^{\prime \prime}(\mathrm{j}, \mathrm{PMO5})$ & R"(j,CROM2L) & $R^{\prime \prime}(\mathrm{j}, \mathrm{CROM} 3 \mathrm{R})$ & $R^{\prime \prime}(j, M K 67814)$ & $I^{*}($ ref.,j) \\
\hline \multicolumn{7}{|l|}{2} \\
\hline \multicolumn{7}{|l|}{3} \\
\hline \multicolumn{7}{|l|}{4} \\
\hline \multicolumn{7}{|l|}{5} \\
\hline 6 & 0.999466 & 1.000935 & 1.002605 & & & 1021.54 \\
\hline 7 & 1.000545 & 1.001427 & 1.001035 & & & 1021.19 \\
\hline 8 & 0.998995 & 1.000670 & 1.003344 & & & 1014.17 \\
\hline \multicolumn{7}{|l|}{9} \\
\hline 10 & 1.000006 & 1.000645 & 1.002355 & & & 938.47 \\
\hline 11 & 0.998907 & 1.000895 & 1.003207 & & & 955.69 \\
\hline \multicolumn{7}{|l|}{12} \\
\hline 13 & 0.999837 & 1.000230 & 1.002298 & 0.999542 & & 1018.08 \\
\hline 14 & 0.999147 & 1.000229 & 1.002400 & 1.000131 & & 1016.24 \\
\hline \multicolumn{7}{|l|}{15} \\
\hline 16 & 1.000152 & 1.000903 & 1.003919 & 0.996945 & & 932.49 \\
\hline 17 & 0.999991 & 1.001710 & 1.002895 & 0.997318 & & 932.24 \\
\hline 18 & 0.999487 & 1.000981 & 1.003338 & 0.998104 & & 937.39 \\
\hline \multicolumn{7}{|l|}{19} \\
\hline 20 & 0.999610 & 1.000030 & 1.001817 & 1.000450 & & 953.40 \\
\hline 21 & 0.998941 & 1.001058 & 1.002758 & 0.999152 & & 944.77 \\
\hline 22 & 0.999423 & 1.000825 & 1.002991 & 0.998669 & & 927.01 \\
\hline \multicolumn{7}{|l|}{23} \\
\hline 24 & 0.999800 & 1.000700 & 1.002505 & 0.998902 & & 1000.30 \\
\hline 25 & 0.999601 & 1.000701 & 1.001904 & 0.999701 & & 1000.15 \\
\hline \multicolumn{7}{|l|}{26} \\
\hline \multicolumn{7}{|l|}{27} \\
\hline 28 & 0.999125 & 1.000718 & & 0.999125 & & 941.72 \\
\hline \multicolumn{7}{|l|}{29} \\
\hline 30 & 1.000040 & 1.001515 & & 0.997418 & & 950.37 \\
\hline \multicolumn{7}{|l|}{31} \\
\hline \multicolumn{7}{|l|}{32} \\
\hline \multicolumn{7}{|l|}{33} \\
\hline 34 & 1.000162 & 1.001332 & 1.002611 & & 0.999843 & 941.44 \\
\hline 35 & 0.999815 & 1.000985 & 1.003867 & & 0.999285 & 941.09 \\
\hline 36 & 1.000087 & 1.001039 & 1.002310 & & 1.000510 & 946.55 \\
\hline 37 & 0.999832 & 1.000776 & 1.002142 & & 1.001196 & 953.81 \\
\hline 38 & 0.998813 & 1.001221 & 1.003640 & & 1.000277 & 955.43 \\
\hline 39 & 0.999213 & 1.001090 & 1.002450 & & 1.001194 & 959.35 \\
\hline 40 & 0.999472 & 1.001142 & 1.003133 & & 1.000202 & 958.36 \\
\hline 41 & 1.000052 & 1.000906 & 1.001441 & & 1.001548 & 937.13 \\
\hline \multicolumn{7}{|l|}{42} \\
\hline 43 & 0.999314 & 1.001010 & 1.002612 & & 1.001010 & 1002.32 \\
\hline 44 & 0.999911 & 1.000910 & 1.002814 & & 1.000311 & 1001.54 \\
\hline 45 & 1.000036 & 1.000636 & 1.002038 & & 1.001236 & 1000.60 \\
\hline 46 & 1.000236 & 1.000336 & 1.001838 & & 1.001537 & 1000.64 \\
\hline 47 & 0.999307 & 1.000810 & 1.002820 & & 1.001010 & 998.18 \\
\hline 48 & 0.999308 & 1.001613 & 1.001412 & & 1.001613 & 998.52 \\
\hline \multicolumn{7}{|l|}{49} \\
\hline \multicolumn{7}{|l|}{50} \\
\hline 51 & 0.999792 & 1.001692 & & 0.998424 & 1.000003 & 948.14 \\
\hline 52 & 1.000605 & 1.000919 & & 0.998304 & 1.000081 & 954.97 \\
\hline 53 & & & & & & \\
\hline
\end{tabular}

Table 7.2 Proposed Method to Calculate WRR reduction Factor for HF28968 


\begin{tabular}{|c|c|c|c|c|c|c|}
\hline & G & H & 1 & $\mathbf{J}$ & $\mathbf{K}$ & $L$ \\
\hline \multicolumn{7}{|l|}{54} \\
\hline \multicolumn{7}{|l|}{55} \\
\hline 56 & 0.999141 & 1.000194 & & & 1.001673 & 948.67 \\
\hline \multicolumn{7}{|l|}{57} \\
\hline 58 & 0.999270 & 1.000468 & & & 1.001269 & 1000.75 \\
\hline \multicolumn{7}{|l|}{59} \\
\hline \multicolumn{7}{|l|}{60} \\
\hline 61 & 0.999911 & 1.001506 & 1.000761 & 1.000761 & 0.999911 & 941.56 \\
\hline 62 & 0.999834 & 1.000359 & 1.000780 & 1.000780 & 1.001096 & 951.77 \\
\hline 63 & 1.001406 & 1.001930 & 0.999422 & 0.999422 & 1.000674 & 957.57 \\
\hline 64 & 0.999396 & 1.001385 & 1.003171 & 0.998561 & 1.000337 & 956.05 \\
\hline 65 & 0.999981 & 1.001554 & 1.002501 & 0.997682 & 1.001134 & 954.43 \\
\hline 66 & 0.999837 & 1.001091 & 1.003083 & 0.999315 & 0.999524 & 957.70 \\
\hline 67 & 0.998385 & 0.999433 & 1.002907 & 0.999118 & 1.003013 & 952.43 \\
\hline 68 & 0.999121 & 1.000379 & 1.002271 & 0.998598 & 1.002482 & 953.85 \\
\hline 69 & 0.999435 & 1.000589 & 1.002167 & 0.998702 & 1.001956 & 953.26 \\
\hline 70 & 0.999204 & 1.000567 & 1.003305 & 0.997844 & 1.001934 & 953.27 \\
\hline 71 & 0.998551 & 1.000568 & 1.002487 & 1.000249 & 1.000994 & 941.33 \\
\hline 72 & 0.998967 & 1.001209 & 1.003353 & 0.998328 & 1.000995 & 936.77 \\
\hline 73 & 0.999668 & 1.000632 & 1.003103 & 0.998920 & 1.000525 & 934.07 \\
\hline 74 & 0.998690 & 1.000717 & 1.003612 & 0.999009 & 1.000824 & 936.79 \\
\hline 75 & 0.999897 & 1.001304 & 1.003258 & 0.998710 & 0.999681 & 925.09 \\
\hline 76 & 1.000112 & 1.001414 & 1.003045 & 0.998167 & 1.000112 & 923.31 \\
\hline 77 & 1.000372 & 1.000480 & 1.003641 & 0.998204 & 1.000155 & 921.34 \\
\hline 78 & 0.999373 & 1.000894 & 1.003841 & 0.999698 & 0.999047 & 920.43 \\
\hline 79 & 0.999649 & 1.001510 & 1.002717 & 0.998340 & 1.000633 & 914.63 \\
\hline \multicolumn{7}{|l|}{80} \\
\hline 81 & 1.000328 & 1.000628 & 1.002432 & 0.998232 & 1.001229 & 1000.36 \\
\hline 82 & 0.999328 & 1.000128 & 1.002234 & 1.000629 & 1.000529 & 999.93 \\
\hline 83 & 0.999889 & 1.001291 & 1.000289 & 1.000389 & 1.000990 & 999.95 \\
\hline \multicolumn{7}{|l|}{84} \\
\hline \multicolumn{7}{|c|}{\begin{tabular}{l|l}
85 & $R$ \\
\end{tabular}} \\
\hline 86 & 0.99962755 & 1.00089153 & 1.002527008 & 0.998940082 & 1.000789312 & \\
\hline 87 & SD"(k)= & & & & & \\
\hline 88 & 0.00055147 & 0.00048267 & 0.000925781 & 0.000985592 & 0.000829701 & \\
\hline \multicolumn{7}{|c|}{$89\left(1 / \text { SD" }^{\prime \prime}(\mathrm{k})\right)^{\wedge} 2=$} \\
\hline 90 & 3288234.09 & 4292304.62 & 1166765.713 & 1029450.916 & 1452634.548 & \\
\hline 91 & \multicolumn{6}{|c|}{ WF'(k) WHEN ALL INSTRUMENTS FROM THE WSG ARE PARTICIPATING= } \\
\hline 92 & 0.29282393 & 0.38223845 & 0.103902859 & 0.091674697 & 0.12936006 & \\
\hline 93 & SUM= & 1 & & & & \\
\hline 94 & \multicolumn{6}{|c|}{ WF'(k) WHEN PMO2,PMO5 AND CROM2L ARE PARTICIPATING= } \\
\hline 95 & 0.37591399 & 0.49070027 & 0.133385744 & & & \\
\hline 96 & \multicolumn{6}{|c|}{ WF'(K) WHEN PMO2, PMO5, CROM2L AND CROM3R ARE PARTICIPATING= } \\
\hline 97 & 0.33633184 & 0.43903161 & 0.119340791 & 0.105295763 & & \\
\hline 98 & \multicolumn{6}{|c|}{ WF'(k) WHEN PMO2, PMO5 AND CROM3R ARE PARTICIPATING= } \\
\hline 99 & 0.38190918 & 0.49852611 & & 0.11956471 & & \\
\hline 100 & \multicolumn{6}{|c|}{ WF'(k) WHEN PMO2,PMO5, CROM2L AND MK67814 ARE PARTICIPATING= } \\
\hline 101 & 0.32237782 & 0.4208167 & 0.11438948 & & 0.142416004 & \\
\hline 102 & \multicolumn{6}{|c|}{ WF'(k) WHEN PMO2, PMO5, CROM3R AND MK67814 ARE PARTICIPATING= } \\
\hline 103 & 0.32677699 & 0.42655917 & & 0.102304419 & 0.144359416 & \\
\hline 104 & \multicolumn{5}{|c|}{ WF'(k) WHEN PMO2, PMO5 AND MK67814 ARE PARTICIPATING= } & \\
\hline 105 & 0.3640176 & 0.47517129 & & & 0.160811102 & \\
\hline
\end{tabular}

Table 7.2 Proposed Method to Calculate WRR reduction Factor for HF28968 


\begin{tabular}{|c|c|c|c|c|c|}
\hline & $\mathbf{M}$ & $\mathbf{N}$ & $\mathbf{O}$ & $\mathbf{P}$ & $\mathbf{Q}$ \\
\hline 1 & R(i,PMO2) & $\mathbf{R}(\mathbf{j}, \mathbf{P M O 5 )}$ & R(j,CROM2L) & R(j,CROM3R) & R(j,MK67814) \\
\hline \multicolumn{6}{|l|}{2} \\
\hline \multicolumn{6}{|l|}{3} \\
\hline \multicolumn{6}{|l|}{4} \\
\hline \multicolumn{6}{|l|}{5} \\
\hline 6 & 0.999350345 & 1.00081897 & 1.002488639 & & \\
\hline 7 & 0.999991421 & 1.000873507 & 1.000481277 & & \\
\hline 8 & 0.99908749 & 1.00076348 & 1.003436936 & & \\
\hline \multicolumn{6}{|l|}{9} \\
\hline 10 & 0.999862214 & 1.000501784 & 1.002211313 & & \\
\hline 11 & 0.9989412 & 1.000929039 & 1.003240653 & & \\
\hline \multicolumn{6}{|l|}{12} \\
\hline 13 & 0.999886904 & 1.000279864 & 1.002347983 & 0.999592387 & \\
\hline 14 & 0.999355319 & 1.000437511 & 1.002608942 & 1.000339033 & \\
\hline \multicolumn{6}{|l|}{15} \\
\hline 16 & 0.999881785 & 1.000632849 & 1.003648426 & 0.996675665 & \\
\hline 17 & 0.999504203 & 1.001221749 & 1.00240599 & 0.996832304 & \\
\hline 18 & 0.999353094 & 1.000846895 & 1.003203341 & 0.99796998 & \\
\hline \multicolumn{6}{|l|}{19} \\
\hline 20 & 0.999786282 & 1.000205832 & 1.001992852 & 1.000625734 & \\
\hline 21 & 0.998915587 & 1.001032382 & 1.002732288 & 0.999126863 & - \\
\hline 22 & 0.999360263 & 1.000762798 & 1.002928248 & 0.998606679 & \\
\hline \multicolumn{6}{|l|}{23} \\
\hline 24 & 0.999698868 & 1.000598867 & 1.002403735 & 0.998800487 & \\
\hline 25 & 0.99955379 & 1.000653849 & 1.001856679 & 0.999653696 & \\
\hline \multicolumn{6}{|l|}{26} \\
\hline \multicolumn{6}{|l|}{27} \\
\hline 28 & 0.999173745 & 1.000766477 & & 0.999173745 & \\
\hline \multicolumn{6}{|l|}{29} \\
\hline 30 & 0.999547174 & 1.001021122 & & 0.996925893 & \\
\hline \multicolumn{6}{|l|}{31} \\
\hline \multicolumn{6}{|l|}{32} \\
\hline \multicolumn{6}{|l|}{33} \\
\hline 34 & 0.999827056 & 1.000996445 & 1.002275265 & & 0.999508606 \\
\hline 35 & 0.999674386 & 1.000843844 & 1.003725967 & & 0.999143717 \\
\hline 36 & 0.999838763 & 1.000790185 & 1.002061568 & & 1.000261394 \\
\hline 37 & 0.999697818 & 1.00064172 & 1.002008286 & & 1.001061805 \\
\hline 38 & 0.998781059 & 1.001188264 & 1.003607102 & & 1.000244934 \\
\hline 39 & 0.999111965 & 1.000988428 & 1.00234804 & & 1.001092882 \\
\hline 40 & 0.999328499 & 1.000998569 & 1.002989043 & & 1.000058469 \\
\hline 41 & 0.999822352 & 1.000676445 & 1.001210994 & & 1.001317972 \\
\hline \multicolumn{6}{|l|}{42} \\
\hline 43 & 0.999221154 & 1.000917455 & 1.002519244 & & 1.000917455 \\
\hline 44 & 0.999744442 & 1.000743387 & 1.002646894 & & 1.000143781 \\
\hline 45 & 0.999901088 & 1.000500969 & 1.001903494 & & 1.00110157 \\
\hline 46 & 1.000143013 & 1.000242987 & 1.001745004 & & 1.00144424 \\
\hline 47 & 0.99927689 & 1.000779712 & 1.002790521 & & 1.00098043 \\
\hline 48 & 0.999015746 & 1.001319934 & 1.001119148 & & 1.001319934 \\
\hline \multicolumn{6}{|l|}{49} \\
\hline \multicolumn{6}{|l|}{50} \\
\hline 51 & 0.999407759 & 1.001307573 & & 0.998040148 & 0.999618493 \\
\hline 52 & 1.000285064 & 1.000599487 & & 0.997985317 & 0.999761464 \\
\hline 53 & & & & & \\
\hline
\end{tabular}

Table 7.2 Proposed Method to Calculate WRR reduction Factor for HF28968 


\begin{tabular}{|c|c|c|c|c|c|}
\hline & $M$ & $\mathbf{N}$ & 0 & $\mathbf{P}$ & $\mathbf{Q}$ \\
\hline \multicolumn{6}{|l|}{54} \\
\hline \multicolumn{6}{|l|}{55} \\
\hline 56 & 0.999337763 & 1.000391583 & & & 1.001870671 \\
\hline \multicolumn{6}{|l|}{57} \\
\hline 58 & 0.999354327 & 1.000553312 & & & 1.001354235 \\
\hline \multicolumn{6}{|l|}{59} \\
\hline \multicolumn{6}{|l|}{60} \\
\hline 61 & 0.999637419 & 1.001231907 & 1.00048718 & 1.00048718 & 0.999637419 \\
\hline 62 & 0.999863574 & 1.000389044 & 1.000809817 & 1.000809817 & 1.00112563 \\
\hline 63 & 1.000696422 & 1.00121958 & 0.998713398 & 0.998713398 & 0.999964918 \\
\hline 64 & 0.999215976 & 1.001204153 & 1.002989767 & 0.998381209 & 1.000156759 \\
\hline 65 & 0.999611824 & 1.001184694 & 1.002130795 & 0.997313865 & 1.000764778 \\
\hline 66 & 0.99968485 & 1.000938636 & 1.002930241 & 0.999163366 & 0.999371895 \\
\hline 67 & 0.998877003 & 0.999925693 & 1.003402046 & 0.999610855 & 1.003507768 \\
\hline 68 & 0.999218435 & 1.000476105 & 1.002368556 & 0.998695339 & 1.002579271 \\
\hline 69 & 0.999429041 & 1.000582995 & 1.00216087 & 0.998696091 & 1.001950199 \\
\hline 70 & 0.999237509 & 1.000601011 & 1.00333921 & 0.997877717 & 1.00196824 \\
\hline 71 & 0.998761241 & 1.000778726 & 1.002697561 & 1.000459634 & 1.001204499 \\
\hline 72 & 0.998896999 & 1.001138833 & 1.003283288 & 0.998258318 & 1.000924891 \\
\hline 73 & 0.999645283 & 1.000609054 & 1.00308049 & 0.998896965 & 1.000501877 \\
\hline 74 & 0.998821489 & 1.000849011 & 1.003744427 & 0.999141077 & 1.000955951 \\
\hline 75 & 0.999663256 & 1.001069557 & 1.003023287 & 0.998476392 & 0.999447253 \\
\hline 76 & 0.999789637 & 1.001090458 & 1.002721253 & 0.997844731 & 0.999789637 \\
\hline 77 & 1.000258837 & 1.000367443 & 1.003527301 & 0.998091664 & 1.000041696 \\
\hline 78 & 0.999379858 & 1.000901315 & 1.003848674 & 0.999705495 & 0.999054433 \\
\hline 79 & 0.999376273 & 1.001236086 & 1.002443188 & 0.998067618 & 1.000360018 \\
\hline \multicolumn{6}{|l|}{80} \\
\hline 81 & 1.000155056 & 1.000455133 & 1.00225938 & 0.99805955 & 1.001055827 \\
\hline 82 & 0.999530556 & 1.0003305 & 1.002436459 & 1.000831116 & 1.000730953 \\
\hline 83 & 0.999647673 & 1.001048721 & 1.000047572 & 1.000147597 & 1.000748166 \\
\hline 84 & WRR(IPC8) & & & & \\
\hline 85 & PMO2 & PMO5 & CROM2L & CROM3R & MK67814 \\
\hline 86 & 0.999516088 & 1.000779929 & 1.002419267 & 0.99883547 & 1.000676103 \\
\hline 87 & $\operatorname{SD}(\mathbf{k})=$ & & & & \\
\hline 88 & 0.00040699 & 0.00032042 & 0.000985037 & 0.001113079 & 0.000940421 \\
\hline 89 & $(1 / S D(k))^{\wedge} 2=$ & & & & \\
\hline 90 & 6037150.257 & 9740021.616 & 1030610.526 & 807138.9198 & 1130720.495 \\
\hline 91 & \multicolumn{5}{|c|}{ WF'(k) WHEN ALL INSTRUMENTS FROM THE WSG ARE PARTICIPATING= } \\
\hline 92 & 0.322056205 & 0.519588591 & 0.054978674 & 0.043057417 & 0.060319113 \\
\hline 93 & SUM= & 1 & & & \\
\hline 94 & \multicolumn{5}{|c|}{ WF'(k) WHEN PMO2,PMO5 AND CROM2L ARE PARTICIPATING= } \\
\hline 95 & 0.359187792 & 0.579494747 & 0.06131746 & & \\
\hline 96 & \multicolumn{5}{|c|}{ WF'(k) WHEN PMO2, PMO5, CROM2L AND CROM3R ARE PARTICIPATING= } \\
\hline 97 & 0.342729334 & 0.552941534 & 0.058507813 & 0.045821318 & \\
\hline 98 & \multicolumn{5}{|c|}{ WF'(k) WHEN PMO2, PMO5 AND CROM3R ARE PARTICIPATING= } \\
\hline 99 & 0.364027805 & 0.58730337 & & 0.048668825 & \\
\hline 100 & \multicolumn{5}{|c|}{ WF'(k) WHEN PMO2,PMO5, CROM2L AND MH67814 ARE PARTICIPATING= } \\
\hline 101 & 0.336547051 & 0.542967363 & 0.057452427 & & 0.063033158 \\
\hline 102 & \multicolumn{5}{|c|}{ WF'(k) WHEN PMO2, PMO5, CROM3R AND MK67814 ARE PARTICIPATING= } \\
\hline 103 & 0.340792526 & 0.549816789 & & 0.045562376 & 0.063828309 \\
\hline 104 & \multicolumn{5}{|c|}{ WF'(k) WHEN PMO2, PMO5 AND MK67814 ARE PARTICIPATING= } \\
\hline 105 & 0.357061077 & 0.576063616 & & & 0.066875307 \\
\hline
\end{tabular}

Table 7.2 Proposed Method to Calculate WRR reduction Factor for HF28968 


\begin{tabular}{|c|c|c|c|}
\hline & $\mathbf{R}$ & s & $\mathbf{T}$ \\
\hline 1 & WRR(IPC8,j) & i(j,HF28968) & WRR(IPC8,j,HF) \\
\hline \multicolumn{4}{|r|}{ 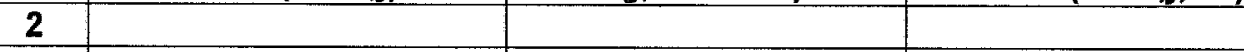 } \\
\hline \multicolumn{4}{|l|}{3} \\
\hline \multicolumn{4}{|l|}{4} \\
\hline \multicolumn{4}{|l|}{5} \\
\hline 6 & 1021.57 & 1022.9 & 0.99869913 \\
\hline 7 & 1021.08 & 1021.7 & 0.999395947 \\
\hline 8 & 1014.28 & 1016.9 & 0.997420162 \\
\hline \multicolumn{4}{|r|}{0.001720102} \\
\hline 10 & 938.52 & 940.2 & 0.998210065 \\
\hline 11 & 955.75 & 957 & 0.998698127 \\
\hline \multicolumn{4}{|r|}{ 0.00000 } \\
\hline 13 & 1018.21 & 1020.1 & 0.998142998 \\
\hline 14 & 1016.41 & 1017.7 & 0.998733845 \\
\hline \multicolumn{4}{|l|}{15} \\
\hline 16 & 932.47 & 933 & 0.999436578 \\
\hline 17 & 932.10 & 934.9 & 0.997005415 \\
\hline 18 & 937.41 & 938.5 & 0.998833462 \\
\hline \multicolumn{4}{|l|}{19} \\
\hline 20 & 953.56 & 955.6 & 0.99786098 \\
\hline 21 & 944.81 & 946 & 0.998739203 \\
\hline 22 & 927.05 & 929.1 & 0.997790334 \\
\hline \multicolumn{4}{|l|}{23} \\
\hline 24 & 1000.34 & 1001.9 & 0.998441457 \\
\hline 25 & 1000.21 & 1001.9 & 0.998308727 \\
\hline \multicolumn{4}{|l|}{26} \\
\hline \multicolumn{4}{|l|}{27} \\
\hline 28 & 941.83 & 942.8 & 0.998971806 \\
\hline \multicolumn{4}{|l|}{29} \\
\hline 30 & 950.31 & 952.3 & 0.997913256 \\
\hline \multicolumn{4}{|l|}{31} \\
\hline \multicolumn{4}{|l|}{32} \\
\hline \multicolumn{4}{|l|}{33} \\
\hline 34 & 941.31 & 942.8 & 0.998414529 \\
\hline 35 & 941.03 & 942.9 & 0.998018196 \\
\hline 36 & 946.48 & 950 & 0.996298439 \\
\hline 37 & 953.82 & 954.9 & 0.998873456 \\
\hline 38 & 955.42 & 958 & 0.997306988 \\
\hline 39 & 959.35 & 962 & 0.997243484 \\
\hline 40 & 958.31 & 960.7 & 0.997511224 \\
\hline 41 & 937.12 & 938.7 & 0.998313301 \\
\hline \multicolumn{4}{|l|}{42} \\
\hline 43 & 1002.32 & 1004 & 0.998329325 \\
\hline 44 & 1001.51 & 1003.2 & 0.998312875 \\
\hline 45 & 1000.63 & 1002 & 0.998628461 \\
\hline 46 & 1000.71 & 1002.6 & 0.998118944 \\
\hline 47 & 998.22 & 1001.7 & 0.996523854 \\
\hline 48 & 998.43 & 1001.1 & 0.997329218 \\
\hline \multicolumn{4}{|l|}{49} \\
\hline \multicolumn{4}{|l|}{50} \\
\hline 51 & 948.00 & 948.5 & 0.999469589 \\
\hline 52 & 954.91 & 956.8 & 0.998024108 \\
\hline 53 & & & \\
\hline
\end{tabular}

Table 7.2 Proposed Method to Calculate WRR reduction Factor for HF28968 


\begin{tabular}{|c|c|c|c|}
\hline & $\mathbf{R}$ & $\mathbf{S}$ & $T$ \\
\hline \multicolumn{4}{|l|}{54} \\
\hline \multicolumn{4}{|l|}{55} \\
\hline 56 & 948.87 & 951.2 & 0.997548646 \\
\hline \multicolumn{4}{|l|}{57} \\
\hline 58 & 1000.90 & 1002.6 & 0.998300916 \\
\hline \multicolumn{4}{|l|}{59} \\
\hline \multicolumn{4}{|l|}{60} \\
\hline 61 & 941.39 & 942.8 & 0.998507506 \\
\hline 62 & 951.83 & 954.2 & 0.99752081 \\
\hline 63 & 957.23 & 959.8 & 0.997317815 \\
\hline 64 & 955.95 & 957.2 & 0.998694747 \\
\hline 65 & 954.27 & 956.3 & 0.997879468 \\
\hline 66 & 957.60 & 960.6 & 0.99687918 \\
\hline 67 & 952.80 & 954.3 & 0.998431339 \\
\hline 68 & 954.00 & 955.7 & 0.998216097 \\
\hline 69 & 953.33 & 955.7 & 0.997515705 \\
\hline 70 & 953.36 & 954.6 & 0.998705135 \\
\hline 71 & 941.45 & 943.2 & 0.998146782 \\
\hline 72 & 936.74 & 938.7 & 0.997915211 \\
\hline 73 & 934.09 & 934.7 & 0.999343136 \\
\hline 74 & 936.87 & 938.7 & 0.998055551 \\
\hline 75 & 924.96 & 926.8 & 0.998012245 \\
\hline 76 & 923.15 & 924.6 & 0.998430799 \\
\hline 77 & 921.32 & 924.4 & 0.99667282 \\
\hline 78 & 920.39 & 922.5 & 0.997717964 \\
\hline 79 & 914.50 & 916.8 & 0.997491694 \\
\hline \multicolumn{4}{|l|}{80} \\
\hline 81 & 1000.34 & 1001.4 & 0.998938854 \\
\hline 82 & 1000.07 & 1001.5 & 0.998571168 \\
\hline 83 & 999.84 & 1002.1 & 0.997739958 \\
\hline \multicolumn{4}{|l|}{84} \\
\hline 85 & MEAN, M(IPC8) & & WRR(IPC8,HF28968) \\
\hline 86 & 1.00 & & 0.998103001 \\
\hline 87 & & & SD(IPC8,HF28968) \\
\hline 88 & MEAN, M(IPC7) & & 0.000697432 \\
\hline 89 & 1.00 & & \\
\hline 90 & $D=-124 p p m$ & & \\
\hline \multicolumn{4}{|l|}{91} \\
\hline \multicolumn{4}{|l|}{92} \\
\hline \multicolumn{4}{|l|}{93} \\
\hline \multicolumn{4}{|l|}{94} \\
\hline \multicolumn{4}{|l|}{95} \\
\hline \multicolumn{4}{|l|}{96} \\
\hline \multicolumn{4}{|l|}{97} \\
\hline \multicolumn{4}{|l|}{98} \\
\hline \multicolumn{4}{|l|}{99} \\
\hline \multicolumn{4}{|l|}{100} \\
\hline \multicolumn{4}{|l|}{101} \\
\hline \multicolumn{4}{|l|}{102} \\
\hline \multicolumn{4}{|l|}{103} \\
\hline \multicolumn{4}{|l|}{104} \\
\hline 105 & & & \\
\hline
\end{tabular}

Table 7.2 Proposed Method to Calculate WRR reduction Factor for HF28968 


\section{Chapter 8}

\section{Observations and Conclusions Drawn from the International Pyrheliometer Comparisons IPC-VIII}

8.1. Using the PMOD/WRC method, a single instrument, PMO2, is used as a transfer instrument through which all instruments are compared to each other, resulting in a larger random component of uncertainty than if that transfer instrument were not interposed in the process.

8.2. Using the PMOD/WRC method, if an irradiance reading of PMO2 were out of tolerance, then all ratios to PMO2 would be rejected for that irradiance reading, which would result in rejection of good data.

8.3. The proposed method showed, independently, that PMO2 has a small standard deviation. This finding supports the PMOD/WRC choice to use it as a transfer instrument for its stability during the comparison. The proposed method also showed that PMO5 has an even smaller standard deviation than PMO2, which makes PMO5 a good candidate for future considerations and that CROM2L and CROM $3 R$ have the largest standard deviations of all the WSG.

8.4. The standard deviation of the WRR reduction factor derived by using the proposed method is smaller than the standard deviation derived by using the PMOD/WRC method (see Table 8.1).

8.5. The difference between the WRR reduction factors derived by each method is much smaller than the standard deviations (see Table 8.1). Thus, the results of both methods are comparable. 
Table 8.1 WRR Reduction Factor for HF28968

\begin{tabular}{cccc}
\hline \hline & $\begin{array}{c}\text { PMOD/WRC } \\
\text { Method }\end{array}$ & $\begin{array}{c}\text { Proposed } \\
\text { Method }\end{array}$ & $\begin{array}{c}\text { Difference } \\
\text { WRC - Prop. }\end{array}$ \\
\hline WRR & 0.998244 & 0.998103 & 0.000141 \\
\hline SD & 0.000867 & 0.000697 & 0.000170 \\
\hline
\end{tabular}

8.6. Fig. 8.1 and 8.2 show the WRR reduction factors and standard deviations calculated using the PMOD/WRC method and the proposed method.

8.7. Fig. 8.3 shows the means of WRR reduction factors of the WSG instruments, the difference between the means using the two methods is on the order of 0.01 percent, which is smaller than the standard deviations of the two methods.

8.8. Figs. 8.4 through 8.6 show the change of the M factor with time and irradiance calibration levels, which are the irradiance levels at which the HF28968 calibrations were performed, on three different days. Figs. 8.7 through 8.9 show the change of temperature of the sensing element, in degrees centigrade, with time and irradiance calibration levels for the three days.

Fig. 8.8 shows that the temperature of the sensing element decreased between $8: 37$ to $10: 02$; Fig. 8.5 shows that the $M$ factor increased during the same period. When the temperature increased, during the period 10:02 to $13: 12$, the M Factor decreased. From $13: 12$ to $15: 53$, the rate of temperature change was different, the $M$ factor changed in the same way, inversely proportional to the change in temperature. The same trend is shown in Figs. $8.4,8.6,8.7$ and 8.9 for two other days. Fig. 8.10 shows the change of the $M$ factor with temperature for the three 


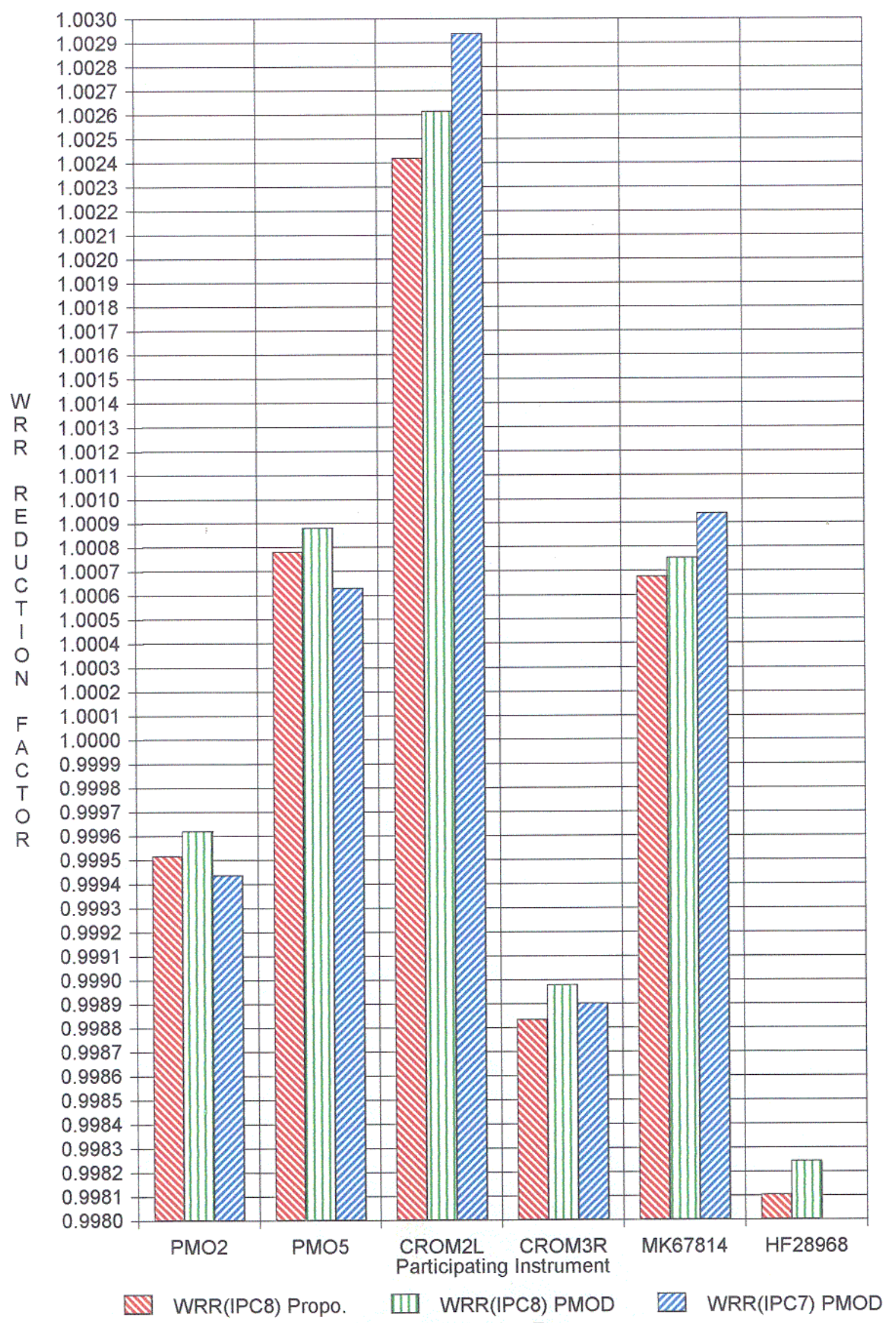

Fig. 8.1 WRR Reduction Factors 


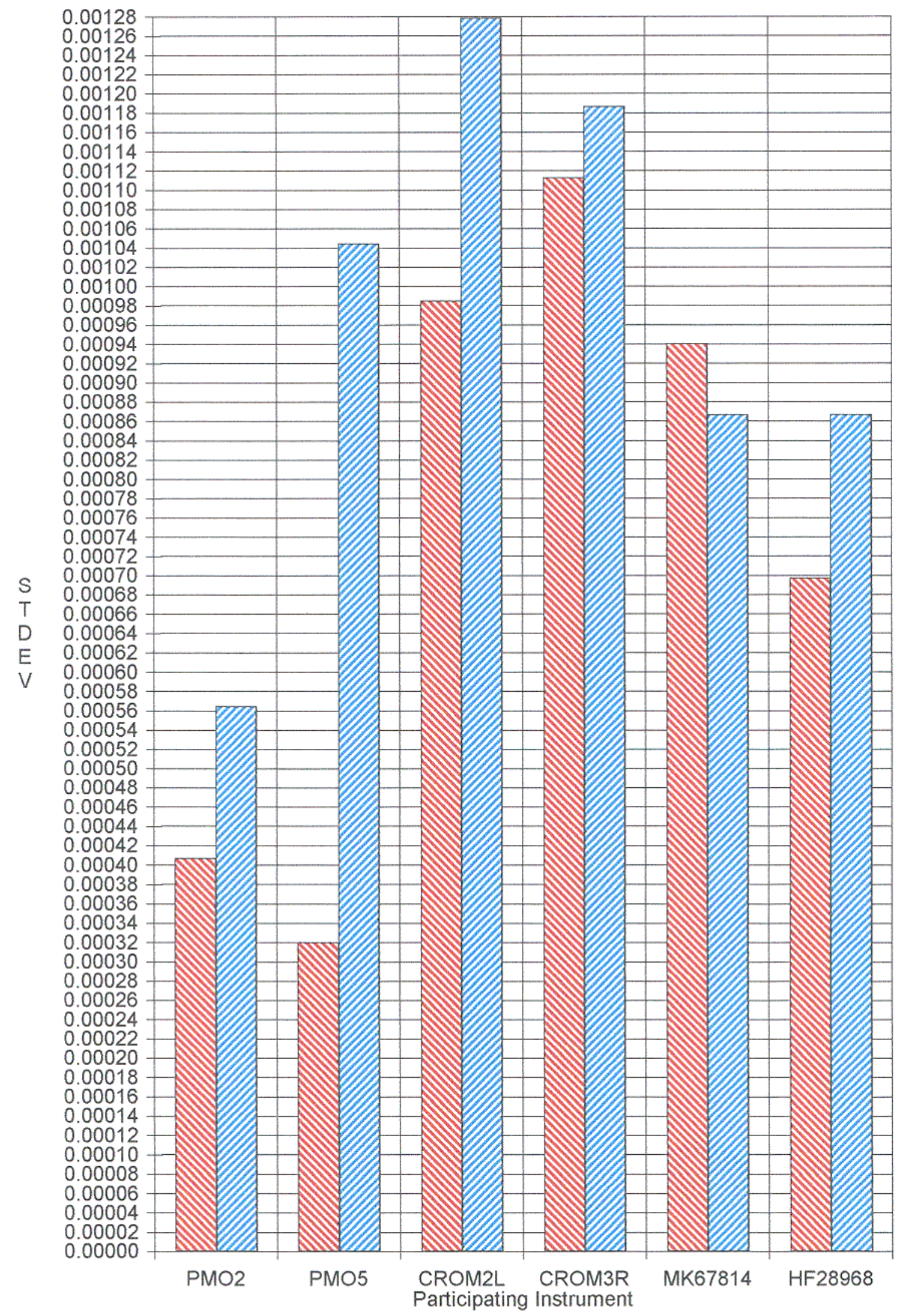

SD(IPC8) Proposed SD(IPC8) PMOD

Fig. 8.2 Standard Deviations 


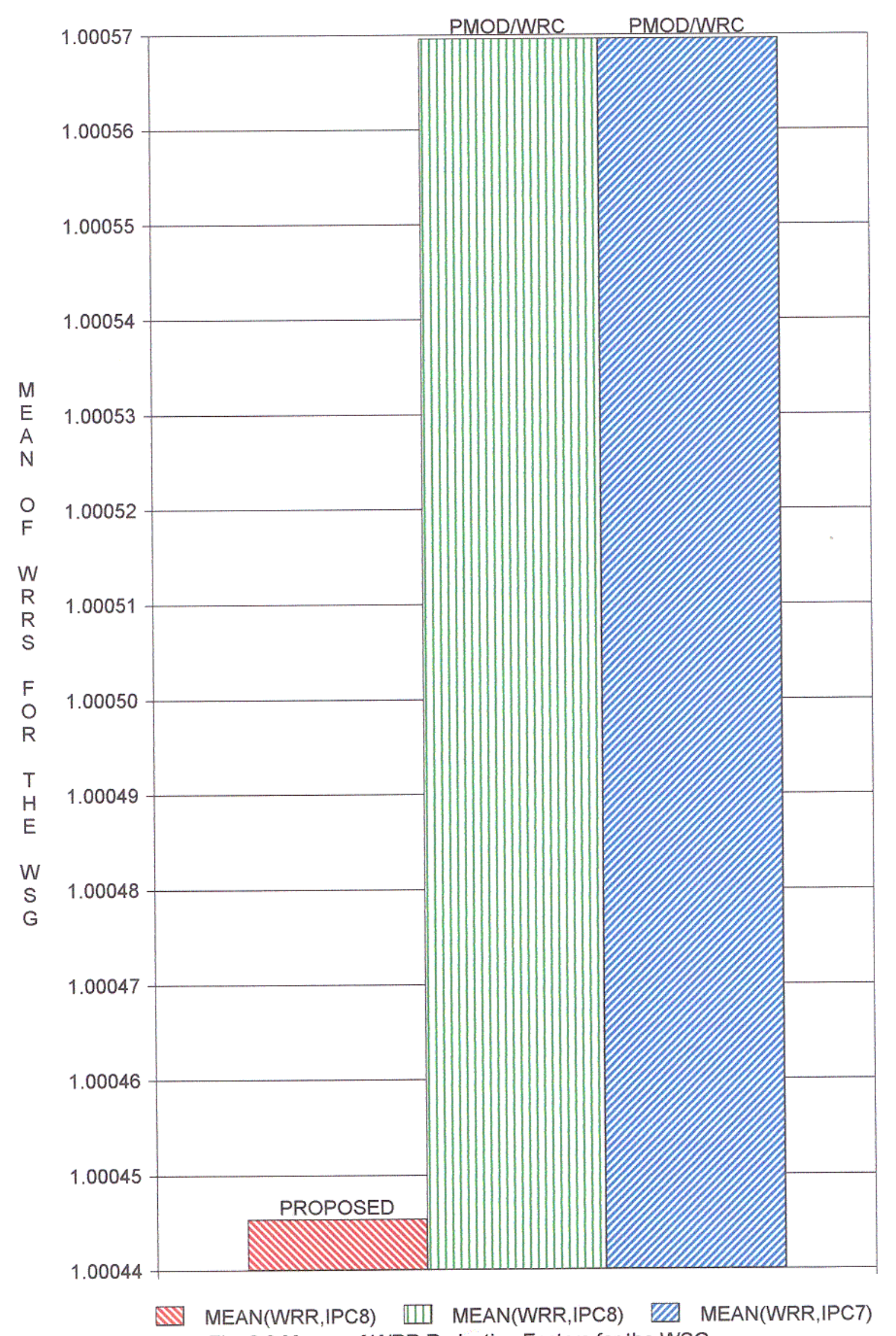

Fig. 8.3 Means of WRR Reduction Factors for the WSG 59 
M Factor For HF28968

7 October 1995

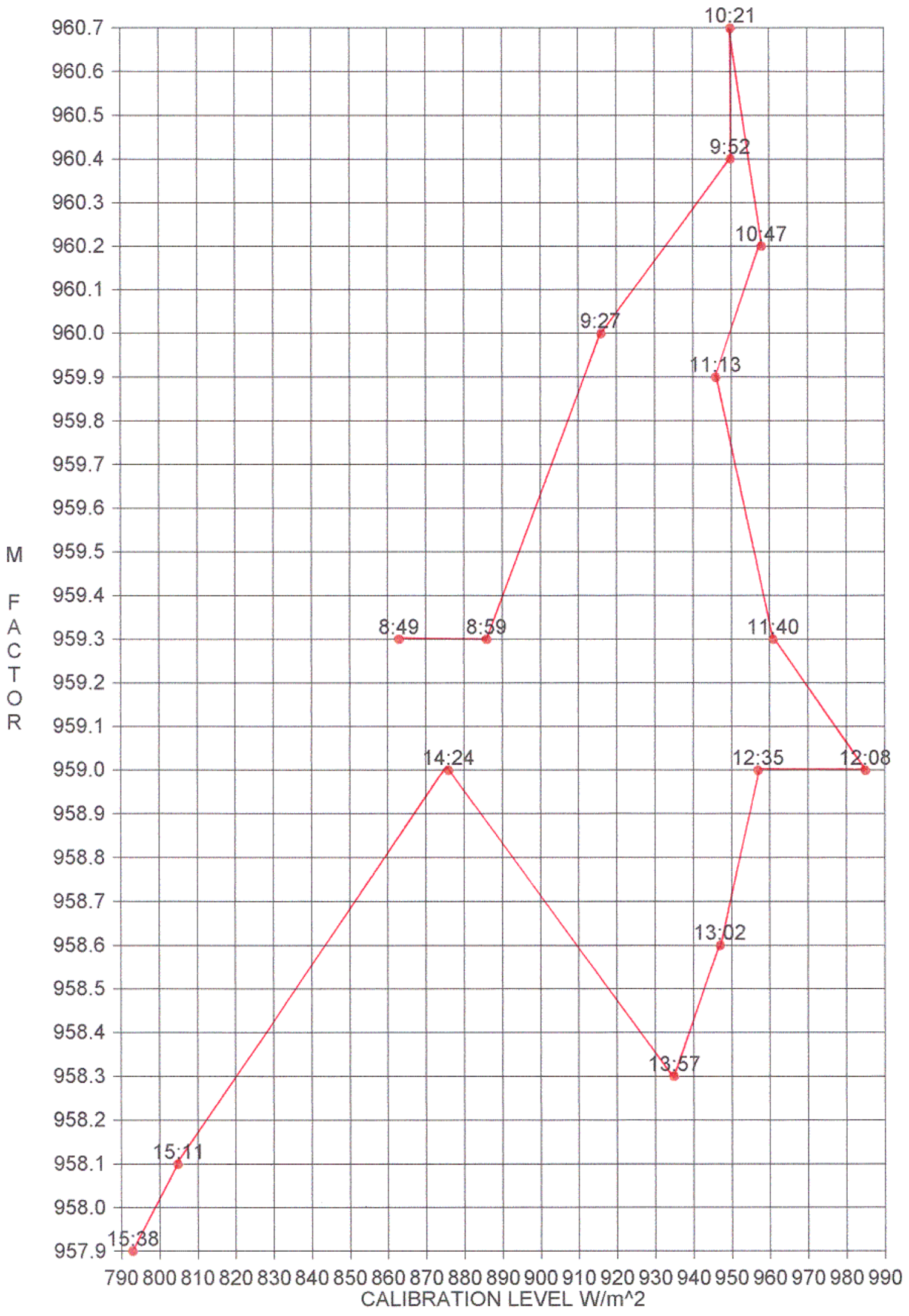

Fig. 8.4 Change of The M Factor With Different Irradiance Calibration Levels And Time 60 


\section{Factor For HF28968}

11 October 1995

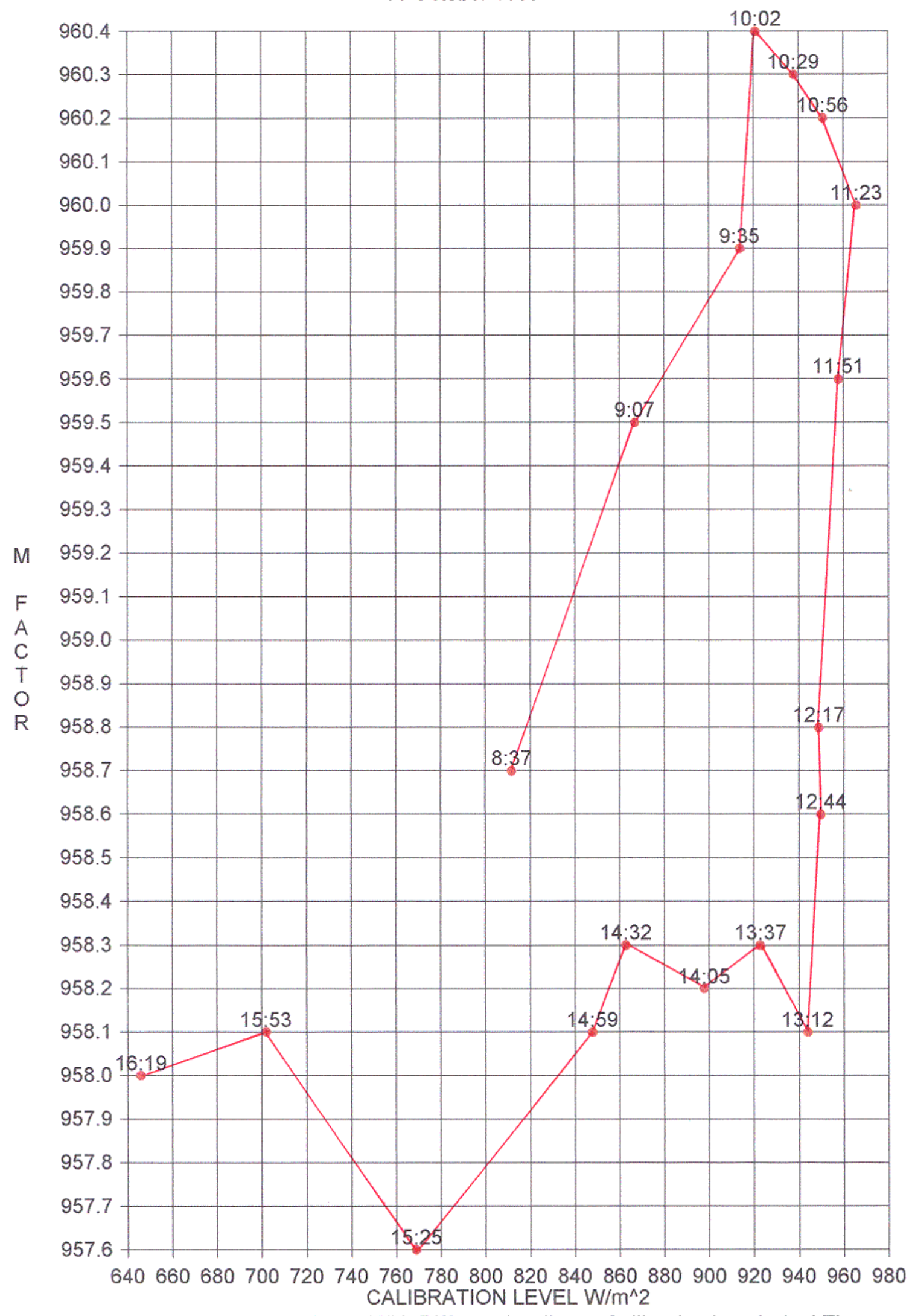

Fig. 8.5 Change of The M Factor With Different Irradiance Calibration Levels And Time 61 


\section{Factor For HF28968}

12 October 1995

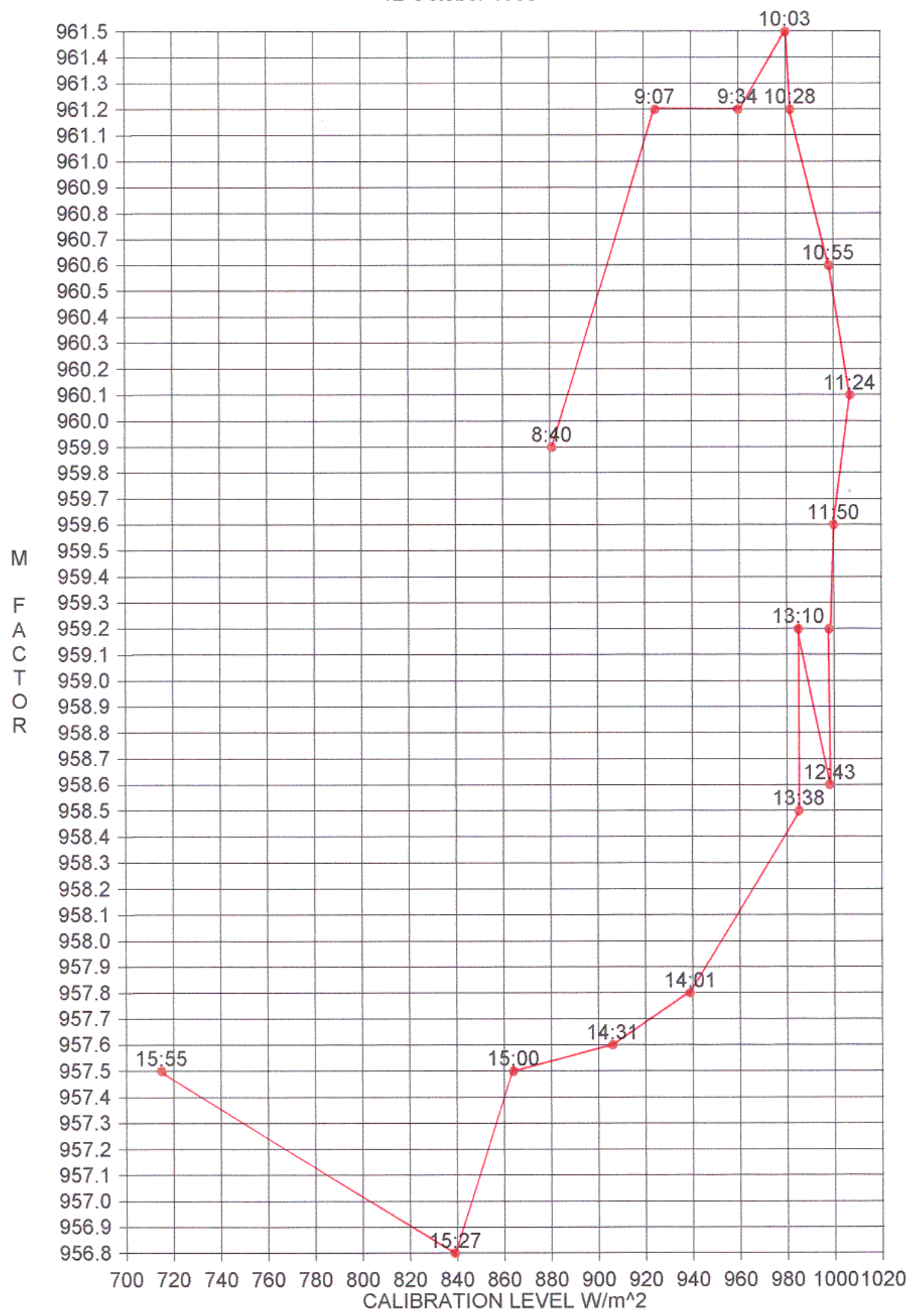

Fig. 8.6 Change of The M Factor With Different Irradiance Calibration Levels And Time 


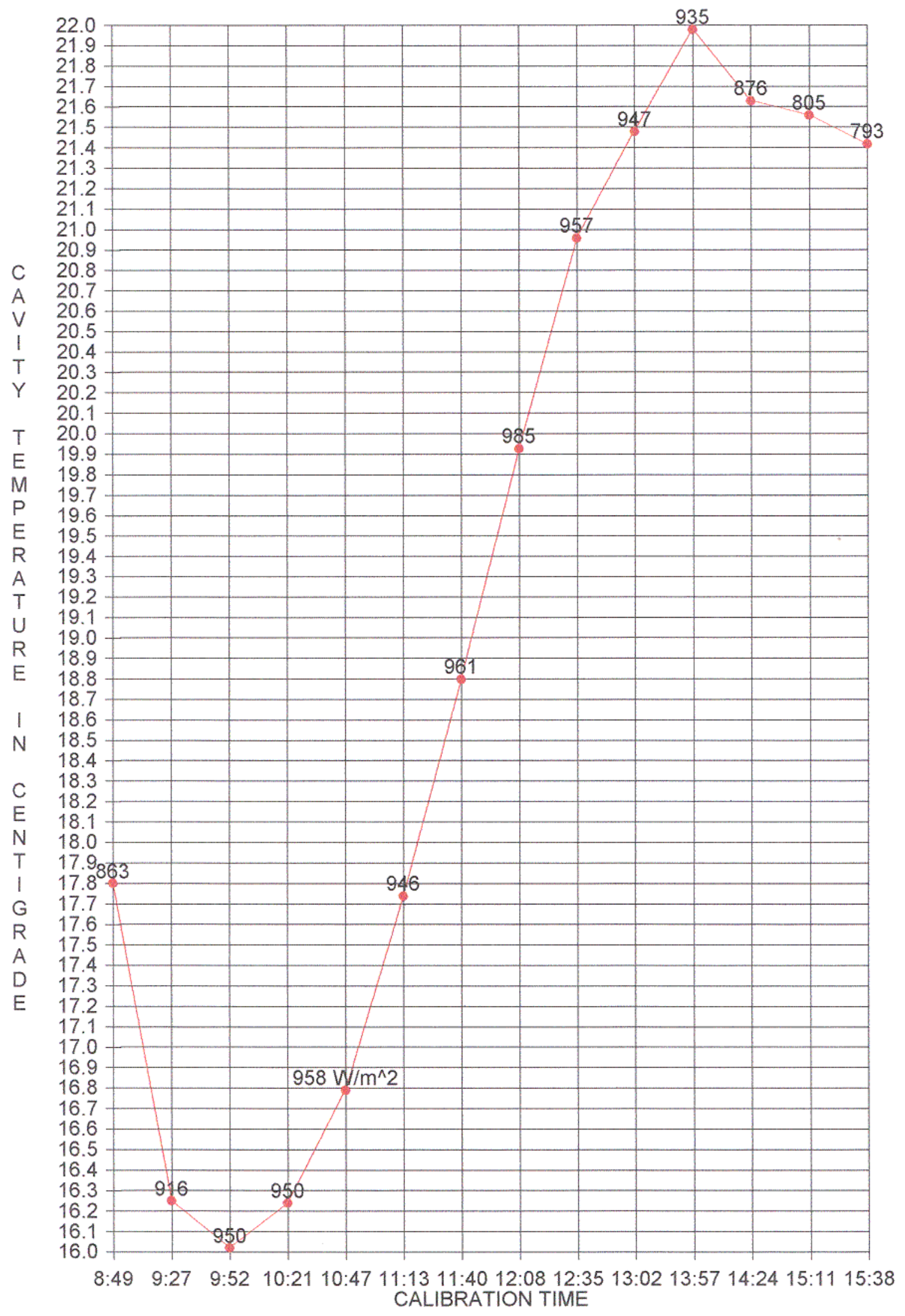

- $10 / 7 / 95$

Fig. 8.7 Change of Cavity Temperature with Time and Irradiance Calibration Levels 


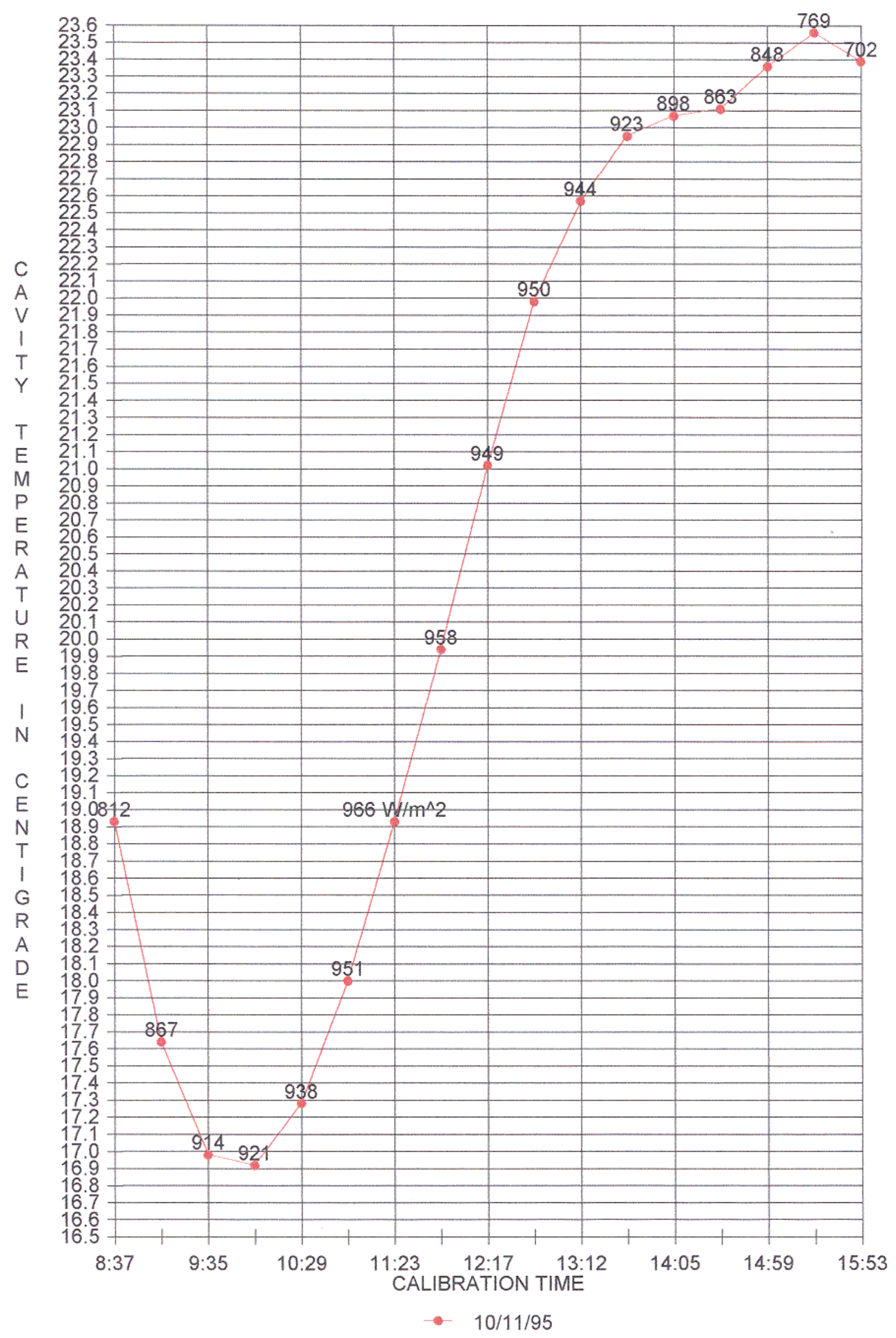

Fig. 8.8 Change of Cavity Temperature with Time and Irradiance Calibration Levels $\quad 64$ 


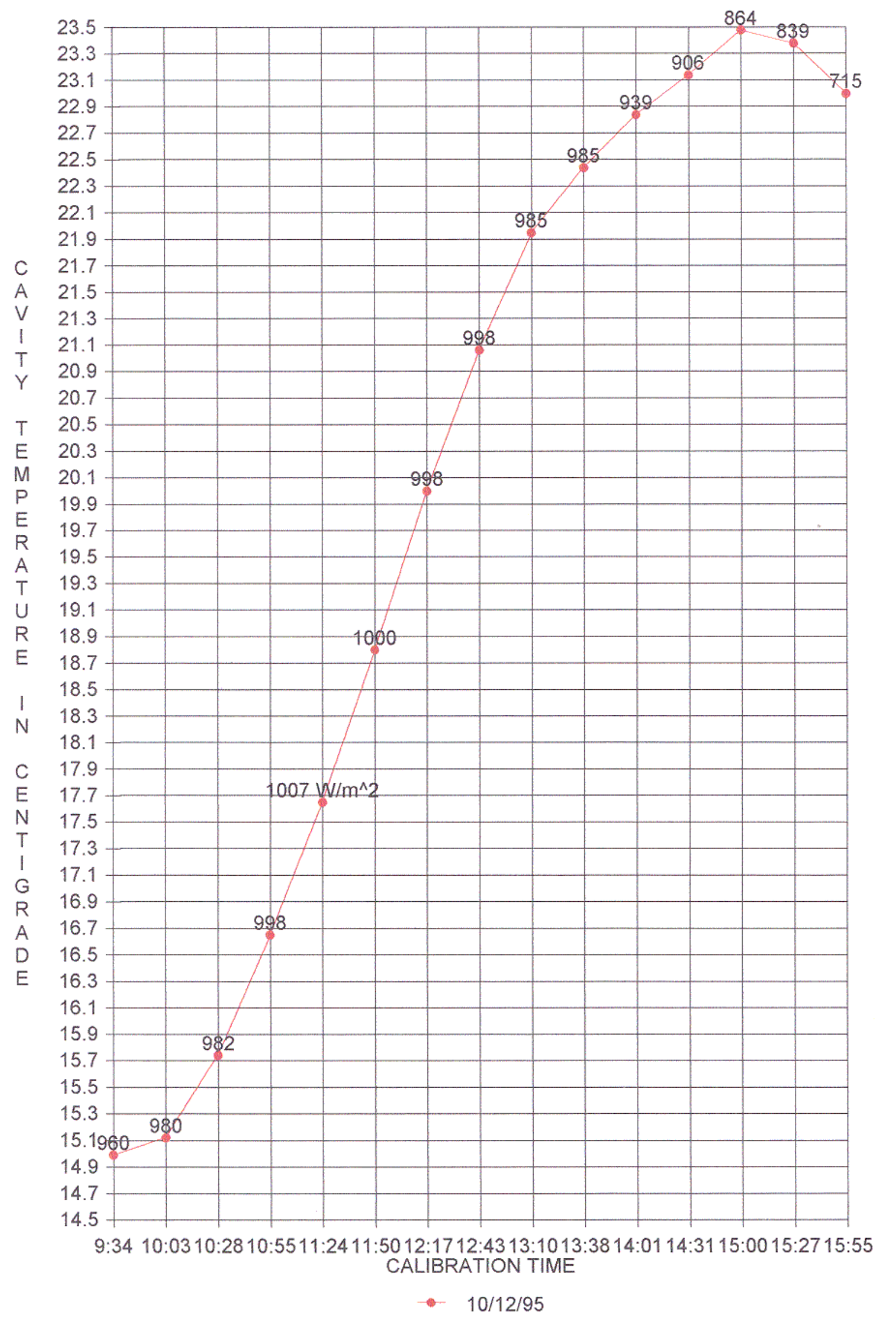

Fig. 8.9 Change of Cavity Temperature with Time and Irradiance Calibration Levels 


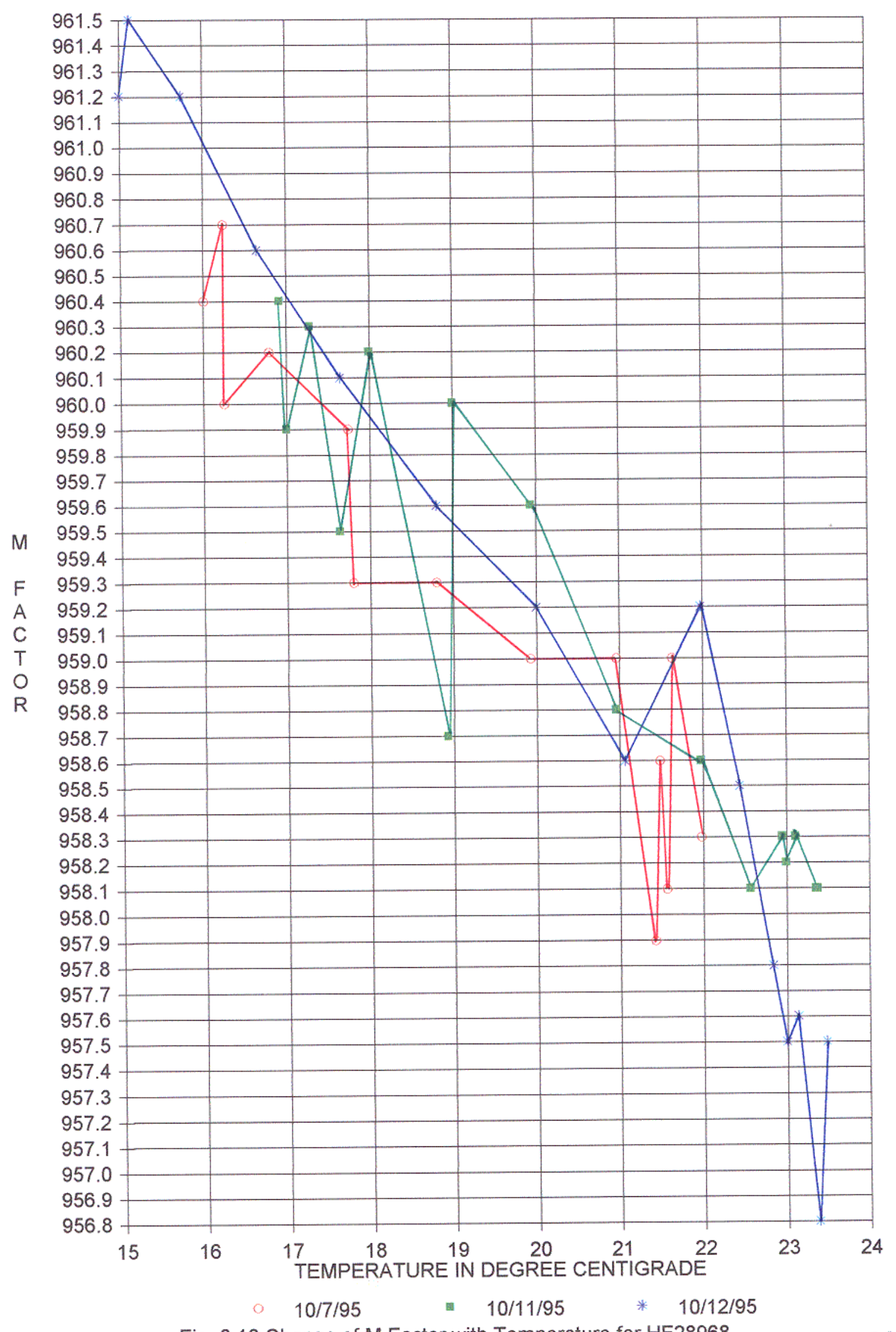

Fig. 8.10 Change of M Factor with Temperature for HF28968 
days, the slope of the three days trend is approximately -0.44 ; then, the change of the $M$ factor with temperature is approximately $-0.44 /{ }^{\circ} \mathrm{C}\left(-0.046\right.$ percent $\left./{ }^{\circ} \mathrm{C}\right)$. That shows the importance of calibrating the absolute cavity radiometers more often when large changes in ambient temperature are expected.

8.9. Table 8.2 shows the calculated $M$ factor when the HF28968 is calibrated at three different irradiance levels and temperature of the sensing element is at $18.9^{\circ} \mathrm{C}$. The values are obtained using Figures 8.4 through 8.9 .

Table 8.2 Change of the M Factor for HF28968

\begin{tabular}{cccc}
\hline \hline Date & $10 / 11 / 1995$ & $10 / 7 / 1995$ & $10 / 12 / 1995$ \\
\hline Irradiance & 812 & 960 & 1000 \\
Cal. Levels & $\mathrm{W} / \mathrm{m}^{2}$ & $\mathrm{~W} / \mathrm{m}^{2}$ & $\mathrm{~W} / \mathrm{m}^{2}$ \\
\hline Temperature & $18.9^{\circ} \mathrm{C}$ & $18.9^{\circ} \mathrm{C}$ & $18.9^{\circ} \mathrm{C}$ \\
\hline M Factor & 958.7 & 959.3 & 959.6 \\
\hline
\end{tabular}

If the HF28968 is calibrated at an irradiance level that equals $812 \mathrm{~W} / \mathrm{m}^{2}$, and the irradiance to be measured is at $1000 \mathrm{~W} / \mathrm{m}^{2}$, then an error of $-0.9,1958.7$ is subtracted from 959.6), will be noticed in the irradiance reading at $1000 \mathrm{~W} / \mathrm{m}^{2}$. This error, which appears because the output voltage of the thermopile will be multiplied by 958.7 instead of 959.6 , is on the order of -0.09 percent of the irradiance being measured, which is on the same order of magnitude of the standard deviation of the WRR reduction factor ( 0.08 percent). This shows the importance of minimizing this error to improve the measurement process during absolute cavity radiometers comparisons. The change in the $M$ factor is attributed to the change of the cavity sensitivity with the change in irradiance levels, the change in barometric pressure, and/or the noise from the 
Digital Multimeter, the control box, and the signal connection from the control box to the DMM. Noise can be minimized by using Digital Multimeters with less noise and better zero stability; and also by using, thermal insulated, and electromagnetic interference (EMI) shielded signal connection from the control box to the DMM. Changing barometric pressure changes the thermal impedance inside the sensing element; although the changes are negligible, they should be characterized in the future by monitoring the barometric pressure during the cavity calibrations (M factor calculations). After eliminating the errors due to noise, and characterizing the barometric pressure effect on cavity sensitivity, the change of the $M$ factor with irradiance levels can be characterized.

8.11. Fig. 8.11 shows the difference in the irradiance readings during a run of 13 readings, when the calibration is done at irradiance levels of $812 \mathrm{~W} / \mathrm{m}^{2}$ and $908 \mathrm{~W} / \mathrm{m}^{2}$. The difference is in the order of 0.07 percent of the irradiance being measured. The temperature of the sensing element is the same during both calibrations. These results show the importance of calibrating the HF28968 (calculating the $M$ factor) using electrical power that is as close as possible to the irradiance level being measured during the comparisons of absolute cavity radiometers.

\subsection{The temperature dependency of absolute cavity} radiometers shows the need to develop the cryogenic absolute cavity solar radiometers to define the WRR with a smaller uncertainty than 0.3 percent. 


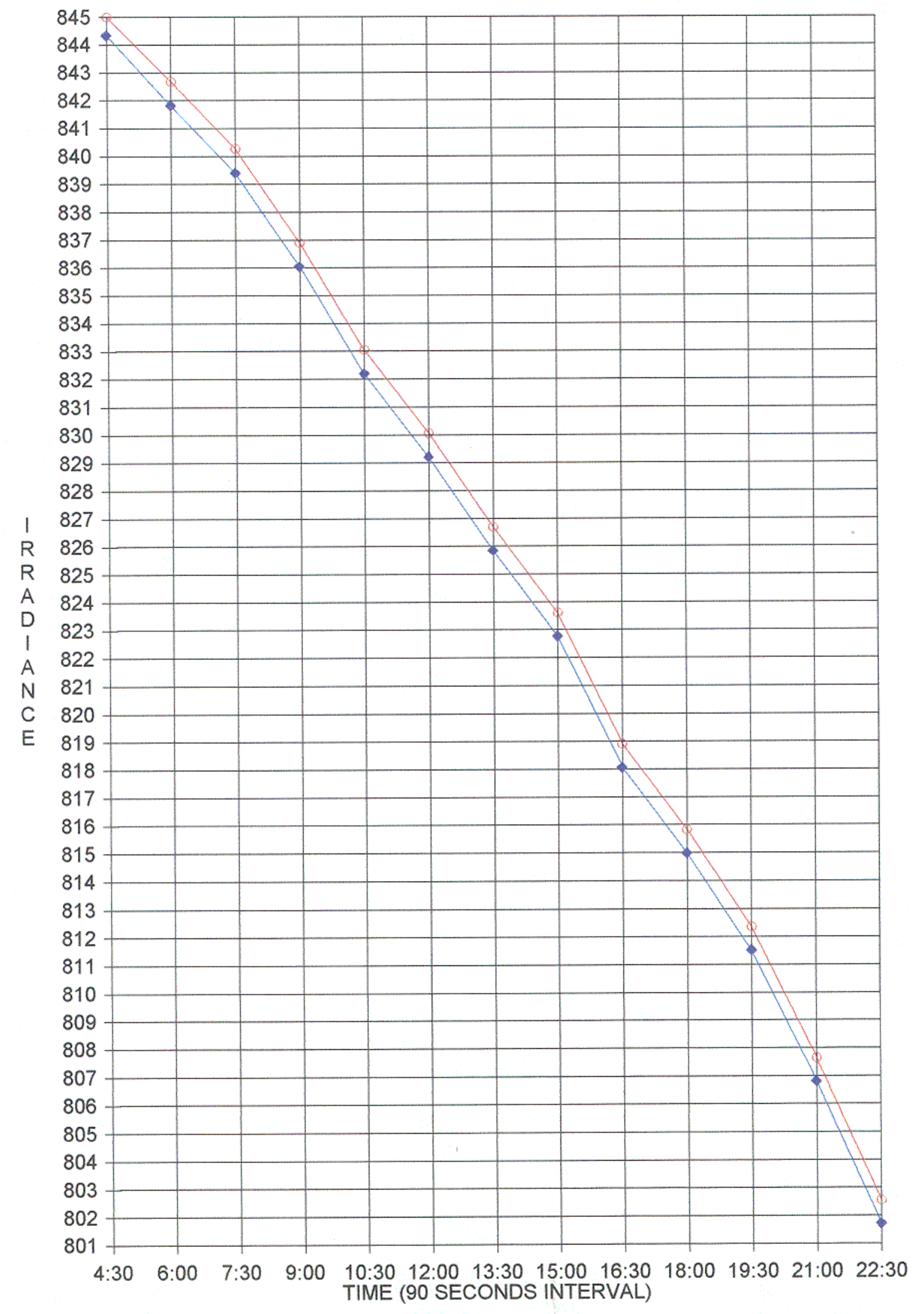

$\because 908 \mathrm{~W} / \mathrm{m}^{\wedge} 2 \multimap 821 \mathrm{~W} / \mathrm{m}^{\wedge} 2$

Fig. 8.11 Irradiance Readings with Time and Irradiance Calibration Levels 


\section{References}

1. Wells, Chester. (16 March 1993). Personal Communication. "The NREL Reference Absolute Cavity Radiometer at the World Radiation Center in Davos, Switzerland." NREL, Golden, Colorado, USA; $3 p$.

2. Fröhlich, C.; Philipona, R.; Romero, J.; Wehrli, C. (September 1995). "Radiometry at the Physikalisch Meteorologisches Observatorium Davos and World Radiation Center." Journal of Optical Engineering. Vol.34, no.9; pp. 2757-66.

3. Karoli, Alton R.; Hickey, John R.; Frieden, Roger G. (7-8 April, 1983). "Self Calibrating Cavity Radiometers at the Eppley Laboratory: Capabilities and Applications." Proceedings of The International Society for Optical Engineering. Vol.416, SPIE, Bellingham, WA, USA; pp.43-50.

4. Swiss Meteorological Institute. (December 1985).

"International Pyrheliometer Comparisons IPC VI." Part I of Working Report No. 137, Davos and Zurich, Switzerland; p.4.

5. Swiss Meteorological Institute. (March 1991).

"International Pyrheliometer Comparisons IPC VII." Working Report No. 162,Davos and Zurich, Switzerland; p.7.

6. Romero, José. (September 1995). "Direct Solar Irradiance Measurements with Pyrheliometers: Instruments and Calibrations." IPC VIII, Davos, Switzerland; 16p.

7. Dieck, R. H. (Copy right 1992, second printing January 1995). "Weighting Method for Multiple Results." Unit 6 in Measurement Uncertainty: Methods and Applications. North Carolina, Instrument Society of America; pp.117-24. 


\section{REPORT DOCUMENTATION PAGE}

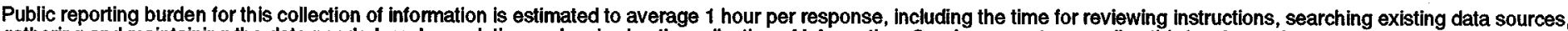

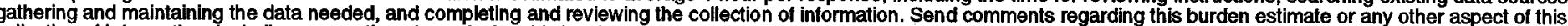

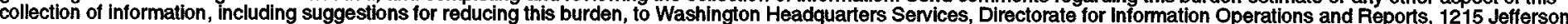

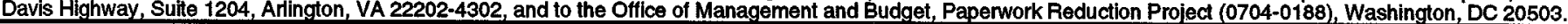
1. AGENCY USE ONLY (Leave
2. REPORT DATE
blank) January 1996

\section{REPORT TYPE AND DATES COVERED}
Technical Report

4. TITLE AND SUBTITLE

Calibration of a Solar Absolute Cavity Radiometer with Traceability to the World Radiometric Reference

6. AUTHOR(S)

Ibrahim Reda

7. PERFORMING ORGANIZATION NAME(S) AND ADDRESS(ES)

\section{FUNDING NUMBERS}

0832.1000

8. PERFORMING

ORGANIZATION REPORT

NUMBER

\section{SPONSORING/MONITORING AGENCY NAME(S) AND ADDRESS(ES)}

Natonal Renewable Energy Laboratory

1617 Cole Boulevard

Golden, Colorado 80401

10.

SPONSORING/MONITORING

AGENCY REPORT NUMBER

NREL/TP-463-20619

DE9600519

\section{SUPPLEMENTARY NOTES}

\section{2a. DISTRIBUTION/AVAILABILITY STATEMENT}

National Technical Information Service

U.S. Department of Commerce

5285 Port Royal Road

Springfield, VA 22161 12b. DISTRIBUTION CODE

UC Category: 920

\section{ABSTRACT (Maximum 200 words)}

This report describes the present method of establishing traceability of absolute cavity radiometers to the World Radiometric Reference (WRR) through the process employed in the International Pyrheliometer Comparisons (IPC). This method derives the WRR reduction factor for each of the participating cavity radiometers. An alternative method is proposed, described, and evaluated as a way to reduce the uncertainty in the comparison process. The two methods are compared using a sample of data from the recent IPC-VIII conducted from September 25th to October 13th, 1995 at the World Radiation Center in Davos, Switzerland. A description of absolute cavity radiometers is also included, using a PMO-6 as an example of active cavity radiometers, and a HF as an example of passive cavity radiometers.

\section{SUBJECT TERMS}

calibration; absolute cavity radiometers; traceability
15. NUMBER OF PAGES

16. PRICE CODE
19. SECURITY CLASSIFICATION OF ABSTRACT
20. LIMITATION OF ABSTRACT
CLASSIFICATION

OF REPORT
18. SECURITY

CLASSIFICATION

OF THIS PAGE 